\title{
Correlation between Compaction Characteristics with undrained Shear Strength of Soils found in Burayu Town
}

SOLOMON KORMU

AMBO UNIVERSITY WOLISO CAMPUS https://orcid.org/0000-0002-6143-6815

Alemineh Sorsa ( $\square$ soorummaa@gmail.com)

Jimma University

\section{Research Article}

Keywords: clay soils, Compaction, Correlation, undrained shear strength

Posted Date: October 7th, 2021

DOI: https://doi.org/10.21203/rs.3.rs-958664/v1

License: (c) (i) This work is licensed under a Creative Commons Attribution 4.0 International License.

Read Full License 


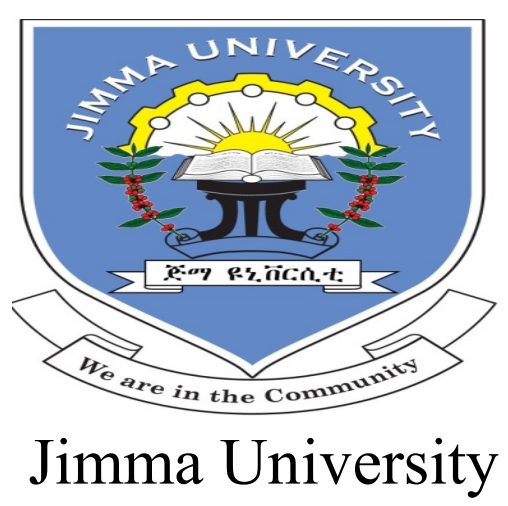

Jimma Institute of Technology

School of Graduate Studies

\section{Faculty of Civil and Environmental Engineering Geotechnical Engineering Stream}

Correlation between Compaction Characteristics with undrained Shear Strength of Soils found in Burayu Town

A Thesis Submitted to School of Graduate Studies of Jimma University in Partial Fulfilment of the Requirement of Degree of Master of Science in Civil Engineering (Geotechnical Engineering).

By:

Solomon Kormu

November, 2018

Jimma, Ethiopia 


\section{Jimma University \\ Jimma Institute of Technology \\ School of Graduate Studies \\ Faculty of Civil and Environmental Engineering \\ Geotechnical Engineering Stream}

Correlation between Compaction Characteristics with undrained Shear

Strength of Soils found in Burayu Town

A Thesis Submitted to School of Graduate Studies of Jimma University in Partial Fulfilment of the Requirement of Degree of Master of Science in Civil Engineering (Geotechnical Engineering).

By:

Solomon kormu

Main advisor: Prof. Emer T. Quezon, P. Eng

Co-advisor: Engr. Alemneh Sorisa (PhD Candidate)

November, 2018

Jimma Ethiopia 


\section{Jimma University \\ Jimma Institute of Technology \\ School of Graduate Studies \\ Faculty of Civil and Environmental Engineering Geotechnical Engineering Stream}

Correlation between Compaction Characteristics with undrained Shear Strength of Soils found in Burayu Town

By

Solomon Kormu

APPROVED BY BOARD OF EXAMINERS

1.

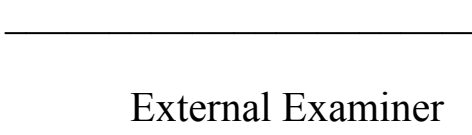

2.

Internal Examiner

3.

Chairman of Examiner

4. Prof. Emer T. Quezon, P.Eng

Main Advisor

5. Alemneh Sorsa, MSc

Co- Advisor

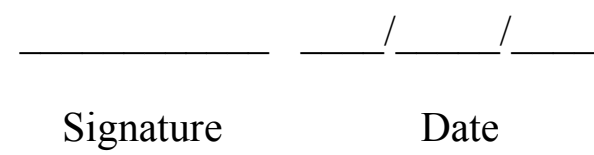

Signature Date
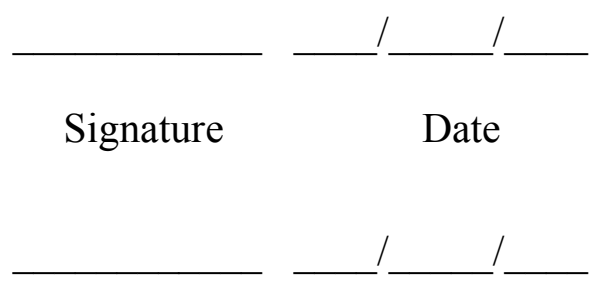

Signature

Date

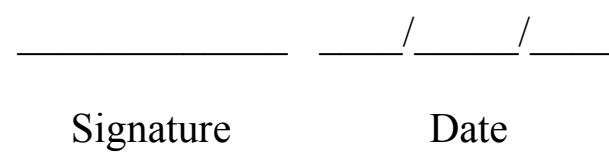

Signature

Date 


\section{DECLARATION}

I, the undersigned, declare that this thesis entitled: "Correlation between Compaction Characteristics with undrained Shear Strength of Soils found in Burayu Town" is my original work, and has not been presented by any other person for an award of a degree in this or any other University, and all sources of material used for this thesis have been duly acknowledged.

Candidate:

\section{Solomon Kormu}

Signature

As Master's Research Advisors, we hereby certify that we have read and evaluated this MSc Thesis prepared under our guidance by Solomon Kormu entitled: "Correlation between Compaction Characteristics with undrained Shear Strength of Soils found in Burayu Town".

We recommend that it can be submitted as fulfilling the MSc Thesis requirements.

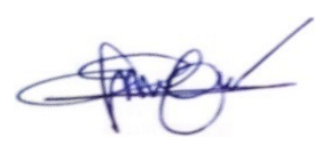

$23 / 11 / 2018$

Prof. Emer T. Quezon, P.Eng

Advisor

Signature

Date

Engr. Alemneh Sorsa, MSc

Co- Advisor

Signature

Date 


\section{ACKNOWLEDGEMENT}

I would like to express sincere and special thanks to Prof. Emer T. Quezon, P.Eng, for his continuous support, guidance, Lecturing and efforts in doing this Thesis. I would like to thank Mr. Alemneh Sorisa for his genuine help. Special thanks to Jimma University and Ethiopian road authority work at large glance in the country for Master Program.

I would like to thank my classmates, for a memorable friendly atmosphere, assistance and invaluable comments. Finally, I would like to express my deepest gratitude to my parents, my friends and all who contributed to this research work in one way or another. 


\begin{abstract}
The shear strength of the soil is an important factor to know the internal resistance of soil against external loads causing shearing forces. Shear strength parameters are mandatory for the analysis of load bearing capacity of the soil, the stability of Geotechnical structures and in analysing stress and strain characteristics of soils. The undrained shear strength is one type of shear strength parameter. This parameter is conducted by undisturbed samples. But due to handling, transportation, release of overburden pressure and poor laboratory conditions, it is difficult to obtain accurate undisturbed samples. So, prediction of undrained shear strength parameters (cu) for cohesive soil with the help of compaction characteristics provides a good alternative to minimize this problem.

Therefore, this study was conducted to develop the correlation between undrained shear strength values with soil compaction characteristics specifically located in Burayu town. The study was carried out using thirty samples collected from the town. By using the test result regression based statistical analysis was carried out to develop the intended correlation.
\end{abstract}

The parameters considered for this study are Atterberg's limits, Grain size analysis, Specific gravity, Compaction tests and unconfined compression test. The test procedures were based on AASHTO and ASTM laboratory test standards. These parameters are used to establish equations of correlations between undrained shear strength values with soil compaction. The soil type found in Burayu town was highly plastic red clay soil.

Based on both single and multiple linear regression analysis relatively good correlation is obtained by combining undrained shear strength $\left(q_{u}\right)$ with maximum dry density and optimum moisture content of red clay soil. From the correlation analysis the equations developed are $q_{u}=-3105+1625 M D D+40.9$ OMC with coefficient of determination of $R^{2}=0.828$ for multiple linear regression and $q_{u}=-1473+57.8$ OMC and $q_{u}=-4861+$ $3910 M D D$ with coefficient of determination of $R^{2}=0.787$ and $R^{2}=0.601$ for single linear regression respectively.

Generally, the intended correlation obtained from the study area fulfil the basic requirement of regression.

Keywords: clay soils, Compaction, Correlation, undrained shear strength 


\section{TABLE OF CONTENTS}

DECLARATION

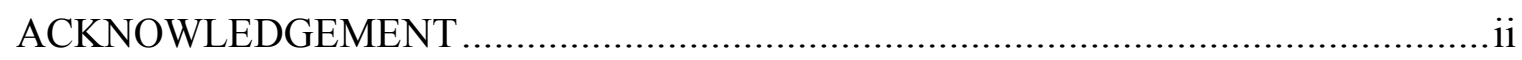

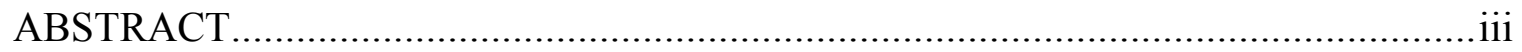

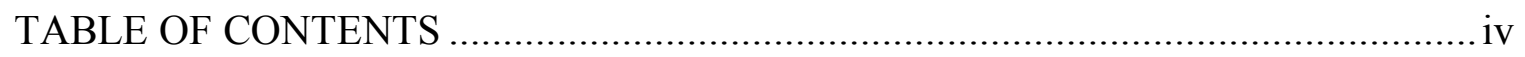

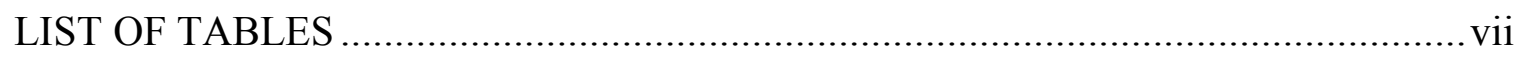

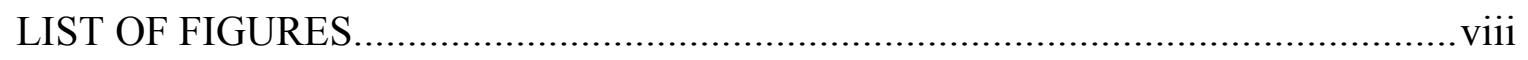

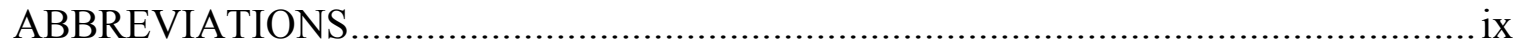

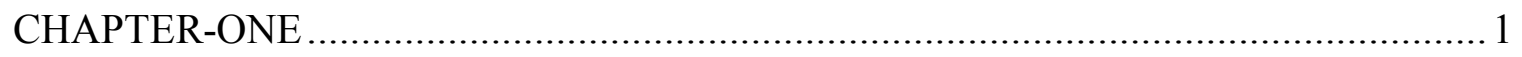

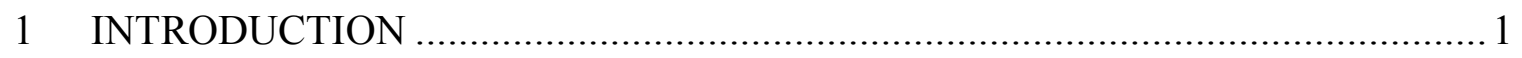

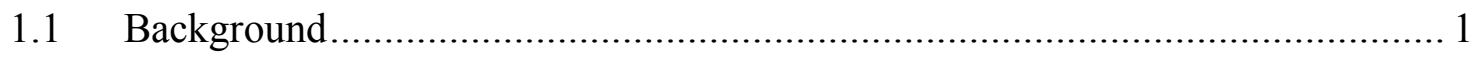

1.2 Statement of the Problem ............................................................................... 1

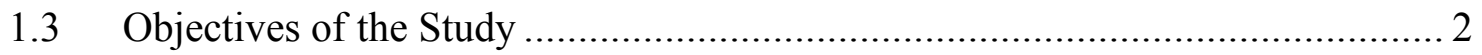

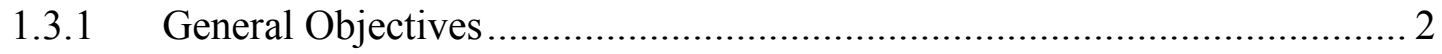

1.3.2 Specific Objectives ............................................................................ 3

1.4 Research Questions ................................................................................ 3

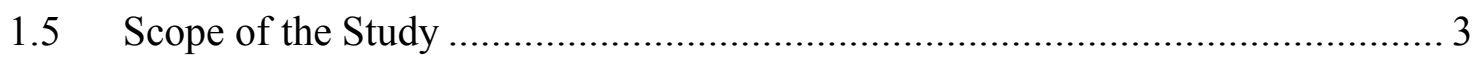

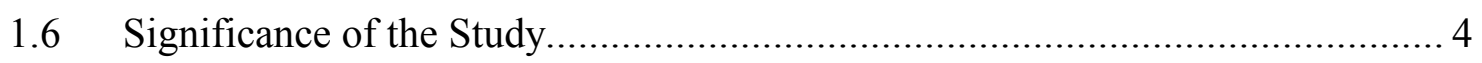

1.7 Organization of the Thesis......................................................................... 4

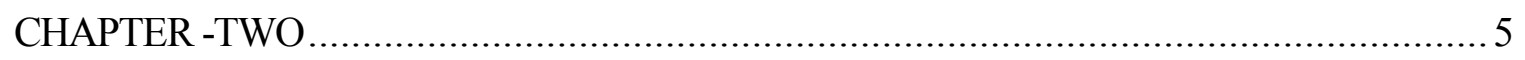

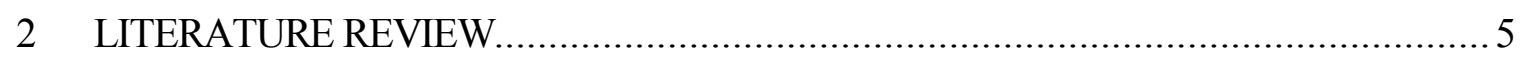

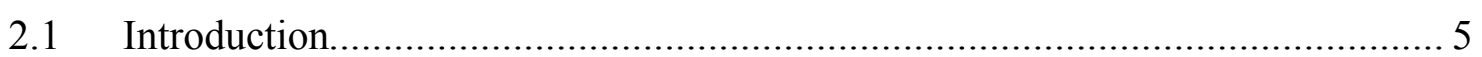

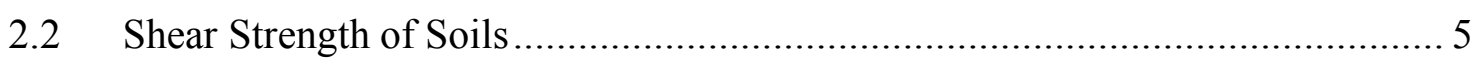

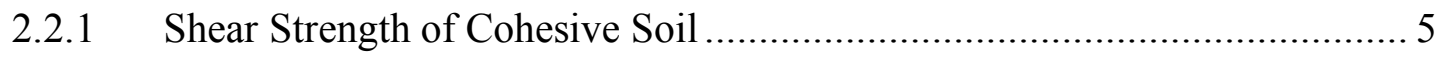

2.2.2 Application of Unconsolidated Undrained Test ................................... 5

2.2.3 Predicting Undrained Shear Strength.................................................... 6

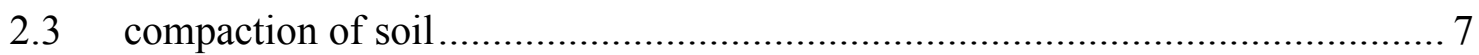

2.3.1 Factors Affecting Compaction............................................................. 7

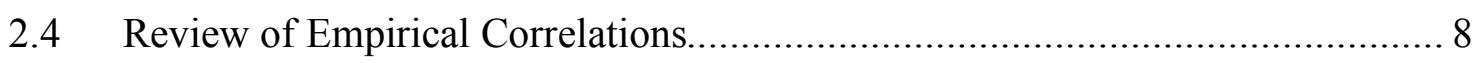

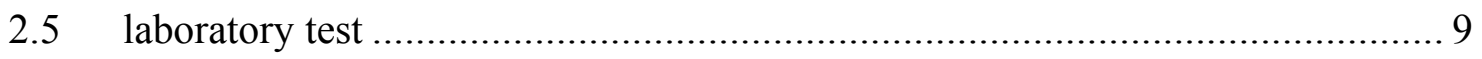

2.5.1 Natural Moisture Content ............................................................... 9

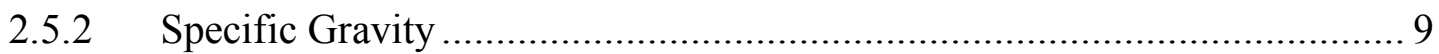

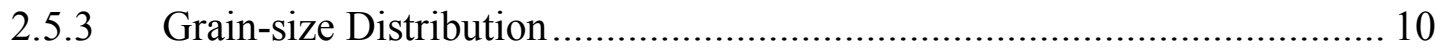

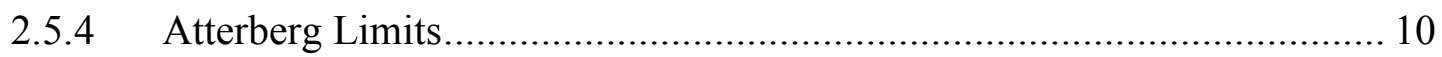




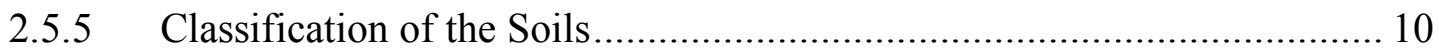

2.5.6 Unified Soil Classification System .................................................... 11

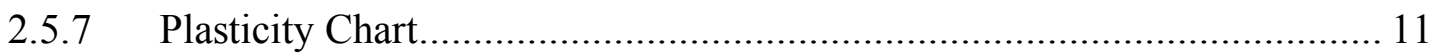

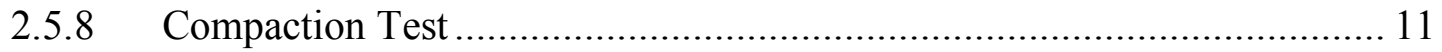

2.5.9 Method of laboratory soil compaction .................................................. 12

2.5.10 Unconfined Compression Strength (UCS) Test ................................... 13

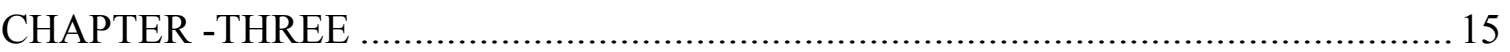

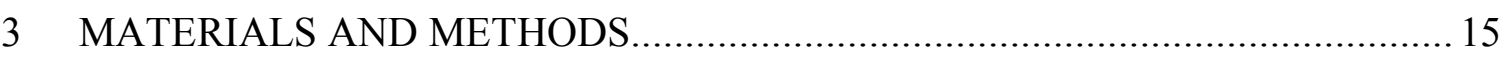

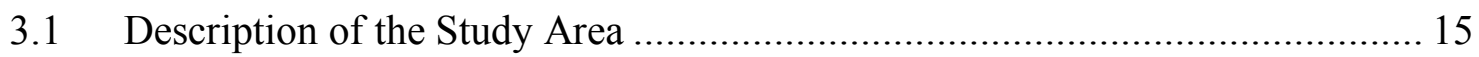

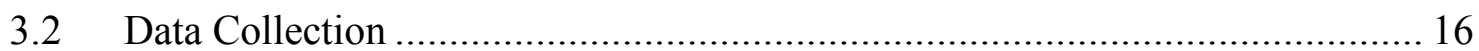

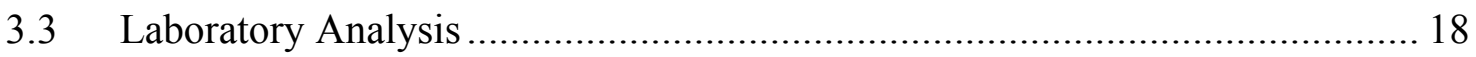

3.4 Steps for correlation and Regression Analysis ........................................... 18

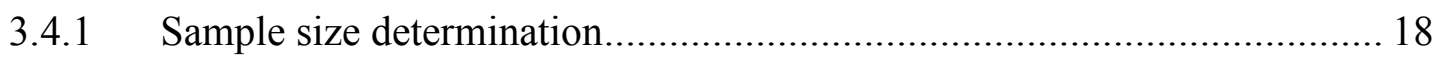

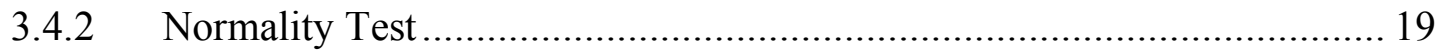

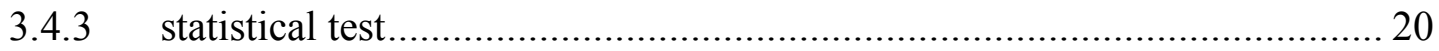

3.4.4 Transformation of data(normalization) …......................................... 22

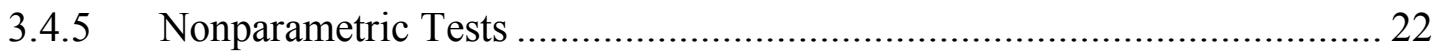

3.4.6 Multicollinearity (interdependency check)....................................... 23

3.4.7 Correlation and regression methods.................................................. 24

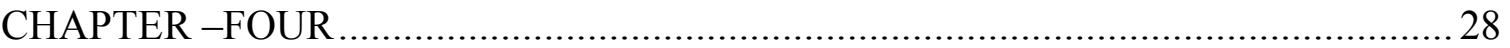

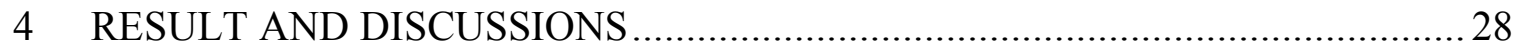

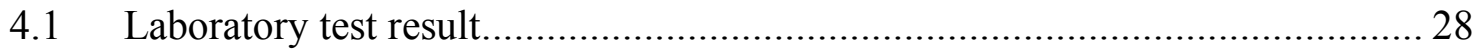

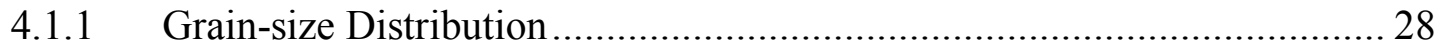

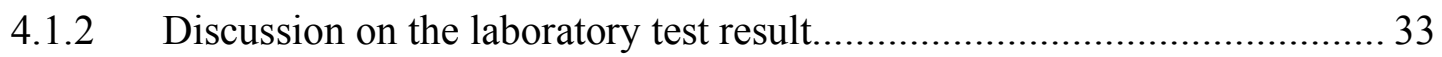

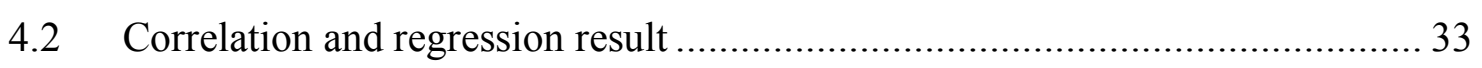

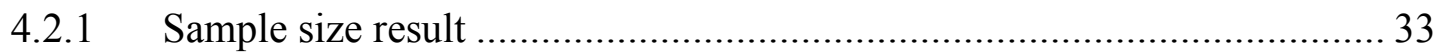

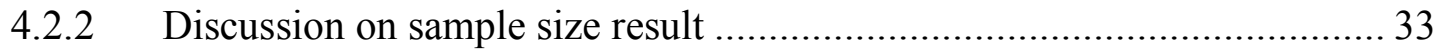

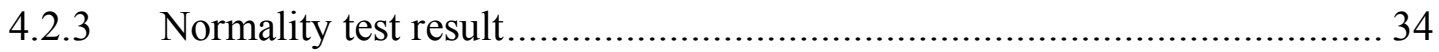

4.2.4 Discussion on normality test result ...................................................... 36

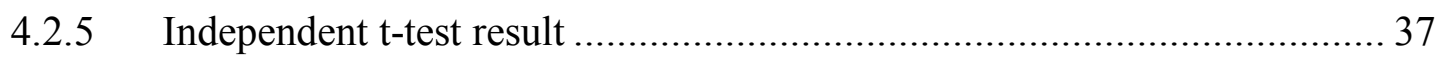

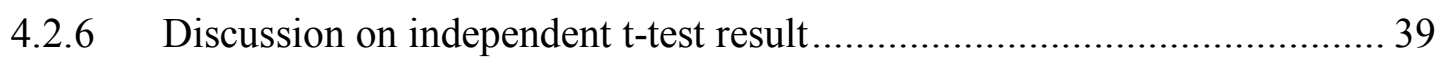

4.2.7 Multicollinearity (interdependency) test result..................................... 39

4.2.8 Discussion on multicollinearity test result .......................................... 40

4.2.9 Scatter Plots (univariate analysis) result ............................................. 40 


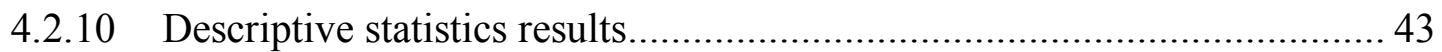

4.2.11 Discussion on the descriptive statistics result...................................... 44

4.2.12 Correlation matrix result of data ............................................................ 45

4.2.13 Discussion of the correlation matrix result............................................ 46

4.2.14 Single Linear Regression Analysis ......................................................... 46

4.2.15 Multiple Linear Regression Analysis ..................................................... 47

4.2.16 Validation of the developed equations ................................................ 48

4.2.17 Discussion on cross validation result ................................................... 50

4.2.18 Evaluation of the Developed and Existing Correlations ...........................5 50

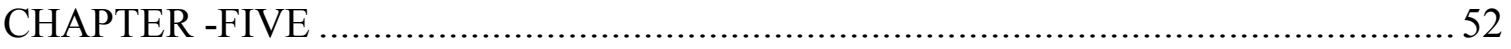

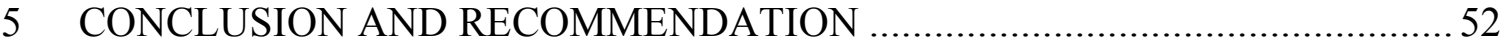

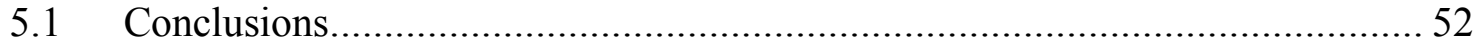

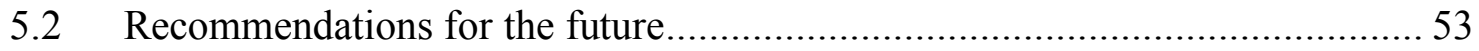

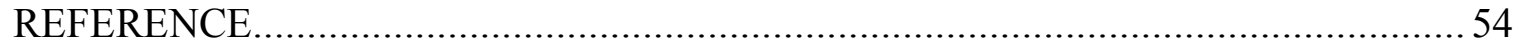

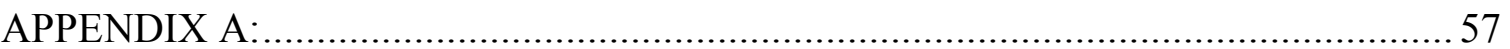

Normality Test Result of Each Variable and Residual for Primary Data .......................57

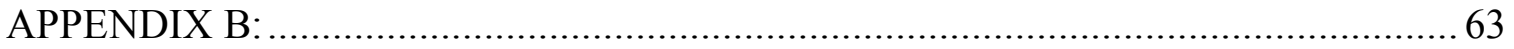

Normality Test Result of Each Variable and Residual for combined Data...................... 63

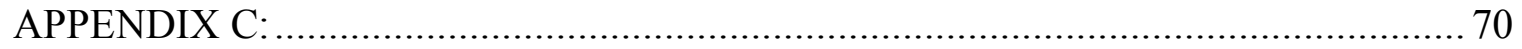

Single linear regression analysis result between UCS with MDD for primary Data........ 70

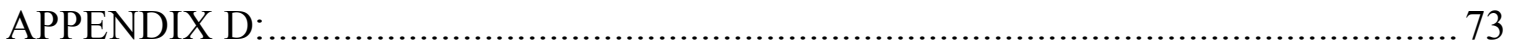

Single linear regression analysis result between UCS with OMC for primary Data........ 73

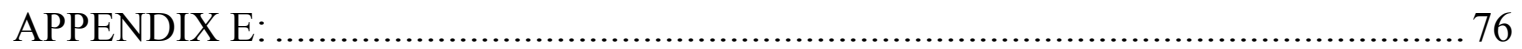

Single linear regression analysis result between UCS with MDD for Combined Data.... 76

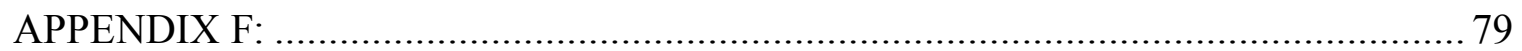

Single linear regression analysis result between UCS with omc for combined Data ....... 79

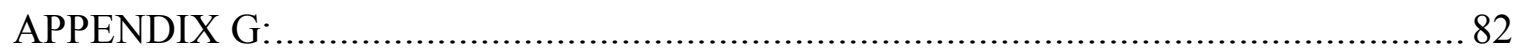

Multiple linear regression analysis result between UCS with MDD and OMC for primary

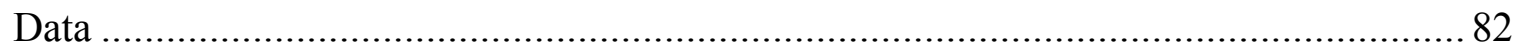

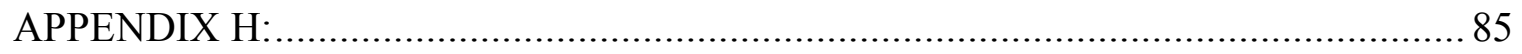

Multiple linear regression analysis result between UCS with MDD and OMC for combined

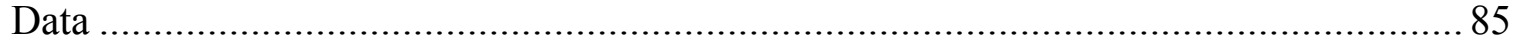




\section{LIST OF TABLES}

Table 2-1 General Relationship of Consistency and UCS of Clays [8] ......................... 6

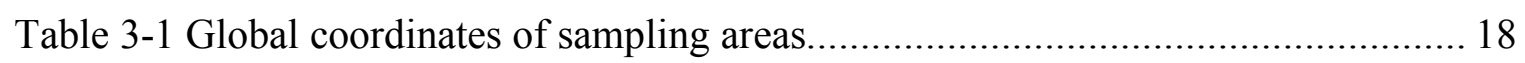

Table 3-2 Summary of laboratory testing procedure standards .................................... 18

Table 3-3:Variable selected for checking normality of parametric test ....................... 20

Table 3-4: Methods for determining parameter and non-parametric statistical test ......... 21

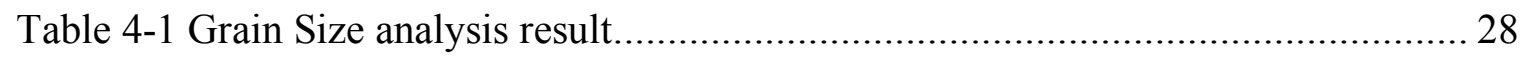

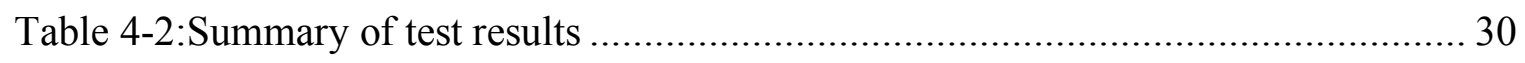

Table 4-3 Secondary Data of UCS and Compaction Characteristics Value..................... 32

Table 4-4 Normality Test result of residual for primary and secondary data................... 34

Table 4-5 Histogram plot of unstandardized residual for primary data ........................... 34

Table 4-6 QQ plot of unstandardized residual for primary data.................................. 35

Table 4-7 Histogram plot of unstandardized residual for combined data ...................... 35

Table 4-8 QQ plot of unstandardized residual for combined data ................................ 36

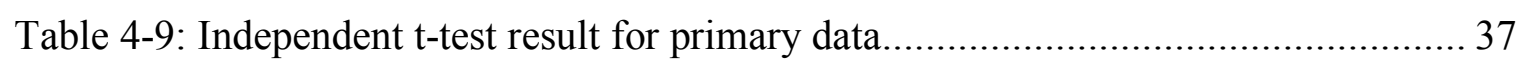

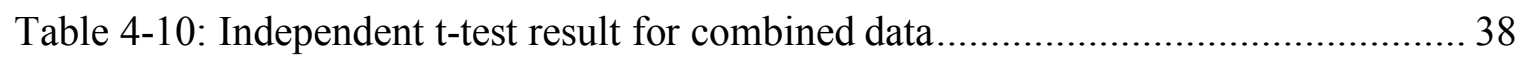

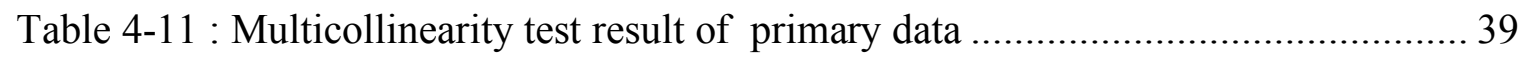

Table 4-12 Multicollinearity test result of combined data .......................................... 40

Table 4-13: Statistical Information of Dependent and Independent Variables for primary data

Table 4-14: Statistical Information of Dependent and Independent Variables for combined

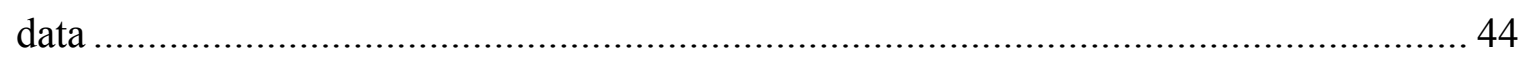

Table 4-15 Correlation Matrix of Pearson Correlation Coefficient for primary data....... 45

Table 4-16: Summary of laboratory results for control tests ...................................... 48

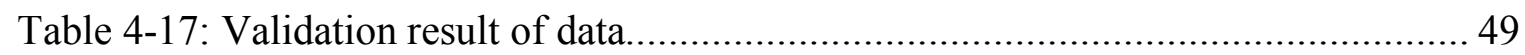

Table 4-18 Validation of UCS From Correlation Developed with The Actual Test Data50 


\section{LIST OF FIGURES}

Figure 2-1 Effect of Compaction Effort in Compaction Curve [12] .............................. 8

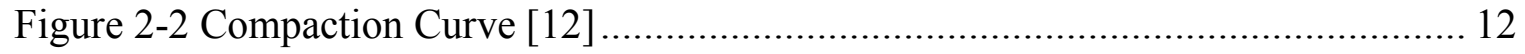

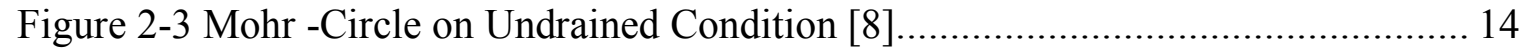

Figure 3-1 Location of the research area (Source: From Google Map) ......................... 15

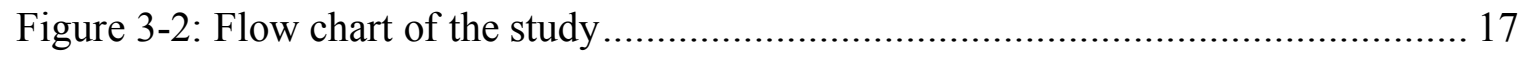

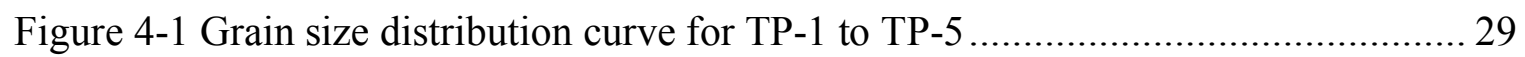

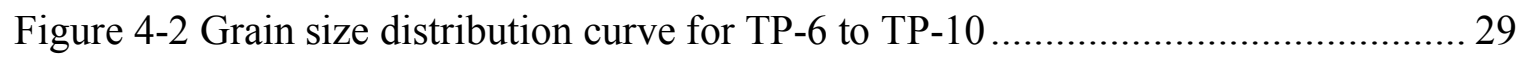

Figure 4-3:Scatter diagram of UCS versus MDD of primary data .............................. 40

Figure 4-4: Scatter diagram of UCS versus OMC of primary data .............................. 41

Figure 4-5:Scatter diagram of UCS versus MDD of combined data ........................... 41

Figure 4-6:Scatter diagram of UCS versus OMC of combined data ............................ 42

Figure 4-7:Matrix plot of dependent and independent variable for primary data............ 42

Figure 4-8: Matrix plot of dependent and independent variable for combined data......... 43

Figure 4-9 Graphical comparison of the developed model with previous correlations .... 51 


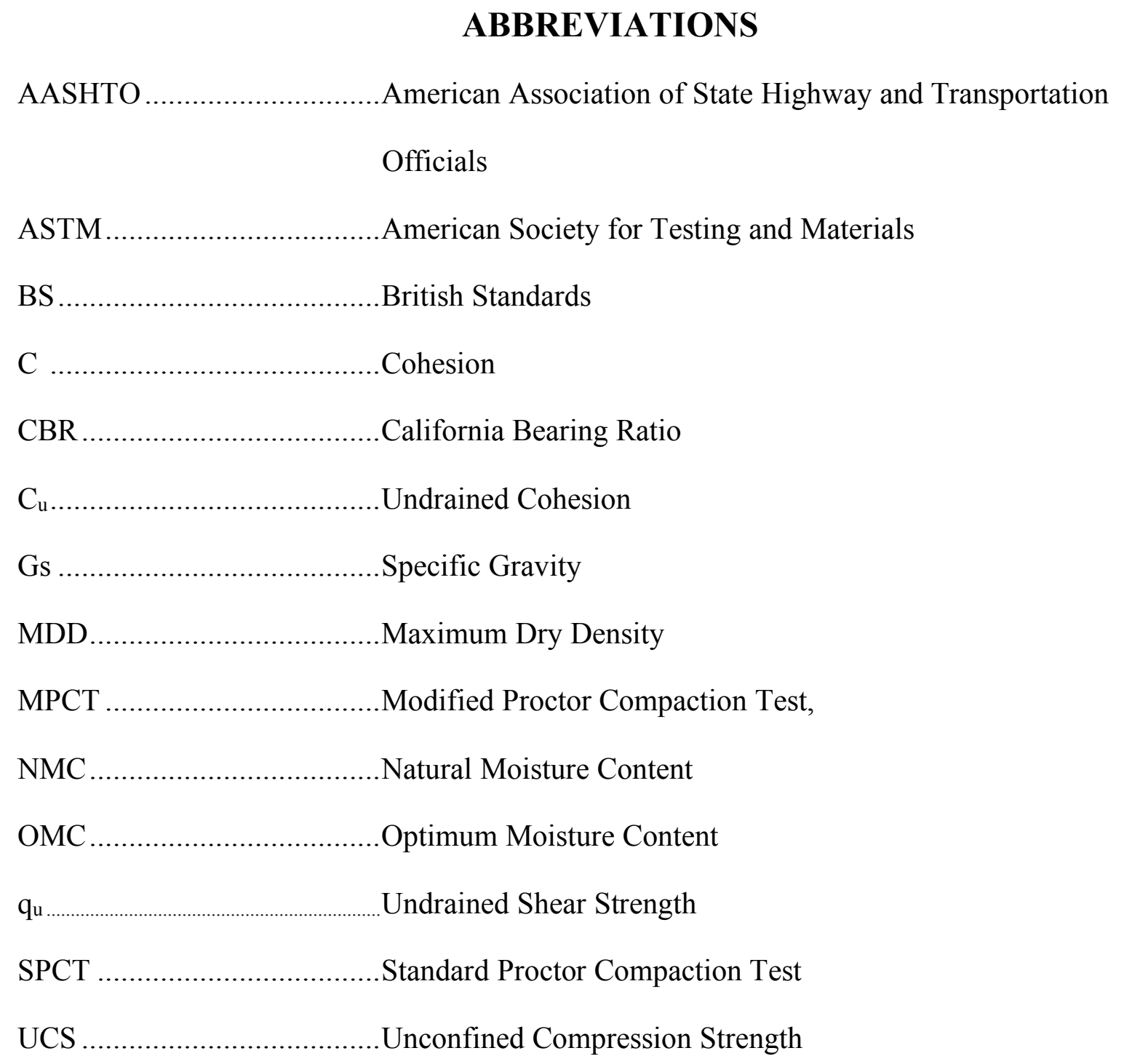




\section{CHAPTER-ONE}

\section{INTRODUCTION}

\subsection{Background}

determining the engineering properties of soil plays a significant role to solve different geotechnical engineering problems. shear strength tests are one of the major tests used to know shear strength parameters of soil.

Shear strength of soil is characterized by cohesion (c) and friction angle $(\phi)$. The two parameters mentioned primarily, define the soil maximum ability to resist shear stress under defined load [1]

These Soil properties such as cohesion and angle of internal friction of soil are necessary for estimating the load bearing capacity of the soil, the stability of geotechnical structures and in analysing stress and strain characteristics of soils [2]

But due to handling, transportation, release of overburden pressure and poor laboratory conditions. it is difficult to obtain accurate undisturbed samples for shear strength tests [3] And also due to the ever-increasing cost of shear strength laboratory equipment and tests, it raise the cost of construction projects [4].

According to [5] Compaction of soil means densify the soil by using mechanical technique. Compaction of soil is important for improve the engineering properties of soil. Soil compaction is a general practice and common methods in geotechnical engineering to construct; road, dams, landfills, airfields, foundations, hydraulic barriers, and ground improvements.

Laboratory compaction tests are a very common and wide practice for geotechnical projects. So, prediction of some properties such as undrained shear strength parameters of soil with the help of compaction characteristics provides a good alternative to obtain undrained shear strength parameters without conducting undisturbed samples. Therefore, a correlation between these soil parameters will be highly welcome.

\subsection{Statement of the Problem}

Some empirical relationships exist in geotechnical engineering between one soil property and another. The main reason is some soil properties are time consuming and expensive to conduct in the laboratory [6]. 
Due to The inherent nature and variety of geological processes occurred in the soil formation, soil properties vary from region to region and season to season. Studying this variation in different soil type and origin are a very important task for geotechnical engineers. To overcome the effects from this variation geotechnical engineers as well as other professional's attempt to develop empirical equations specific to a certain region and soil type in order to use the soil for different purpose. However, these empirical equations are more reliable for the type of soil where the correlation is developed [7].

Determining the undrained shear strength is used to determine the bearing capacity as well as the stability of Geotechnical structure in short term loading condition. The undrained shear strength of soil may depend on natural water content, type of soil considered, permeability of soil, etc[8].

To conduct this test Undisturbed soil samples are used. The handling, transporting and extracting condition of soil changes the grain to grain structure as well as the loss of its natural moisture content of the soil. due to this reason it is difficult to get accurate undisturbed soil samples without changing its characteristics of the soil in its inherent state [3].

Various researchers have been trying to predict the unconfined compressive strength (UCS) value with different parameter from samples of their respective localities. adopting those developed prediction models without adjustment leads us to misinterpretation of soil behaviour due to the above stated reasons. Therefore, identification of factors that influence the soil strength, studying their relationship with UCS value and performing necessary tests on local representative soil sample can give a rational basis in speculating soil behaviour, which ultimately minimizes both cost and time dedicated for carrying out actual laboratory exercise [7]

So that prediction of undrained shear strength of soil with the help of compaction characteristics minimizes the above problems in Burayu Town.

\subsection{Objectives of the Study}

\subsubsection{General Objectives}

The general objective of the study is to correlate the compaction characteristics and undrained shear strength of soil found in Burayu Town. 


\subsubsection{Specific Objectives}

To determine relationship between optimum moisture content (OMC) to unconfined compressive strength test value of fine grained soil found in burayu town

> To determine relationship between Maximum Dry density (MDD) to unconfined compressive strength value test of fine grained soil found in burayu town

$>$ To validate and evaluate the developed equations and compare with the existing correlation approaches related to study.

\section{$1.4 \quad$ Research Questions}

$>$ How optimum moisture content (OMC) could be correlated with unconfined compressive strength test value of fine grained soil found in burayu town?

$>$ How maximum dry density (MDD) could be correlated with unconfined compressive strength test values of fine grained soil found in burayu town?

$>$ How much deviation of the values as a result from the developed equations with the existing correlation approaches related to the study?

\subsection{Scope of the Study}

Thirty representative soil samples from different location were collected to conduct this study in Burayu town. The collected samples were disturbed and undisturbed and taken from 0.5- $3 \mathrm{~m}$ depth. The soil samples were first air dried and laboratory tests were conducted according to ASTM and AASHTO soil testing standard procedures. The study is concerned to conduct a localized research particularly on samples that are recovered from Burayu town. It is required to collect secondary data in order to get a better correlation between the unconfined compression and compaction characteristics. Based on this result, correlation of UCS with compaction characteristics developed using statistical regression. Based on the trends of the scatter plot of test results the correlation was analyzed using a linear regression model. The proposed correlation is carried out by applying a single linear regression model and multiple linear regression models with the help of Microsoft Excel, MINITAB, and SPSS Softwares. The scope of the developed correlation, discussions and result obtained are limited to the test procedures followed, the range and quantity of sample used, apparatus used, sampling areas and methods of analysis used in the subject study. Therefore, the findings should be considered as indicative rather than definitive for the whole study area. 


\subsection{Significance of the Study}

This study is to correlate the compaction characteristics and undrained shear strength parameters found in Burayu town. The finding of this study will provide helpful information to various stakeholders as follows;

The City Administration of Burayu will benefit from the study as a source of information and base for the construction industry that can help to minimize the time and cost of laboratory tests.

$>$ Owners, contractors and consultants will benefit from the study as a source of information on issues to easily determine the bearing capacity as well as the stability of slope by using simple correlation between compaction characteristics and undrained shear strength parameters. In case of Burayu town.

Other researchers will use the findings as a reference for further research on the correlation between compaction characteristics and undrained shear strength parameters.

\subsection{Organization of the Thesis}

In this study, in order to accomplish the proposed objectives, basic theories and descriptions of unconfined compressive strength (UCS) test in general and in relation to compaction test is reviewed. Following that, previous studies of different researchers with concerning prediction of UCS value from other soil parameters were reviewed.

In order to have satisfactory data for utilizing the correlations, laboratory tests were conducted by the researcher on samples collected from Burayu town. Different laboratory tests done and the test results of UCS values along with the associated soil indices particularly the grain size analysis, Atterberg limits and moisture-density relationships and summary of laboratory test results were covered under data collection and analysis. Then, Statistical regression analyses of test results were carried out and correlations were developed and also analysed to fit the test results. Under the discussions of the obtained results the suitability of the developed correlations was examined. Finally, a generalized conclusion and recommendation was made. 


\section{CHAPTER -TWO \\ 2 LITERATURE REVIEW}

\subsection{Introduction}

This chapter provides a review of literature on the correlation between compaction characteristics and undrained shear strength parameters.

\subsection{Shear Strength of Soils}

Shear strength may be defined as the resistance to shearing stresses and a consequent tendency for shear deformation. shear strength of soils is an important parameter for in many foundation engineering problems, like in bearing capacity of shallow foundations and piles, lateral earth pressure on retaining walls and the stability of the slopes of dams and embankments [9].

Basically, a soil derives its shearing strength from Resistance due to the interlocking of particles, Frictional resistance between the individual soil grain due to sliding or rolling friction and Cohesion between soil particles. Granular soils of sands may derive their strength from the first two sources, while cohesive soils may derive their shear strength from the second and third source. Highly plastic clays, however, may exhibit the third source alone for their shearing strength [10].

Shear strength of soil is used to describe the magnitude of shear stress that the soil resist. Shear resistance of soil is depending on friction and interlocking of particles, and possibly bonding or cementation at particle contacts[9].

\subsubsection{Shear Strength of Cohesive Soil}

A characteristic of true clay is the property of cohesion, sometimes referred to as no load shear strength. Unconfined specimens of clay soil derive strength and firmness from cohesion. The shear strength of saturated cohesive soil in undrained shear test (i.e. test in which change in volume is prevented) is derived entirely from cohesion. It is well known that the shear strength of cohesive clay varies with its consistency. Clay which is at liquid limit has very little shear strength, whereas the same clay at lower moisture content may have considerable shear strength [11]

\subsubsection{Application of Unconsolidated Undrained Test}

The choice between total and effective stress analysis depends on the load application, in case of foundation design, because it enforces both shear stresses and compressive stresses 
(confining pressures) on the underlying soil; the shear stresses must be carried by the soil skeleton but the compressive stresses are initially carried largely by the resulting increase in pore water pressures. This leaves the effective stresses little changed, which implies that the foundation loading is not accompanied by any increase in shear strength. As the excess pore pressures dissipate, the soil consolidates, and effective stresses increase, leading to an increase in shear strength. which is by considering and comparing the soil response during and after construction, after construction effective stresses or shear strength increased due to excess pore pressures dissipated as of the soil consolidated. Thus, the immediate total stress response of the soil during construction is most critical. This is the justification for the use of quick undrained shear strength tests rather than effective stress analysis for foundation design [10]

\subsubsection{Predicting Undrained Shear Strength}

Using the consistency of molded clay soil physical property, one may predict the undrained shear strength of clay soils in the field simply by using one's finger. Table 2.1 shows general relationship of consistency and Unconfined Compression Strength (UCS) of clays [8]

Table 2-1 General Relationship of Consistency and UCS of Clays [8]

\begin{tabular}{|c|c|c|}
\hline Consistency & $\mathbf{q u}_{\mathbf{u}}\left(\mathbf{k} \mathbf{N} / \mathbf{m}^{\mathbf{2}}\right)$ & Remark \\
\hline Very Soft & $0-25$ & Squishes between finger when squeezed \\
\hline Soft & $25-50$ & Very easily deformed by squeezing \\
\hline Medium Stiff (firm) & $50-100$ & Thumb makes impression to deform \\
\hline Stiff & $100-200$ & Hard to deform by hand squeezing \\
\hline Very Stiff & $200-400$ & Very hard to deform by hand \\
\hline Hard & $>400$ & Nearly impossible to deform by hand \\
\hline
\end{tabular}




\section{3 compaction of soil}

compaction means pressing the soil particle close to each other by mechanical means. It is improving of the soil by increasing the dry density of a soil [5].

Compaction is required in many instances; examples include for the base layer of pavements, for embankment fills, for retaining wall backfills, for fill around pipes, and for landfills[12].

\subsubsection{Factors Affecting Compaction}

Besides moisture content, other important factors that affect compaction are soil type and compaction effort (energy per unit volume)[13]. The importance of each of these two factors is described below

\subsubsection{Effect of Soil Type}

The soil type - that is, grain-size distribution, shape of the soil grains, specific gravity of soil solids, and amount and type of clay minerals present - has a great influence on the maximum dry unit weight and optimum moisture content. Note also that the bell-shaped compaction curve is typical of most clayey soils. for sands, the dry unit weight has a general tendency first to decrease as moisture content increases and then to increase to a maximum value with further increase of moisture. The initial decrease of dry unit weight with increase of moisture content can be attributed to the capillary tension effect. At lower moisture contents, the capillary tension in the pore water inhibits the tendency of the soil particles to move around and be compacted densely[13]

\subsubsection{Effect of Compaction Effort}

The compactive effort is defined as the amount of energy imparted to the soil. With a soil of given moisture content, increasing the amount of compaction results in closer packing of soil particles and increased dry unit weight.[9]

The compaction energy per unit volume used for the Proctor test

$E=\frac{\left(\begin{array}{c}\text { number of } \\ \text { blows per } \\ \text { layer }\end{array}\right) *\left(\begin{array}{c}\text { Number of } \\ \text { layers }\end{array}\right) *\left(\begin{array}{c}\text { weight of } \\ \text { hammer }\end{array}\right) *\left(\begin{array}{c}\text { height of } \\ \text { drop hammer }\end{array}\right)}{\text { Volume of mold }}$ 


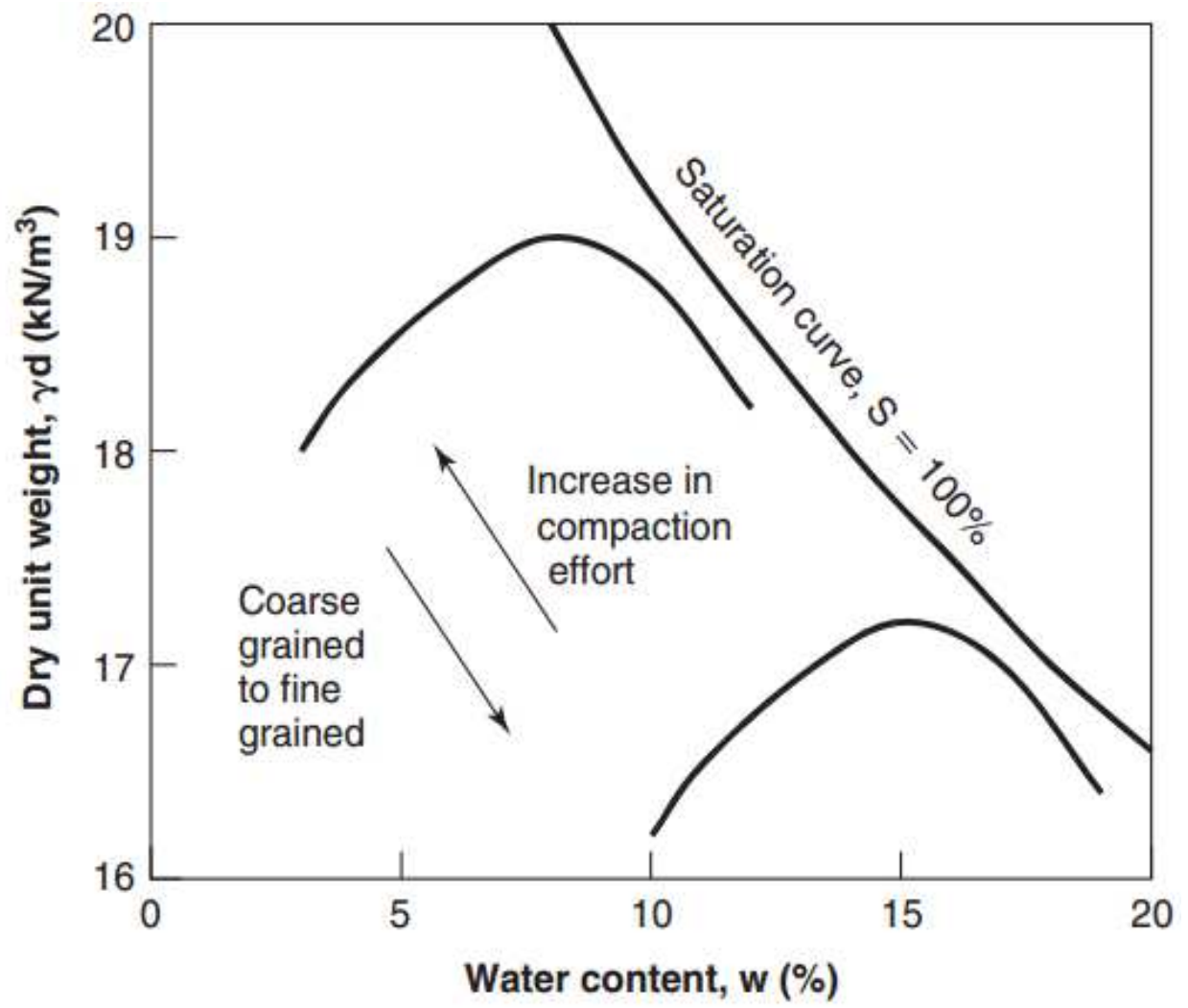

Figure 2-1 Effect of Compaction Effort in Compaction Curve [12]

As the compaction effort is increased, the maximum dry unit weight of compaction is increased and the optimum moisture content is decreased to some extent [9]

Also, coarse-grained soils tend to reach optimum compaction at water contents lower than fine-grained soils. However, coarse-grained soils tend to reach maximum dry densities that are higher than those of fine-grained soils [12]

\subsection{Review of Empirical Correlations}

In Geotechnical engineering different correlations have been conducted. the study presented by[4] studied Correlation Between Maximum Dry Density And Cohesion Of Remoulded Nsukka Clays. The results were given by this research was $C=2.4267 \gamma_{d}{ }^{2}+$ $80.5 \gamma_{d}-743.86$ with a correlation coefficient of $\mathrm{R}=0.679$ for low plasticity clay (CL) and $C=2.5058 \gamma_{d}^{2}+89.195 \gamma_{d}-871.06$ with a correlation coefficient of $\mathrm{R}=0.93$ for High plasticity clay $(\mathrm{CH})$.

[14]tried to investigate fine grained soil to determine correlations between compaction characteristics and Atterberg limits. The soils used were obtained from Addis Ababa. From statistical analysis, he was correlate optimum moisture content and maximum dry density with plastic limit and plasticity index. The results were given separately as $\mathrm{OMC}=$ 
$0.916 * \mathrm{PL}-0.030 * \mathrm{PI}-0.875$ and $\mathrm{MDD}=-0.18 * \mathrm{PL}-0.027 * \mathrm{PI}+$ 21.182. the Functional Correlations between Compaction Characteristics, Un-drained Shear Strength and Atterberg Limits presented by [15]. The results were given as $O M C=$ $0.233 P I+8$ with a regression coefficient of $\mathrm{R}^{2}=0.979$ and $\gamma d=-0.035 P I+18.498$ with a regression coefficient of 0.976 .

the Empirical correlation between undrained shear strength and pre-consolidation pressure in Swedish soft clays showed by[16]. The results were given as $\frac{S_{u}}{\sigma_{c}}=0.15+0.16 W_{L}$ with a regression coefficient of $\mathrm{R}^{2}=0.979$. this result showed that the undrained shear strength is mainly depends on the stress history in a given soil.

the correlation of the undrained shear strength and plasticity index of tropical clays studied by [17]. The results were given as $\log q u=2.342-2.175(P I / 100)$ a regression coefficient of $\mathrm{R}^{2}=-0.882 \%$. from the result the undrained shear strength (qu) value are inversely proportional to the plasticity index of the clay soil. If the plasticity index increases the undrained shear strength decreases.

according to the study conducted by [18] studied Developing Correlation between Dynamic Cone Penetration Index (DCPI) and Unconfined Compression Strength (UCS) of the Soils in Alem Gena Town. The results were given as UCS $=-24.56 * \ln (D C P I)+223.05$ with a regression coefficient of $\mathrm{R}^{2}=0.805 \%$ for black expansive soil. $U C S=-58.59 *$ $\ln (D C P I)+308.04$ with a regression coefficient of $\mathrm{R}^{2}=0.831 \%$.

\section{5 laboratory test}

\subsubsection{Natural Moisture Content}

for many soils, the water content is one of the most important index properties used in establishing the relationship between soil behavior and its index properties. The water content of a soil is used in expressing the phase relationships of air, water, and solids in a given volume of soil. In (cohesive) soils, the consistency of a given soil type depends on its water content [19]

\subsubsection{Specific Gravity}

Specific gravity of soil is the ratio of weight of a given volume of soil particles in air at a stated temperature to the weight of an equal volume of distilled water at a stated temperature. The specific gravity of a soil is used to relate a weight of soil to its volume. It also used to calculate phase relationships of soils [20] 


\subsubsection{Grain-size Distribution}

Grain size analysis is an important parameter, to determine the percentage of different grain sizes contained within a soil. It is required for classifying the soil as well as provides the grain size distribution of the soil. Two methods are mostly used to determine grain size distribution are Sieve analysis for coarse grained portion of the soil (size coarser than $0.075 \mathrm{~mm}$ ) and Hydrometer analysis for fine grained. Simple sieve analysis is used for particles larger than $0.075 \mathrm{~mm}$ while sedimentation analysis for particles smaller than $0.075 \mathrm{~mm}$. For soil sample that contains a measurable portion of their grains both coarser and finer than $0.075 \mathrm{~mm}$ size combined analysis is required. Portions (size finer than $0.075 \mathrm{~mm})$.

\subsubsection{Atterberg Limits}

Atterberg Limits are defined as water contents at certain limiting or critical ranges in soil behavior. It also indicates the points at which the consistency of a fine-grained changes from a liquid state to a plastic state (liquid limit), from a plastic state to a semisolid state (plastic limit), and from a semisolid state to a solid state (shrinkage limit). They are used in classification of fine-grained soils [12]

The sample of soil passing sieve No $40(0.425 \mathrm{~mm})$ is used to determine the Atterberg Limits.

\subsubsection{Classification of the Soils}

Soil classification is the distribution of soils into different groups such that the soils in a particular group have similar property. It is the type of labelling of soils with similar size. As there is a wide variety of soils covering the earth, it is desirable to systemize or classify the soils into broad groups of similar property [5]

there are various soil classification systems are existing in the world, Presently, two of classification systems are frequently used by geotechnical and soil engineers. Both systems take into account the particle-size distribution and Atterberg limits. They are the American Association of State Highway and Transportation Officials (AASHTO) classification system and the Unified Soil Classification System. The soils in this study have been classified according to UCSC. 


\subsubsection{Unified Soil Classification System}

This type of classification system is the most common for use in all types of engineering problems including soils. This type of system classifies soils into two broad categories:

Coarse-grained soils that are gravelly and sandy in nature with more than $50 \%$ retained through the No.200 sieve. The group symbols start with a prefix of G or S. $\mathrm{G}$ stands for gravel or gravelly soil, and $\mathrm{S}$ for sand or sandy soil.

$>$ Fine-grained soils are with less than 50\% retained through the No.200 sieve. The group symbols start with prefixes of $\mathrm{M}$, which stands for inorganic silt, $\mathrm{C}$ for inorganic clay, or $\mathrm{O}$ for organic silts and clays. The symbol $\mathrm{Pt}$ is used for peat, muck, and other highly organic soils [8]

\subsubsection{Plasticity Chart}

The plasticity chart is a plot of the plasticity index versus the liquid limit of a soil and it is used for classifying fine-grained soils according to their plasticity. The A line is an empirically chosen line that splits the chart between clays above the A line and silts below the A line. The vertical line, corresponding to a liquid limit equal to $50 \%$, separates highplasticity fine-grained soils $(w L>50)$ from low-plasticity fine-grained soils $(w L<50)$. To classify a soil, the plasticity index and liquid. limit of that soil are plotted on the chart; the region in which the point falls indicates what type of fine-grained soil it is or what kind of fines are encountered in a coarse-grained soil. The plasticity chart is the basis for the classification of fine-grained soils and of the fines fraction of coarse-grained soils [12]

\subsubsection{Compaction Test}

compaction means pressing the soil particle close to each other by mechanical means. It is improving of the soil by increasing the dry density of a soil[5].

To determine the dry density of the soil, the wet unit weight of the soil is first determining by using the following equation.

$$
\rho_{w e t}=\frac{M_{t}}{V_{t}}
$$

Then, to determine the dry density of the soil by the following equation

$$
\gamma_{\mathrm{d}}=\frac{\gamma_{\mathrm{wet}}}{1+\mathrm{w}}
$$

Compaction is the process of compressing the soil and reducing the air void by using mechanical means. The purpose of compaction is increasing soil physical properties used 
for a particular project. Compaction is measured quantitively by using maximum dry density and the moisture content of soil. In the figure below, the compaction curve shows the relationship between dry density and moisture content of the soil. when the water content is low, the soil is very stiff and has much air voids but if the water content of a soil increased up to optimum moisture content, the soil will be increase the dry density and has no air voids in soil pores [8]

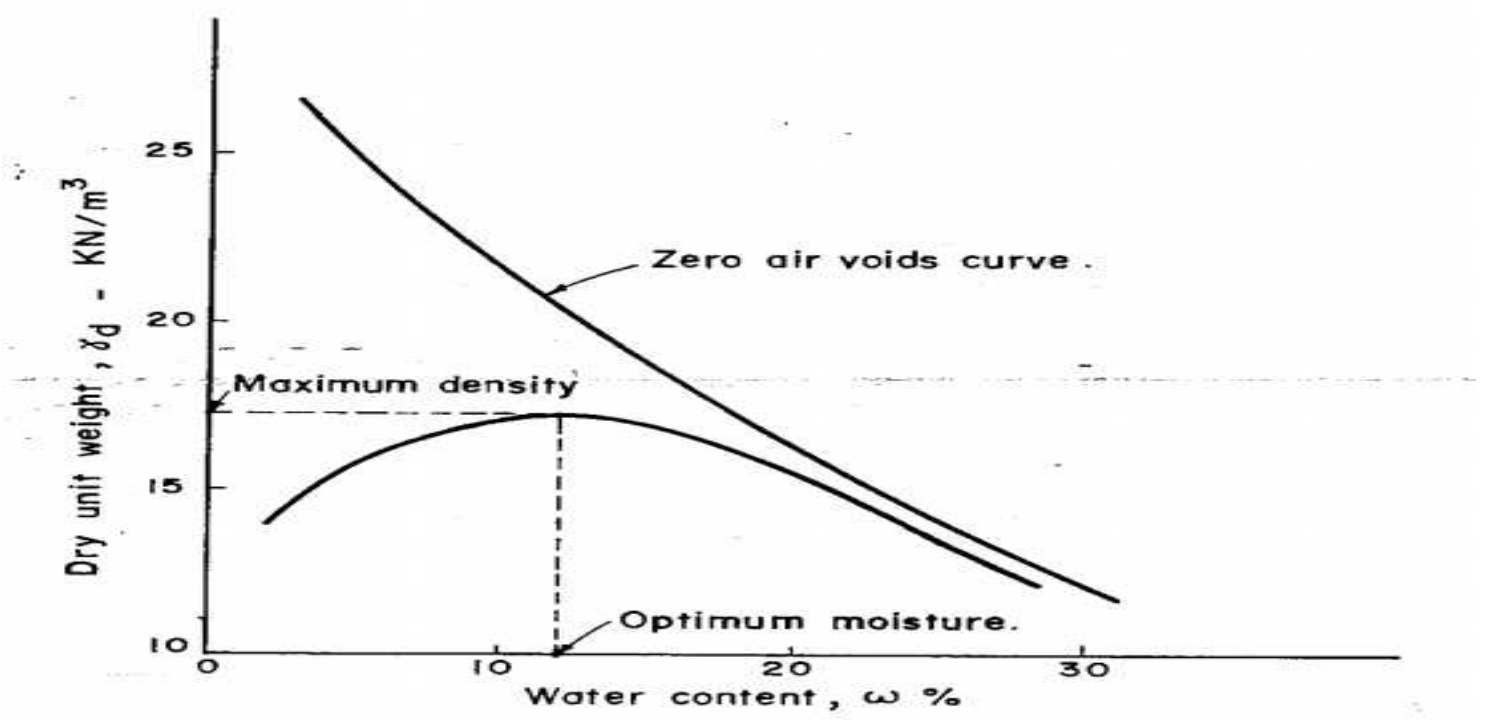

Figure 2-2 Compaction Curve [12]

\subsubsection{Method of laboratory soil compaction}

To attain the required maximum dry unit weight in the field, first appropriate tests to determine in the laboratory and this laboratory results must be confirmed in the field. The following tests are normally carried out in a laboratory.

\subsubsection{Standard proctor compaction test (ASTMD-698)}

A soil at selected water content is placed in three layers in to a mold of $101.6 \mathrm{~mm}$ diameter. with each layer compacted by 25 blows of a $2.5 \mathrm{~kg}$ hammer dropped from a height of $305 \mathrm{~mm}$, subjecting the soil to a total compaction effort of about $600 \mathrm{KN} / \mathrm{M}^{2}$. So that the resulting dry unit weight at optimum water content is determined. [9]

\subsubsection{Modified proctor compaction test (ASTMD-698)}

The test method covers laboratory compaction procedures used to determine the relationship between water content and dry unit weight of soils, compacted in 5 layers by $101.6 \mathrm{~mm}$ diameter mold with a $4.5 \mathrm{~kg}$ hammer dropped from a height of $457 \mathrm{~mm}$ producing a compaction effort of $2700 \mathrm{KN} / \mathrm{M}^{2}$. [9] 


\subsubsection{Unconfined Compression Strength (UCS) Test}

The most direct quantitative measure of consistency is the load per unit area at which unconfined cylindrical samples of the soil fails in compression test. This quantity is known as the unconfined compressive strength of the soil[12].

The unconfined compression test is a special case of a triaxial compression test in which the tests are carried out only on saturated samples which can stand without any lateral support. The test, is, therefore, applicable to cohesive soils only. The test Shear Strength of Soil is an undrained test and is based on the assumption that there is no moisture loss during the test[8].

In this test the sample is a cylinder with a diameter $d$ and a height $h$ equal to about 2 times the diameter. The ratio $\mathrm{h} / \mathrm{d}$ is about 2 to ensure that the oblique shear plane that typically develops during failure can propagate through the entire sample without intersecting the top or bottom platen. The sample remains unconfined during the test; therefore, the minor principal stress $\sigma 3$ is zero. A vertical load is applied to the sample by pushing upon the bottom platen at a constant rate of displacement while holding the top platen in a fixed position[12].

The vertical total stress $\sigma$ is calculated by dividing the vertical load by the cross-sectional area of the sample. Because it is assumed that there is no shear between the top of the sample and the bottom of the top platen that stress is the major principal stress $\sigma 1$. the unconfined compression test gives both an undrained shear strength and a modulus of deformation for fine-grained soils. Axial stress on the specimen is gradually increased until the specimen fails. The sample fails either by shearing on an inclined plane (if the soil is of brittle type) or by bulging. The vertical stress at any stage of loading is obtained by dividing the total vertical load by the cross-sectional area. The cross-sectional area of the sample increases with the increase in compression [8]

The cross-sectional area A at any stage of loading of the sample may be computed on the basic assumption that the total volume of the sample remains the same. That is

$$
\text { Aoho }=A h
$$

Where Ao, ho is equal to initial cross-sectional area and height of sample respectively. And also, A, h is equal to cross-sectional area and height respectively at any stage of loading.

If $\Delta \mathrm{h}$ is the compression of the sample, the strain $\varepsilon$

$$
\varepsilon=\frac{\Delta \mathrm{h}}{\mathrm{h}}
$$


since $\Delta \mathrm{h}=\mathrm{ho}-\mathrm{h}$, we may write Aoho $=\mathrm{A}($ ho- $\Delta \mathrm{h})$ Therefore,

$$
A=\frac{A_{o h o}}{h_{o-\Delta h}}=\frac{A_{o}}{1-\frac{\Delta h}{h_{o}}}=\frac{A_{o}}{1-\varepsilon}
$$

The average vertical stress at any stage of loading may be written as

$$
\sigma_{1}=\frac{P}{A}=\frac{P(1-\varepsilon)}{A}
$$

where $\mathrm{P}$ is the vertical load at the strain $\varepsilon$. Using the relationship given by Eq. (2.7) stressstrain curves may be plotted. The peak value is taken as the unconfined compressive strength $\mathrm{q}_{\mathrm{u}},[9]$

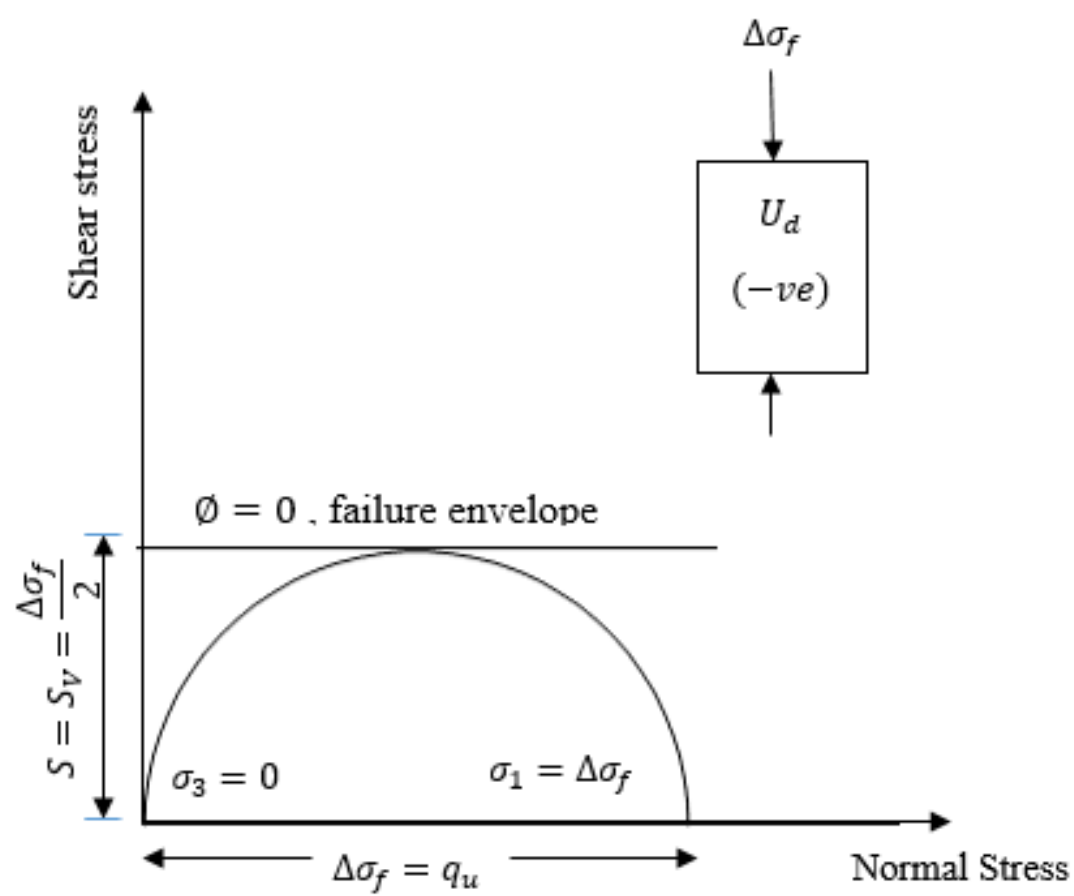

Figure 2-3 Mohr -Circle on Undrained Condition [8]

The unconfined compression test (UC) is a special case of the unconsolidated-undrained (UU) triaxial compression test. The only difference between the UC test and UU test is that a total confining pressure under which no drainage was permitted was applied in the latter test. Because of the absence of any confining pressure in the UC test, a premature failure through a weak zone may terminate an unconfined compression test [8] 


\section{CHAPTER -THREE}

\section{MATERIALS AND METHODS}

In this Chapter laboratory analysis of collected samples and correlation and regression methods were presented. Laboratory tests were conducted in Jimma University, geotechnical Engineering Laboratory. Secondary data which was used to describe geological condition of the study area as well as test result of unconfined compressive strength and compaction test value was obtained from Google Map and some construction projects in burayu town.

\subsection{Description of the Study Area}

The study was conducted in the western Oromia Burayu town. Burayu town is located in the Oromia National, Regional State on the western fringe of Addis Ababa, along the Addis Ababa-Ambo road; $15 \mathrm{~km}$ away from the center of Addis Ababa measured from the Piazza. Astronomically the town extends roughly from $9^{\circ} 02^{\prime}$ to $9^{\circ} 02^{\prime} 30^{\prime \prime}$ North latitudes and $38^{\circ} 03^{\prime} 30^{\prime \prime}$ to $38^{\circ} 41^{\prime} 30^{\prime \prime}$ East longitudes. According to census, the population of Burayu town was 4,138 in 1984; 10,027 in 1994, 63,873 in 2007 and 100,200 in 2010 (estimated). The Burayu town administration has estimated that the population of the town has grown to more than 250,000 in 2018 [21].Location of the research area is shown in figure 3.1 below.

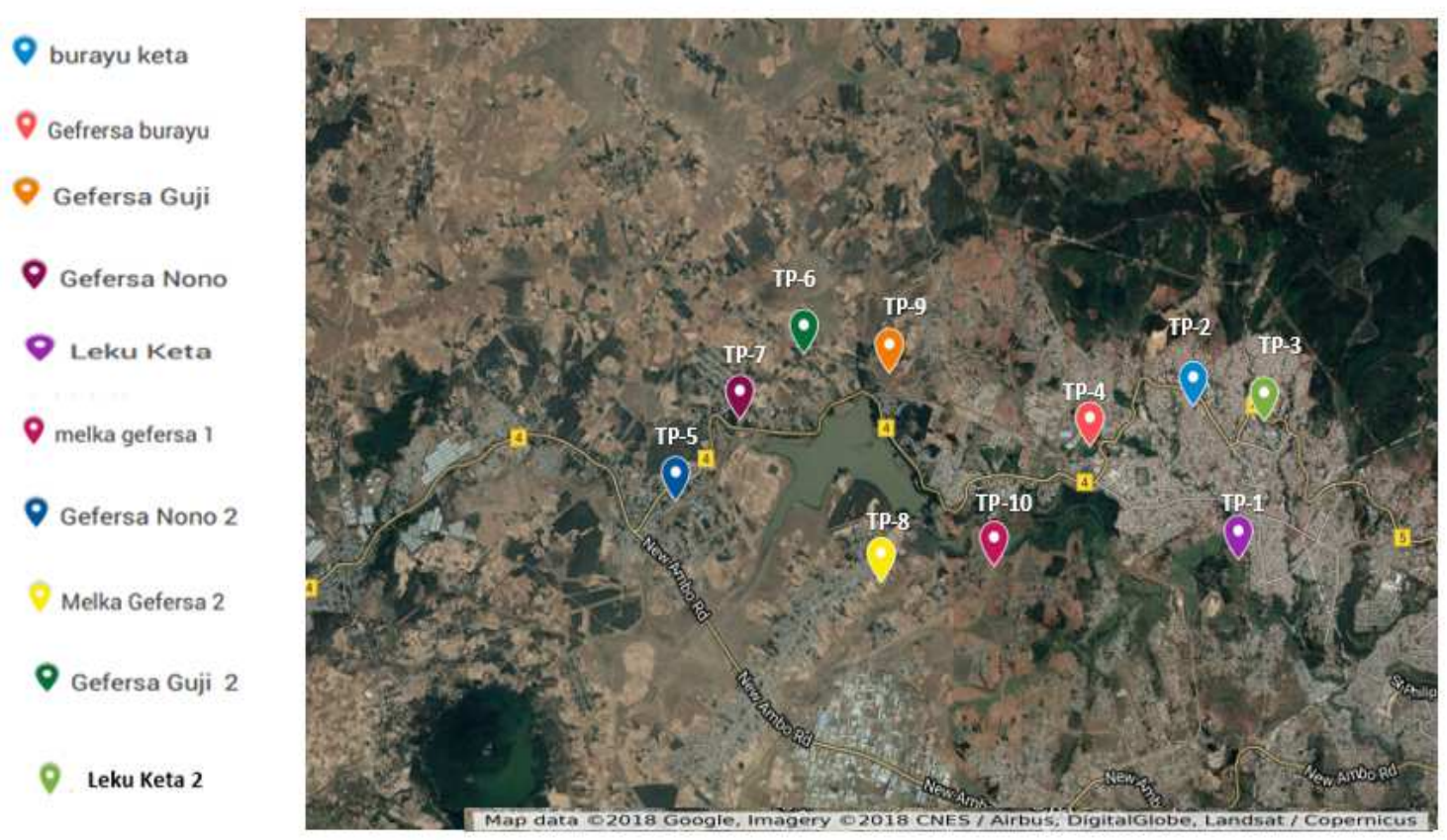

Figure 3-1 Location of the research area (Source: From Google Map) 


\subsection{Data Collection}

The data collection process consists of gathering relevant information from google map, Burayu Town Municipality and collection of soil samples during site visits.

Sampling locations were selected within and outskirt of Burayu Town using random sampling technique. Soil samples were collected. The collected soil samples from the field are further analysed in the laboratory to classify and categorize the soil type and determine the regression and correlation analysis.

Ten test pits were excavated using local labour and samples were collected from each test pits at different depth in different parts of Burayu Town. Up to three soil samples are taken from one test pit, in total thirty disturbed and undisturbed samples collected for further laboratory investigations.

Disturbed and undisturbed soil samples were gathered from test pits to determine index properties, soil classification, compaction test and Unconfined Compression Strength (UCS), etc.

Thin walled Tube sampling methods used to extract undisturbed soil as per ASTM D158794 specification in different area of Burayu Town. Polythene bag, due to its very minimum degree of disturbance, was used for sampling and transporting representative disturbed soil samples at different layers of test pits according to ASTM D 4220-95.

before selecting sampling areas, visual site investigation and information from administrator, residents and construction organization were collected to consider soil types and to take sample evenly in the whole town. After observation of the soil type in the whole town, ten sampling areas were selected from different locations of the town. Pits were excavated to the maximum depth of 3 meters by excavation manually, but in some areas boulders were encountered making the digging difficult. Both disturbed and undisturbed samples were taken. Sample for laboratory testing were collected. The figure below shows the general flow chart of the study. 


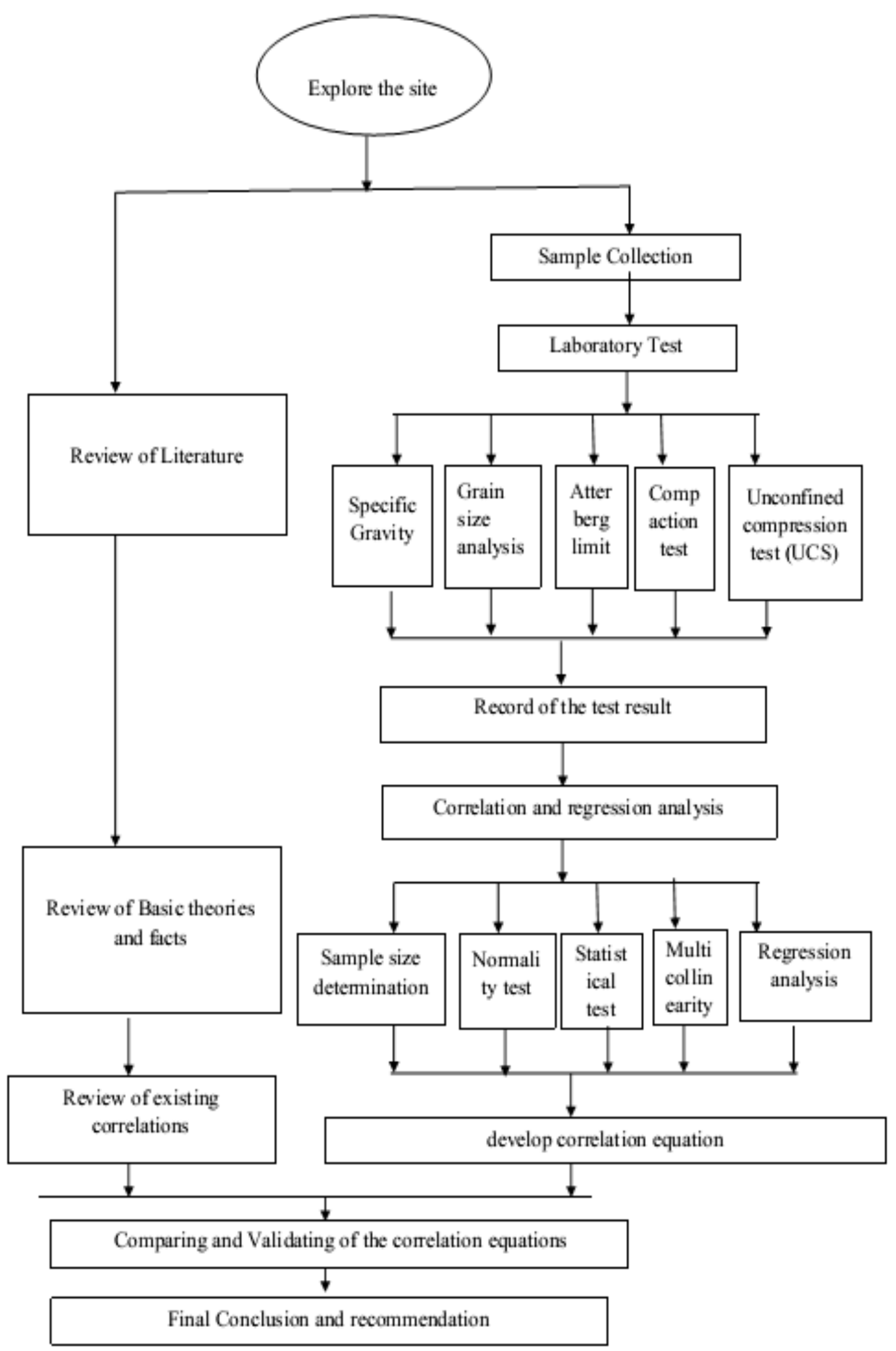

Figure 3-2: Flow chart of the study 
The global coordinates of sampling location i.e. northing, easting and elevations are shown in Table 3.1

Table 3-1 Global coordinates of sampling areas

\begin{tabular}{|c|c|c|c|c|}
\hline Test Pit & Location & Northing & Easting & Elevation $(\mathrm{m})$ \\
\hline TP-1 & Leku Keta & 9.05716 & 38.68164 & 2512 \\
\hline TP-2 & Burayu Keta & 9.07458 & 38.67604 & 2585 \\
\hline TP-3 & Leku Keta 2 & 9.07283 & 38.68488 & 2586 \\
\hline TP-4 & Gefersa Burayu & 9.07001 & 38.66317 & 2616 \\
\hline TP-5 & Gefersa Nono 2 & 9.06383 & 38.61156 & 2619 \\
\hline TP-6 & Gefersa guji 2 & 9.08048 & 38.62752 & 2640 \\
\hline TP-7 & Gefersa Nono & 9.07306 & 38.61956 & 2615 \\
\hline TP-8 & Melka gefersa 2 & 9.05467 & 38.63716 & 2605 \\
\hline TP-9 & Gefersa guji & 9.07831 & 38.63816 & 2610 \\
\hline TP-10 & Melka gefersa & 9.05647 & 38.65123 & 2600 \\
\hline \multicolumn{5}{|r}{}
\end{tabular}

\subsection{Laboratory Analysis}

The engineering properties soils are classified and identified based on index properties and other tests. Some of this properties of soil are; Natural moisture content, Specific gravity, consistency limits, Grain size analysis, compaction test and unconfined compressive strength. The entire laboratory tests were performed in Jimma institute of Technology geotechnical engineering Laboratory using the following standard testing procedures, (Table 3-2).

Table 3-2 Summary of laboratory testing procedure standards

\begin{tabular}{|l|l|}
\hline Test Description & Standard Testing Procedure \\
\hline Grain Size Distribution Analysis & ASTM D 1140-97 and D 422-98 \\
\hline Natural Moisture Content & ASTM D 2216-98a \\
\hline Atterberg Limits & ASTM D 4318-98 \\
\hline Specific Gravity & ASTM D 854-98 \\
\hline Compaction test & ASTM D698 \\
\hline Unconfined Compressive Strength & ASTM D2166-98a \\
& \\
\hline
\end{tabular}

\subsection{Steps for correlation and Regression Analysis}

\subsubsection{Sample size determination}

In most studies the sample size is determined effectively by two factors: (1) the nature of data analysis proposed and (2) estimated response rate. [22] 
Margin of error is the statistics, expressing the amount of random variable sampling error in the survey analysis. The higher margin of error the lessor confidence interval. It is $1 / 2$ half the width of confidence interval. A larger sample size produces the smaller the margin error. The standard deviation of population found from previous researches and literatures. confidence interval is used to indicate the reliability of an estimate. The calculation is worked firstly by selection of the desired confidence level. To determine the sample size, if the standard deviation of the population known, the following formula is used

$$
N=\frac{t_{\alpha / 2}^{2} * \sigma^{2}}{E^{2}}
$$

If the population is unknown, the following formula is used to determine sample size for sample proportion

$$
N=\frac{t_{\alpha / 2}^{2} * \bar{p}(1-\bar{p})}{E^{2}}
$$

$\sigma^{2}=$ standard deviation

$\mathrm{E}^{2}=$ Margin of error rate

$\bar{p}=$ percentage picking a choice or population proportion response

$\mathrm{t}_{\alpha / 2}=1.96^{2}$ at $95 \%$ of confidence level

$\mathrm{N}=$ sample size

\subsubsection{Normality Test}

Normality test is used to check whether the data fulfill assumption of normally distributed or not. It also helps to choose parametric or Non-parametric statistical tests. There are many tests to check whether the data is normally distributed or not. these tests basically classified as graphical and non-graphical tests for assessing univariate normality. One of the most popular graphical tests is the normal probability plot, where the observations are arranged in increasing order of magnitude and then plotted against expected normal distribution values. The plot should resemble a straight line if normality is tenable. [23]

One could also examine the histogram of the variable in each group. This gives some indication of whether normality might be violated. However, with small or moderate sample sizes, it is difficult to tell whether the non-normality is real or apparent, because of considerable sampling error. Therefore, most researcher prefer a non-graphical test. Among the non-graphical tests are the Kolmogorov-Smirnov, the Shapiro-Wilk test, and the use of skewness and kurtosis coefficients. the Kolmogorov-Smirnov test was shown not to be as 
powerful as the Shapiro-Wilk test. The combination of skewness and kurtosis coefficients and the Shapiro-Wilk test were the most powerful in detecting departures from normality. The procedure also yields the skewness and kurtosis coefficients, along with their standard errors. All of this information is useful in determining whether there is a significant departure from normality, and whether skewness or kurtosis is primarily responsible.[24]

Data showing a moderate departure from normality can usually be used in parametric procedures without loss of integrity. Also, for comparing means and sample size (for each group) is "large" (say,>=30), we can invoke the central limit theorem (CLT) to justify using parametric procedures even when the data are not normally distributed. Briefly, the CLT states that sample means are approximately normal for sufficiently large sample sizes even when the original populations are non-normal.[25]

The following table shows which variable is selected to check the normality of the data in statistical test. In most cases normality of residual is enough to accept the total data is normally distributed or not because The standard assumption in linear regression is that the theoretical residuals are independent and normally distributed.

Table 3-3:Variable selected for checking normality of parametric test

\begin{tabular}{|c|c|}
\hline Parametric test & What to check for normality \\
\hline Independent t-test & Dependent variable or residual \\
\hline Paired t-test & Paired differences \\
\hline One-way ANOVA & Residuals \\
\hline Repeated measures ANOVA & Residuals at each time point \\
\hline Pearson's correlation coefficient & Both variables are normally distributed \\
\hline Simple linear regression & Residuals \\
\hline
\end{tabular}

\subsection{3 statistical test}

A statistical test provides a mechanism for making qualitative decisions about a process or processes. The intent is to determine whether there is enough evidence to "reject" a null hypothesis or hypothesis about the process. Not rejecting may be a good result if we want to continue to act as if we "believe" the null hypothesis is true. Or it may be a disappointing result, possibly indicating we may not yet enough data to "prove" something by rejecting the null hypothesis. [25] 


\subsubsection{Parametric and non-parametric statistical tests}

Parametric tests are more strong and for the most part require less data to make a stronger conclusion than nonparametric tests. However, to use a parametric test, the data must be fulfilling normality test and also the data need to be continuous and Interval or ratio level of measurement. If the data do not meet the criteria for a parametric, before we conduct non -parametric test it must be checked by data transformation method or normalization method. It is not possible; it must be analyzed with a nonparametric test. If a nonparametric test is required, more data will be needed to make the same conclusion. [23]

Non-parametric tests make no assumptions about the distribution of the data. Nonparametric techniques are usually based on ranks or signs rather than the actual data and are usually less powerful than parametric tests.[24]

Commonly used parametric and nonparametric tests are described below by the following table.

Table 3-4: Methods for determining parameter and non-parametric statistical test

\begin{tabular}{|l|l|}
\hline Parametric Test & Non-parametric test \\
\hline Independent - samples T-test & Mann-Whitney Test \\
\hline Paired samples T-test & Wilcoxon Signed-Rank Test \\
\hline One-Way ANOVA & \multirow{2}{*}{ Kruskal-Wallis and Friedman's ANOVA } \\
\cline { 1 - 2 } One-Way repeated measures of ANOVA
\end{tabular}

\subsubsection{Parametric Tests}

\subsubsection{1 t-Test}

The Student t-test is probably the most widely used parametric test. A single sample t-test is used to determine whether the mean of a sample is different from a known average. A pair-sample t-test is used to establish whether a difference occurs between the means of two similar data sets. The independent t-test, also called the two sample t-test, independentsamples t-test or student's t-test, is a statistical test that determines whether there is a statistically significant difference between the means in two independent variables.[26] The t-test uses the mean, standard deviation, and number of samples to calculate the test statistic. In a data set with a large number of samples, the critical value for the t-test is 1.96 for an alpha of 0.05 , obtained from a t-test table. 


\subsection{The z-Test}

The next test, which is very similar to the t-test, is the z-test. However, with the z-test, the variance of the standard population, rather than the standard deviation of the study groups, is used to obtain the z-test statistic. Using the z-chart, like the t-table, we see what percentage of the standard population is outside the mean of the sample population. If, like the t-test, greater than $95 \%$ of the standard population is on one side of the mean, the p-value is less than 0.05 and statistical significance is achieved. As some assumption of sample size exists in the calculation of the z-test, it should not be used if sample size is less than 30. If both the $\mathrm{n}$ and the standard deviation of both groups are known, a pair sample t-test is best.[26]

\subsection{ANOVA Test}

Analysis of variance (ANOVA) is a test used to determine if one or more of the means of several groups is different from others. it incorporates means and variances to determine the test statistic. The test statistic is then used to determine whether groups of data are the same or different. When hypothesis testing is being performed with ANOVA, the null hypothesis is stated such that all groups are the same. The test statistic for ANOVA is called the F-ratio.[25]

\subsubsection{Transformation of data(normalization)}

Data transformation can correct deviation from normality and uneven variance(heteroscedasticity). If The data is not normally distributed, parametric test is not allowed to use in testing the differences between means of variable. To use the parametric test, we need first of all to normalize the data by using the transformation function recommended in statistics. The logarithm, square root and the reciprocal transformation is commonly used method. After transform the data, histogram, Q-Q plots and Box plot is plot to verify if the log data are approximately normally distributed. If the transformation of data is not fulfilling assumption of normally distributed, we use nonparametric test.[25]

\subsubsection{Nonparametric Tests}

\subsection{Mann-Whitney U Test}

This test uses rank just as the previous test did. It is analogous to the t-test for continuous variable but can be used for ordinal data. This test compares two independent populations to determine whether they are different. The sample values from both sets of data are ranked together. Once the two test statistics are calculated, the smaller one is used to 
determine significance. Unlike other tests, the null hypothesis is rejected if the test statistic is less than the critical value. The U-value is widely available for this test.[26]

\subsection{Kruskal-Wallis Test}

The Kruskal-Wallis test uses ranks of ordinal data to perform an analysis of variance to determine whether multiple groups are similar to each other. This test ranks all data from the groups into one rank order and individually sums the different ranks from the individual groups. These values are then placed into a larger formula that computes an $\mathrm{H}$-value for the test statistic. The degrees of freedom used to find the critical value is the number of groups minus one. [26]

\subsubsection{Multicollinearity (interdependency check)}

Multicollinearity refers to the situation in which two or more independent variables in a multiple linear regression model are highly correlated. Multicollinearity poses a real problem for the researcher it increases the variances of the regression coefficients. The greater these variances, the more unstable the prediction equation will be.[27] The following are two methods for diagnosing multicollinearity:

$>\quad$ Examine the simple correlations among the predictors from the correlation matrix. These should be observed, and are easy to understand, but the researcher needs to be warned that they do not always indicate the extent of multicollinearity.

$>$ Variance inflation factor is the measure that can be used to quantify multicollinearity. The quantity $1 /\left(1-\mathrm{R}_{\mathrm{j}}{ }_{\mathrm{j}}\right)$ is called the $\mathrm{jth}$ variance inflation factor, where $\mathrm{R}_{\mathrm{j}}{ }_{\mathrm{j}}$ is the squared multiple correlation for predicting the jth predictor from all other predictors. the reciprocal of the above formula is called tolerances. The variance inflation factor for a predictor indicates whether there is a strong linear association between it and all the remaining predictors. It is distinctly possible for a predictor to have only moderate or relatively weak associations with the other predictors in terms of simple correlations. If the value for a variance inflation factor VIF exceeds 10, there is multicollinearity between the predictors. [28] 


\subsubsection{Correlation and regression methods}

Various method used for determining the adequacy of the different regression models obtained. A commonly used methods are listed below.

\subsubsection{The Standard Error Statistics}

The standard error of a statistic gives some idea about the precision of an estimate. Estimated standard errors are computed based on sample estimates, as population values are not obtainable using sample surveys [29]. The estimated standard error of a variable with mean $\vec{x}$ and standard deviation of SD is given by

$$
\sigma=\frac{S D}{\sqrt{n}}
$$

Where: $\sigma=$ estimated standard error of a sample.

$$
\mathrm{n}=\text { sample size }
$$

During modelling, a variable that shows the least standard error of estimates is the one to be relatively chosen.

\subsubsection{Residual Analysis}

Residual analysis is Any technique that uses the residuals, usually to investigate the adequacy of the model that was used to generate the residuals. a residual is the difference between the observed value of the response and the corresponding predicted value obtained from the regression model. Analysis of the residuals is frequently helpful in checking the assumption that the errors are approximately normally distributed with constant variance, and in determining whether additional terms in the model would be useful. Residuals that are far outside from the interval from normal probability plots may indicate the presence of an outlier, that is, an observation that is not typical of the rest of the data. Various rules have been proposed for discarding outliers. However, outliers sometimes provide important information about unusual circumstances of interest to experimenters. If the residual of an observation is larger than 3 times of the standard deviation (or standardized residual is larger than 3 ) then the observation may be considered as an outlier [26]

\subsubsection{Coefficient of Determination $\left(R^{2}\right)$}

A quantity used in regression models to measure the proportion of total variability in the response accounted for the model. Computationally, large values of $\mathrm{R}^{2}$ (near unity) are considered good. However, it is possible to have large values of $\mathrm{R}^{2}$ and find that the model 
is unsatisfactory. $\mathrm{R}^{2}$ is also called the coefficient of determination (or the coefficient of multiple determination in multiple regression) [29]

The value of $\mathrm{R}^{2}$ is always between 0 and 1 , because $\mathrm{R}$ is between -1 and +1 , whereby a negative value of $\mathrm{R}$ indicates inversely relationship and positive value implies direct relationship and it is given by the equation[30].

$$
R^{2}=\frac{S S R}{S S T}=1-\frac{S S E}{S S T}
$$

Where:

$$
\begin{aligned}
& S S_{T}=\sum_{i=1}^{n}(y-\bar{y})^{2} \\
& S S_{E}=\sum_{i=1}^{n}\left(y_{i}-\bar{y}_{i}\right)^{2}
\end{aligned}
$$

And $S S_{R}=S S_{T}-S S_{E}=$ regression sum of squares

$S S E$ error sum of squares

$S S T=$ total sum of squares

$Y i=\mathrm{i}^{\text {th }}$ value of the response variable

$\bar{Y}_{i}=\mathrm{i}^{\text {th }}$ value of the fitted response variable.

$\bar{y}=$ average value of the response variable

\subsubsection{Adjusted $R^{2}$}

Another useful criterion used to check the adequacy of a regression model is using a modified $\mathrm{R}^{2}$ that accounts the usefulness of a variable in a model. It essentially penalizes the analyst for adding terms to the model[29].

This statistic is called the adjusted $\mathrm{R}^{2}$ defined as:

$$
R_{P}^{2}=1-\frac{n-1}{n-p p}\left(1-R^{2}\right)
$$

Where: $p p=$ number of regressors in the regression model

$n=$ Sample size

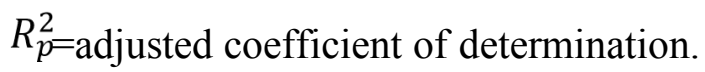

Maximizing the value of $\mathrm{R}^{2}$ by adding variables is inappropriate unless variables are added to the equation for sound theoretical reason. At an extreme, when n-1 variables are added to a regression equation, $\mathrm{R}^{2}$ will be 1 , but this result is meaningless. Adjusted $R^{2}$ is used as 
a conservative reduction to $R^{2}$ to penalize for adding variables and is required when the number of independent variables is high relative to the number of cases or when comparing models with different numbers of independents .During regression analysis, a regression model with higher value of adjusted $R^{2}$ is usually accepted[26]

\subsubsection{Correlation Coefficients}

Correlation coefficients measures the strength of linear association between two measurement variables.

\subsection{Pearson's correlation coefficient}

Pearson's correlation coefficient or simply correlation coefficient, R, measures the strength of linear association between two measurement variables. It is calculated as: [30]

$$
R=\frac{\operatorname{cov}(x, y)}{\operatorname{sd}(x) * s d(y)}
$$

Where:

$\operatorname{cov}(x, y)=\sum_{i=0}^{n}\left(x_{i}-\bar{x}\right)\left(y_{i}-\bar{y}\right)=$ covariance of $\mathrm{x}$ and $\mathrm{y}$ variable

$s d(x)=\sqrt{\sum_{i=0}^{n}\left(x_{i}-\bar{x}\right)}=$ standard deviation of variable $\mathrm{x}$

$s d(y)=\sqrt{\sum_{i=0}^{n}\left(y_{i}-\bar{y}\right)}=$ standard deviation of variable $\mathrm{y}$

The value of $\mathrm{R}$ ranges from -1 to +1 . A value of the correlation coefficient closes to +1 indicates a strong positive linear relationship (i.e. one variable increases with the other) A value close to -1 indicates a strong negative linear relationship (i.e. one variable decreases as the other increases). A value close to 0 indicates no linear relationship; however, there could be a nonlinear relationship between the variables[26]. The following key points shows Assumptions used for conducting Pearson correlation.

The two variables should be measured at the interval or ratio level

$>$ There needs to be a linear relationship between the two variables

$>$ There should be no significant outliers

$>$ The variables should be approximately normally distributed

\subsection{Spearman's correlation coefficient}

Is a nonparametric measure of the strength and direction of association that exists between two variables measured on at least an ordinal scale. It is used for when the assumption necessary for conducting the Pearson's correlation is failed.

\subsubsection{Hypothesis Testing of Regression}

several problems in engineering require that we decide whether to accept or reject a statement about some parameter. The statement is called a hypothesis, and the decision- 
making procedure about the hypothesis is called hypothesis testing. This is one of the most useful aspects of statistical inference, since many types of decision-making problems, tests, or experiments in the engineering world can be formulated as hypothesis-testing problems [7]

The t-test is one of the methods used to accept or reject a given hypothesis. The t- value is simply calculated as

$$
t_{\text {value }}=\frac{B}{S E}=\frac{\text { coef ficient of a variable in the regression equation }}{\text { standard error of the estimated coef ficient }}
$$

Suppose we want to test the validity of a hypothesis; the hypothesis can be formulated as follows:

$$
\left\{\begin{array}{l}
H_{o}: \mu=a \\
H_{1}: \mu \neq a
\end{array}\right.
$$

For an arbitrary population value of "a", here "Ho "and " $\mathrm{H}_{1}$ " are the null hypothesis and alternative hypothesis, respectively. Let $\alpha$ denote the probability of rejecting a true hypothesis (level of significance of the test), then the tabulated t-value (t-tab) that is used to test the importance of a variable in the model is obtained by reading from the t-table with $\alpha / 2$ as column an "n" as row, and $\alpha$ as row and " $n-1$ " as column for two and one-sided hypothesis, respectively. Here " $n-1$ " denotes the degree of freedom[7].

By continuing in such fashion, it will be decided on the importance of each regression variable in the model. If $\mathrm{t}$-cal exceeds $\mathrm{t}$-tab, then "Ho" is accepted; otherwise, the null hypothesis is accepted. If " $a=0$ ", for instance, accepting Ho means the particular variable has no importance in explaining [7].

Nowadays, commercial statistical software can provide p-values. Hence, we may not need tables for our particular decision. The P-value is the smallest level of significance at which a variable is significant. If $p$ - value is smaller than $\alpha$, the particular variable is important in explaining the variation of the response in the model. If $\mathrm{Zo}_{\mathrm{o}}$ is the computed value of the test statistics, then the p- value is $2(1-(\mathrm{Zo}))$ for two-tailed test. Here, (Zo) is the standard normal cumulative distribution at $\mathrm{Zo}[26]$.

The p-value for each term tests the null hypothesis that the coefficient is equal to zero (no effect). A low p-value $(<0.05)$ indicates that you can reject the null hypothesis. In other words, a predictor that has a low p-value is likely to be a meaningful addition to your model because changes in the predictor's value are related to changes in the response variable. Conversely, a larger (insignificant) p-value suggests that changes in the predictor are not associated with changes in the response [7] 


\section{CHAPTER -FOUR}

\section{RESULT AND DISCUSSIONS}

\subsection{Laboratory test result}

The following laboratory result shows the primary data of the soil conducted on the study area.

\subsubsection{Grain-size Distribution}

The result of the sieve and hydrometer analysis is shown in the following table and Figure below.

Table 4-1 Grain Size analysis result

\begin{tabular}{|c|c|c|c|c|c|c|c|c|c|c|}
\hline \multirow{3}{*}{$\begin{array}{c}\text { Test } \\
\text { pit }\end{array}$} & \multirow{3}{*}{ Depth } & \multicolumn{8}{|c|}{ Percent Amount Of Particle Size } & \multirow{3}{*}{$\begin{array}{c}\% \\
\text { finer } \\
\text { than } \\
\mathbf{0 . 0 7 5}\end{array}$} \\
\hline & & \multicolumn{4}{|c|}{ AASHTO system } & \multicolumn{4}{|c|}{ USCS system } & \\
\hline & & Gravel & Sand & Silt & Clay & Gravel & Sand & Silt & Clay & \\
\hline \multirow{3}{*}{$\begin{array}{c}\text { TP- } \\
1\end{array}$} & 0.6 & 0.26 & 2.22 & 27.62 & 69.90 & 0.0 & 2.5 & 27.6 & 69.9 & 97.52 \\
\hline & 1.4 & 0.24 & 1.96 & 45.53 & 52.27 & 0.04 & 2.16 & 45.53 & 52.27 & 97.80 \\
\hline & 2.5 & 0.32 & 1.83 & 45.66 & 52.19 & 0.06 & 2.09 & 45.66 & 52.19 & 97.85 \\
\hline \multirow{3}{*}{$\begin{array}{c}\text { TP- } \\
2\end{array}$} & 0.5 & 0.77 & 2.24 & 39.56 & 57.43 & 0.33 & 2.68 & 39.56 & 57.43 & 96.99 \\
\hline & 1.5 & 1.22 & 2.47 & 43.05 & 53.25 & 0.56 & 3.14 & 43.05 & 53.25 & 96.30 \\
\hline & 2.7 & 2.48 & 3.88 & 35.07 & 58.57 & 1.00 & 5.36 & 35.07 & 58.57 & 93.64 \\
\hline \multirow{3}{*}{$\begin{array}{c}\text { TP- } \\
3\end{array}$} & 0.7 & 2.56 & 4.50 & 39.72 & 53.21 & 1.74 & 5.32 & 39.72 & 53.21 & 92.94 \\
\hline & 1.35 & 3.44 & 7.68 & 36.18 & 52.70 & 2.20 & 8.92 & 36.18 & 52.70 & 88.88 \\
\hline & 2.6 & 4.28 & 7.68 & 35.84 & 52.20 & 2.64 & 9.32 & 35.84 & 52.20 & 88.04 \\
\hline \multirow{3}{*}{$\begin{array}{c}\text { TP- } \\
4\end{array}$} & 0.6 & 4.34 & 8.41 & 33.81 & 53.44 & 1.88 & 10.87 & 33.81 & 53.44 & 87.25 \\
\hline & 1.5 & 5.38 & 9.70 & 29.09 & 55.83 & 2.50 & 12.59 & 29.09 & 55.83 & 84.91 \\
\hline & 2.7 & 5.6 & 10.8 & 28.8 & 54.9 & 2.3 & 14.0 & 28.8 & 54.9 & 83.64 \\
\hline \multirow{3}{*}{$\begin{array}{c}\text { TP- } \\
5\end{array}$} & 0.5 & 6.14 & 12.49 & 26.55 & 54.81 & 2.68 & 15.95 & 26.55 & 54.81 & 81.37 \\
\hline & 1.4 & 6.08 & 13.28 & 23.80 & 56.85 & 2.83 & 16.53 & 23.80 & 56.85 & 80.64 \\
\hline & 2.6 & 2.07 & 5.41 & 35.97 & 56.55 & 1.41 & 6.07 & 35.97 & 56.55 & 92.52 \\
\hline \multirow{3}{*}{$\begin{array}{c}\text { TP- } \\
6\end{array}$} & 0.5 & 2.44 & 6.61 & 34.83 & 56.12 & 1.60 & 7.45 & 34.83 & 56.12 & 90.95 \\
\hline & 1.7 & 1.66 & 4.95 & 35.16 & 58.24 & 1.21 & 5.40 & 35.16 & 58.24 & 93.40 \\
\hline & 2.6 & 1.64 & 4.43 & 37.37 & 56.56 & 0.98 & 5.08 & 37.37 & 56.56 & 93.93 \\
\hline \multirow{4}{*}{$\begin{array}{c}\text { TP- } \\
7\end{array}$} & 0.5 & 2.04 & 4.34 & 28.31 & 65.31 & 1.18 & 5.20 & 28.31 & 65.31 & 93.62 \\
\hline & 1.8 & 2.06 & 4.55 & 36.00 & 57.39 & 1.01 & 5.60 & 36.00 & 57.39 & 93.39 \\
\hline & 2.9 & 1.68 & 5.13 & 36.10 & 57.08 & 0.81 & 6.01 & 36.10 & 57.08 & 93.18 \\
\hline & 0.6 & 1.29 & 4.92 & 38.45 & 55.34 & 0.60 & 5.61 & 38.45 & 55.34 & 93.79 \\
\hline
\end{tabular}




\begin{tabular}{|c|c|c|c|c|c|c|c|c|c|c|}
\hline $\begin{array}{c}\text { TP- } \\
8\end{array}$ & 1.7 & 1.94 & 5.38 & 34.22 & 58.46 & 1.01 & 6.30 & 34.22 & 58.46 & 92.68 \\
\cline { 2 - 11 } & 2.7 & 1.95 & 4.37 & 27.68 & 66.00 & 0.81 & 5.51 & 27.68 & 66.00 & 93.68 \\
\hline \multirow{3}{*}{$\begin{array}{c}\text { TP- } \\
9\end{array}$} & 0.54 & 1.10 & 3.34 & 28.00 & 67.56 & 0.44 & 4.00 & 28.00 & 67.56 & 95.56 \\
\cline { 2 - 11 } & 1.6 & 1.73 & 2.96 & 41.04 & 54.28 & 0.66 & 4.02 & 41.04 & 54.28 & 95.32 \\
\cline { 2 - 11 } & 2.6 & 1.65 & 3.30 & 34.48 & 60.57 & 0.78 & 4.17 & 34.48 & 60.57 & 95.05 \\
\hline \multirow{3}{*}{$\begin{array}{c}\text { TP- } \\
10\end{array}$} & 0.6 & 0.85 & 3.10 & 35.58 & 60.47 & 0.21 & 3.74 & 35.58 & 60.47 & 96.05 \\
\cline { 2 - 11 } & 1.7 & 1.30 & 3.83 & 36.80 & 58.07 & 0.46 & 4.68 & 36.80 & 58.07 & 94.87 \\
\cline { 2 - 11 } & 2.8 & 1.65 & 4.69 & 31.20 & 62.47 & 0.60 & 5.73 & 31.20 & 62.47 & 93.67 \\
\hline
\end{tabular}

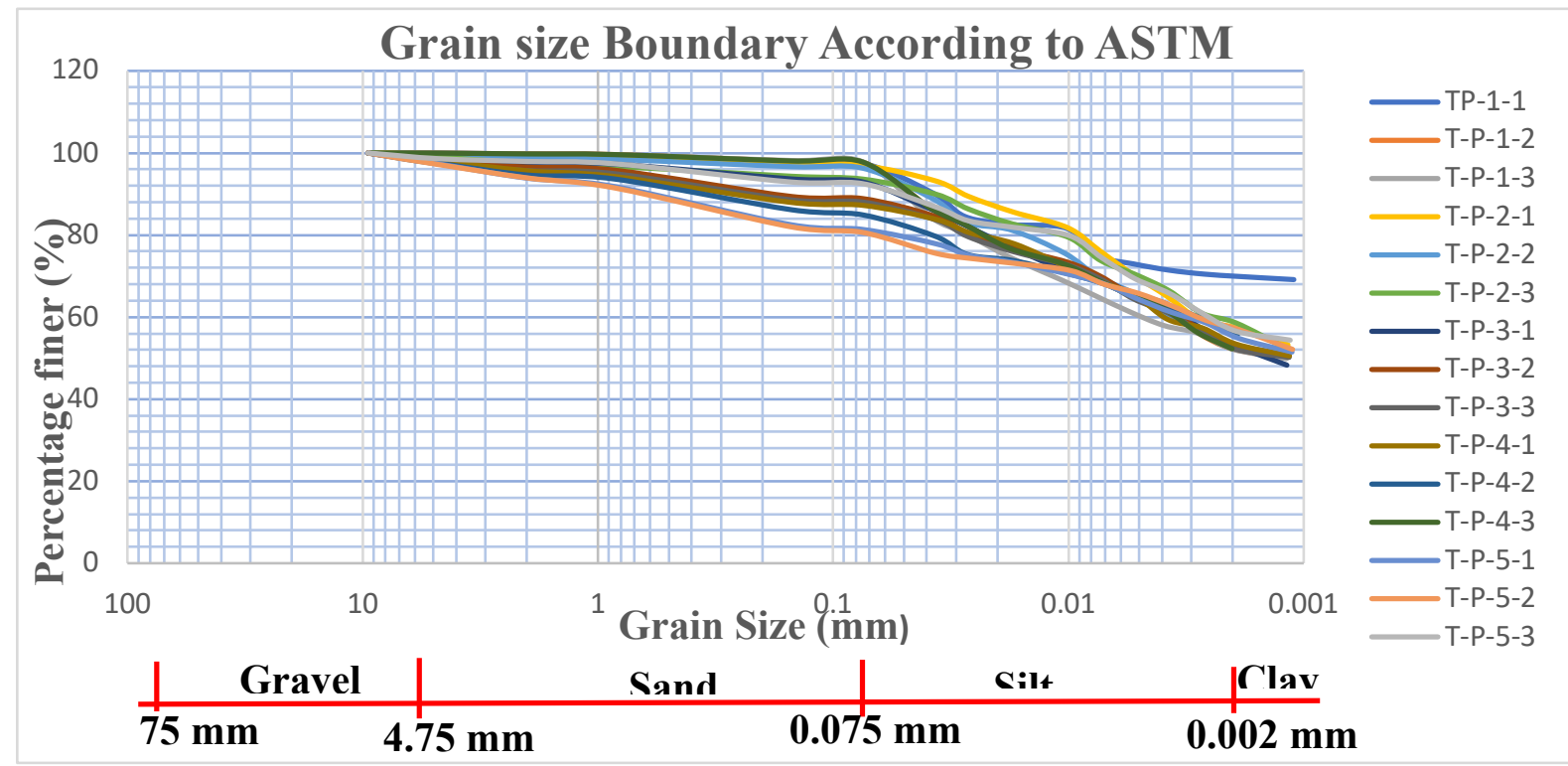

Figure 4-1 Grain size distribution curve for TP-1 to TP-5

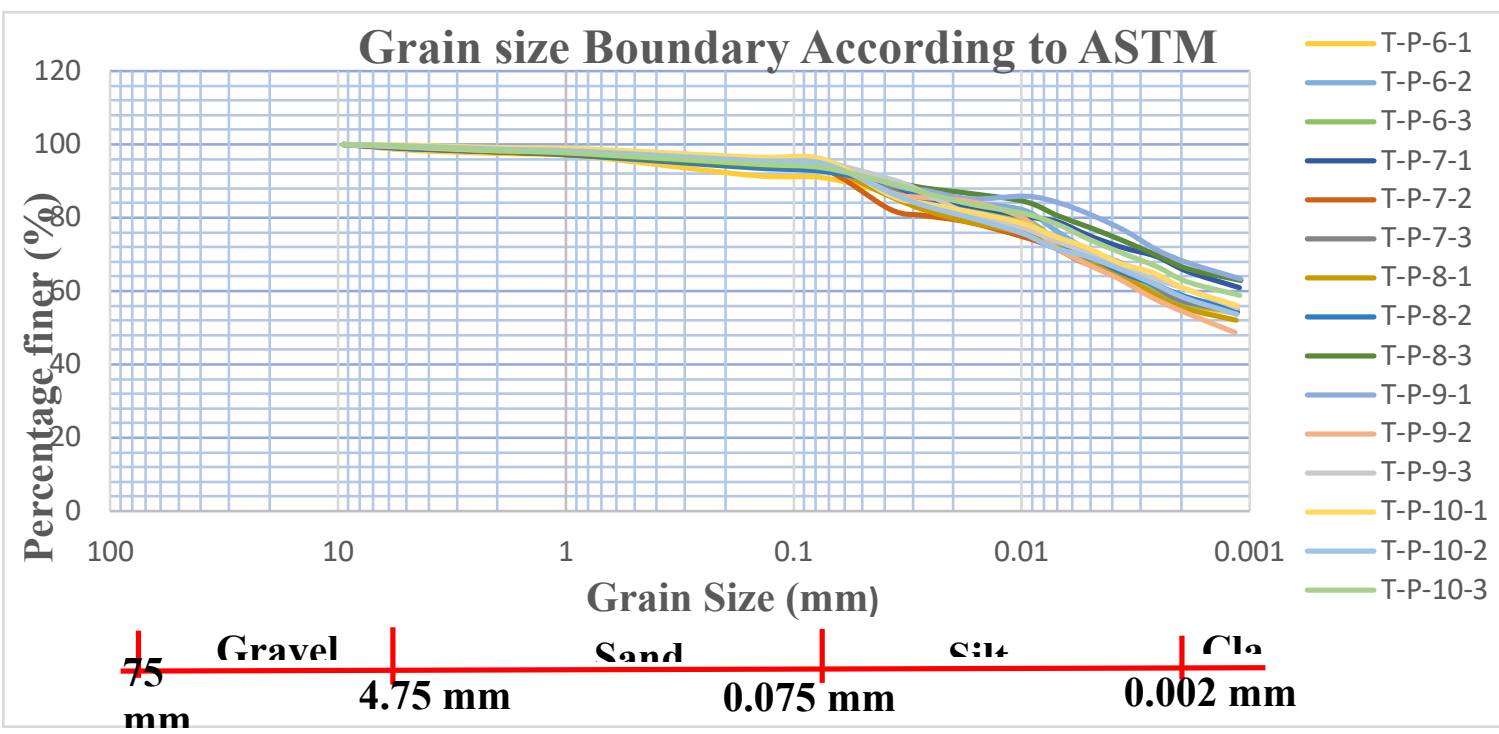

Figure 4-2 Grain size distribution curve for TP-6 to TP-10 
The table below shows the laboratory test result of the soil in the study area.

Table 4-2:Summary of test results

\begin{tabular}{|c|c|c|c|c|c|c|c|c|c|c|c|}
\hline \multirow{2}{*}{$\begin{array}{l}\text { Test pit } \\
\text { location }\end{array}$} & \multirow{2}{*}{$\begin{array}{c}\text { Sample } \\
\text { no }\end{array}$} & $\begin{array}{c}\text { Sample } \\
\text { Depth }\end{array}$ & NMC & \multirow{2}{*}{ Gs } & UCS & MDD & OMC & $\mathbf{L L}$ & PL & PI & \multirow{2}{*}{ USCS } \\
\hline & & $\mathbf{m}$ & $\%$ & & Kра & $\mathrm{g} / \mathrm{cc}^{3}$ & $\%$ & $\%$ & $\%$ & $\%$ & \\
\hline \multirow{3}{*}{ Leku Keta } & 1 & 0.6 & 33.29 & 2.72 & 215.943 & 1.31 & 29.77 & 64.99 & 30.98 & 34.00 & $\mathrm{CH}$ \\
\hline & 2 & 1.4 & 34.33 & 2.73 & 240.998 & 1.32 & 29.417 & 67.44 & 30.11 & 37.32 & $\mathrm{CH}$ \\
\hline & 3 & 2.5 & 34.39 & 2.74 & 253.955 & 1.3 & 29.54 & 61.94 & 30.59 & 31.34 & $\mathrm{CH}$ \\
\hline \multirow{3}{*}{$\begin{array}{c}\text { Burayu } \\
\text { Keta }\end{array}$} & 4 & 0.5 & 32.68 & 2.74 & 314.103 & 1.32 & 30.44 & 59.65 & 30.87 & 28.78 & $\mathrm{CH}$ \\
\hline & 5 & 1.5 & 32.70 & 2.74 & 340.637 & 1.316 & 30.241 & 63.78 & 30.70 & 33.09 & $\mathrm{CH}$ \\
\hline & 6 & 2.7 & 33.04 & 2.74 & 366.051 & 1.319 & 30.361 & 67.32 & 30.43 & 36.89 & $\mathrm{CH}$ \\
\hline \multirow{3}{*}{ Leku Keta 2} & 7 & 0.7 & 32.32 & 2.74 & 240.236 & 1.31 & 30.403 & 61.66 & 30.54 & 31.12 & $\mathrm{CH}$ \\
\hline & 8 & 1.35 & 32.43 & 2.75 & 270.912 & 1.32 & 30.407 & 62.33 & 30.33 & 31.99 & $\mathrm{CH}$ \\
\hline & 9 & 2.6 & 32.44 & 2.75 & 297.224 & 1.33 & 30.48 & 67.67 & 28.87 & 38.79 & $\mathrm{CH}$ \\
\hline \multirow{4}{*}{$\begin{array}{l}\text { Gefersa } \\
\text { Burayu }\end{array}$} & 10 & 0.6 & 32.00 & 2.75 & 239.291 & 1.315 & 30.717 & 59.32 & 30.31 & 29.00 & $\mathrm{CH}$ \\
\hline & 11 & 1.5 & 32.13 & 2.75 & 241.169 & 1.324 & 31.013 & 67.43 & 31.25 & 36.18 & $\mathrm{CH}$ \\
\hline & 12 & 2.7 & 32.29 & 2.76 & 286.22 & 1.319 & 31.032 & 65.60 & 31.63 & 33.97 & $\mathrm{CH}$ \\
\hline & 13 & 0.5 & 31.91 & 2.76 & 336.84 & 1.33 & 31.23 & 61.46 & 31.13 & 30.33 & $\mathrm{CH}$ \\
\hline
\end{tabular}




\begin{tabular}{|c|c|c|c|c|c|c|c|c|c|c|c|}
\hline \multirow{2}{*}{$\begin{array}{l}\text { Gefersa } \\
\text { Nono } 2 \\
\end{array}$} & 14 & 1.4 & 31.94 & 2.76 & 327.745 & 1.302 & 32.42 & 60.67 & 30.59 & 30.09 & $\mathrm{CH}$ \\
\hline & 15 & 2.6 & 31.99 & 2.76 & 355.946 & 1.333 & 32.21 & 61.52 & 30.65 & 30.86 & $\mathrm{CH}$ \\
\hline \multirow{3}{*}{$\begin{array}{c}\text { Gefersa guji } \\
2\end{array}$} & 16 & 0.5 & 31.81 & 2.76 & 335.023 & 1.32 & 31.317 & 65.57 & 31.20 & 34.37 & $\mathrm{CH}$ \\
\hline & 17 & 1.7 & 31.84 & 2.77 & 341.724 & 1.339 & 32.373 & 67.88 & 31.39 & 36.49 & $\mathrm{CH}$ \\
\hline & 18 & 2.6 & 31.84 & 2.77 & 389.993 & 1.342 & 32.441 & 67.32 & 32.65 & 34.67 & $\mathrm{CH}$ \\
\hline \multirow{3}{*}{$\begin{array}{c}\text { Gefersa } \\
\text { Nono }\end{array}$} & 19 & 0.5 & 31.69 & 2.77 & 344.344 & 1.33 & 31.864 & 61.54 & 30.99 & 30.55 & $\mathrm{CH}$ \\
\hline & 20 & 1.8 & 31.77 & 2.78 & 346.119 & 1.344 & 30.73 & 69.37 & 32.98 & 36.39 & $\mathrm{CH}$ \\
\hline & 21 & 2.9 & 31.80 & 2.78 & 349.74 & 1.351 & 31.307 & 67.24 & 32.09 & 35.15 & $\mathrm{CH}$ \\
\hline \multirow{3}{*}{$\begin{array}{c}\text { Melka } \\
\text { gefersa } 2\end{array}$} & 22 & 0.6 & 31.350 & 2.79 & 505.929 & 1.334 & 34.164 & 67.45 & 32.15 & 35.31 & $\mathrm{CH}$ \\
\hline & 23 & 1.7 & 31.423 & 2.79 & 516.787 & 1.354 & 33.541 & 70.36 & 33.19 & 37.18 & $\mathrm{CH}$ \\
\hline & 24 & 2.7 & 31.497 & 2.79 & 503.365 & 1.362 & 34.362 & 70.04 & 32.69 & 37.36 & $\mathrm{CH}$ \\
\hline \multirow{3}{*}{ Gefersa guji } & 25 & 0.54 & 31.28 & 2.80 & 432.729 & 1.367 & 32.54 & 68.96 & 32.68 & 36.28 & $\mathrm{CH}$ \\
\hline & 26 & 1.6 & 31.28 & 2.80 & 433.398 & 1.332 & 32.745 & 70.16 & 32.91 & 37.25 & $\mathrm{CH}$ \\
\hline & 27 & 2.6 & 31.33 & 2.80 & 496.635 & 1.344 & 33.343 & 68.41 & 32.04 & 36.37 & $\mathrm{CH}$ \\
\hline \multirow{3}{*}{$\begin{array}{l}\text { Melka } \\
\text { gefersa }\end{array}$} & 28 & 0.6 & 30.98 & 2.80 & 429.519 & 1.35 & 32.703 & 70.19 & 33.12 & 37.07 & $\mathrm{CH}$ \\
\hline & 29 & 1.7 & 31.19 & 2.80 & 434.613 & 1.363 & 33.4 & 71.34 & 33.08 & 38.26 & $\mathrm{CH}$ \\
\hline & 30 & 2.8 & 31.20 & 2.81 & 483.557 & 1.371 & 32.992 & 69.47 & 33.09 & 36.38 & $\mathrm{CH}$ \\
\hline
\end{tabular}


The following table shows secondary data of Unconfined compressive test and compaction test in Burayu town.

Table 4-3 Secondary Data of UCS and Compaction Characteristics Value

\begin{tabular}{|c|c|c|c|}
\hline no & $\mathrm{UCS}(\mathrm{Kpa})$ & $\operatorname{MDD}(\mathrm{g} / \mathrm{cc} 3)$ & $\operatorname{Omc}(\%$ \\
\hline 1 & 218.5398 & 1.313 & 29.818 \\
\hline 2 & 243.4143 & 1.323 & 29.465 \\
\hline 3 & 256.9529 & 1.313 & 29.588 \\
\hline 4 & 317.4043 & 1.323 & 30.488 \\
\hline 5 & 344.4163 & 1.332 & 31.333 \\
\hline 6 & 369.5853 & 1.335 & 32.268 \\
\hline 7 & 241.7374 & 1.313 & 30.965 \\
\hline 8 & 271.4163 & 1.323 & 30.018 \\
\hline 9 & 299.5853 & 1.333 & 30.768 \\
\hline 10 & 240.4874 & 1.318 & 29.538 \\
\hline 11 & 242.5332 & 1.317 & 30.066 \\
\hline 12 & 287.5432 & 1.322 & 30.179 \\
\hline 13 & 339.5452 & 1.333 & 31.278 \\
\hline 14 & 330.4551 & 1.315 & 32.468 \\
\hline 15 & 358.6683 & 1.336 & 32.258 \\
\hline 16 & 339.5031 & 1.323 & 31.365 \\
\hline 17 & 334.8885 & 1.326 & 32.421 \\
\hline 18 & 382.9476 & 1.339 & 32.489 \\
\hline 19 & 407.6002 & 1.333 & 31.912 \\
\hline 20 & 341.6833 & 1.323 & 30.778 \\
\hline
\end{tabular}




\subsubsection{Discussion on the laboratory test result}

$>$ The specific gravity of the soil from the study area ranges from 2.72-2.81 this shows the soil is clay soil

$>$ The results of grain size analysis for all test pits, the percentage of soil passing sieve no.200 is more than $80 \%$. This means the soil is mainly fine grained soils. The hydrometer analysis indicate that the soil of the study area is clay nature.

$>$ Based on the USCS soil classification, the soil in the study area is categorized as $\mathrm{CH}$ (highly plastic clay soil).

\subsection{Correlation and regression result}

\subsubsection{Sample size result}

$$
N=\frac{t_{\alpha / 2}^{2} * \sigma^{2}}{E^{2}}
$$

$\mathrm{t}_{\alpha / 2}=1.96$ for $95 \%$ confidence interval

$\sigma^{2}=$ Standard deviation $=0.14$ and 0.18

$\mathrm{E}=0.05$ for $95 \%$ confidence interval

For primary data

$N=\frac{(1.96)^{2} * 0.14^{2}}{0.05^{2}}=30$

For combined (primary and secondary data)

$N=\frac{(1.96)^{2} * 0.18^{2}}{0.05^{2}}=50$

\subsubsection{Discussion on sample size result}

The sample size result for primary and combined data was 30 and 50. Those result was depending on the predicted standard deviation, margin of error and t-test value. According to [22] if ten or above tests are made, the variation of their sample average from population would have a standard deviation of $10-16 \%$. Based the above stated reason the predicted standard deviation was 14 and $18 \%$ for sample size 30 and 50 . The margin of error is dependent on the level of confidence. The $95 \%$ percent of level of confidence gives $5 \%$ of error from the population mean. 


\subsubsection{Normality test result}

Table 4-4 Normality Test result of residual for primary and secondary data

\begin{tabular}{|c|c|c|c|}
\hline \multicolumn{2}{|c|}{} & For primary data & $\begin{array}{c}\text { For combined } \\
\text { (primary and } \\
\text { secondary) data }\end{array}$ \\
\cline { 3 - 4 } \multicolumn{2}{|c|}{ Normality test methods } & $\begin{array}{c}\text { Unstandardized } \\
\text { residual }\end{array}$ & $\begin{array}{c}\text { Unstandardized } \\
\text { residual }\end{array}$ \\
\hline \multirow{2}{*}{ mean } & mean & 0.000 & 0.000 \\
\cline { 2 - 4 } & Std.error of mean & 6.716 & 4.6319 \\
\hline median & & -5.284 & -4.480 \\
\hline Kolmogorov-Smirnova & significance & .200 & .200 \\
\hline Shapiro-Wilk & significance & 0.917 & 0.4707 \\
\hline Skewness & skewness & 0.333 & 0.464 \\
\cline { 2 - 4 } & $\begin{array}{c}\text { Std.error of } \\
\text { skewness }\end{array}$ & .427 & 0.3366 \\
\hline Kurtosis & Kurtosis & 0.062 & 0.285 \\
\cline { 2 - 4 } & $\begin{array}{c}\text { Std.error of } \\
\text { kurtosis }\end{array}$ & .833 & 0.6619 \\
\hline
\end{tabular}

Histogram

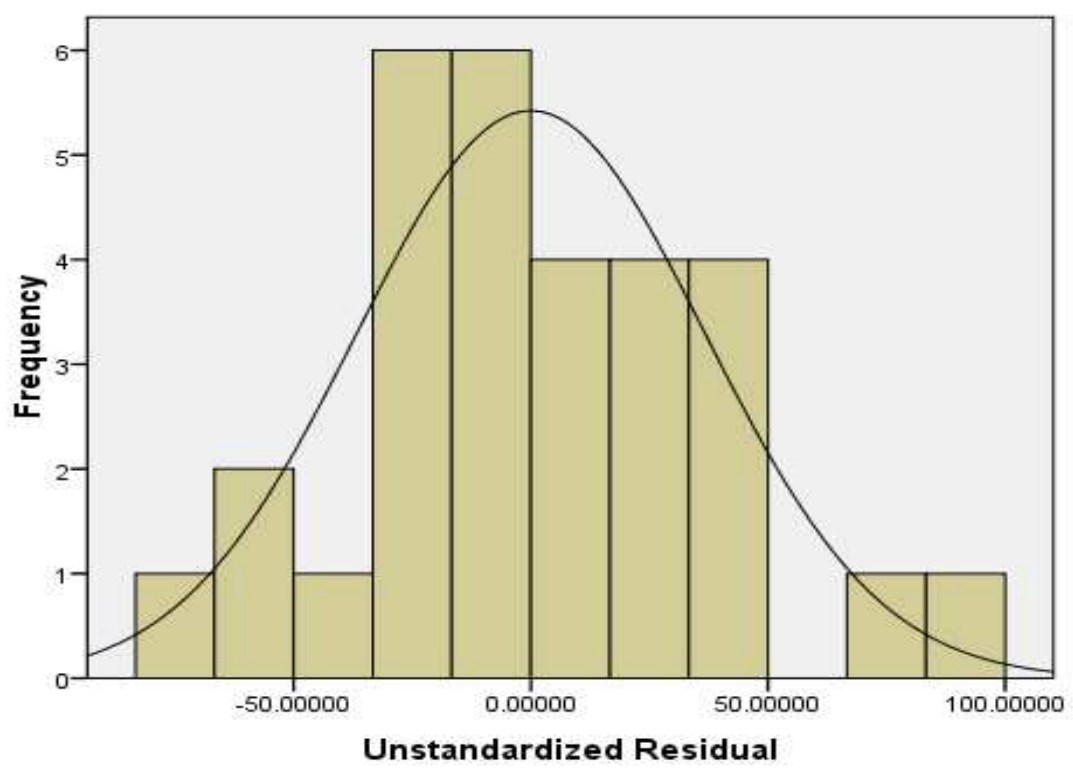

Mean $=-6.21 \mathrm{E}-13$

Std. Dev. $=36.786$

Table 4-5 Histogram plot of unstandardized residual for primary data 


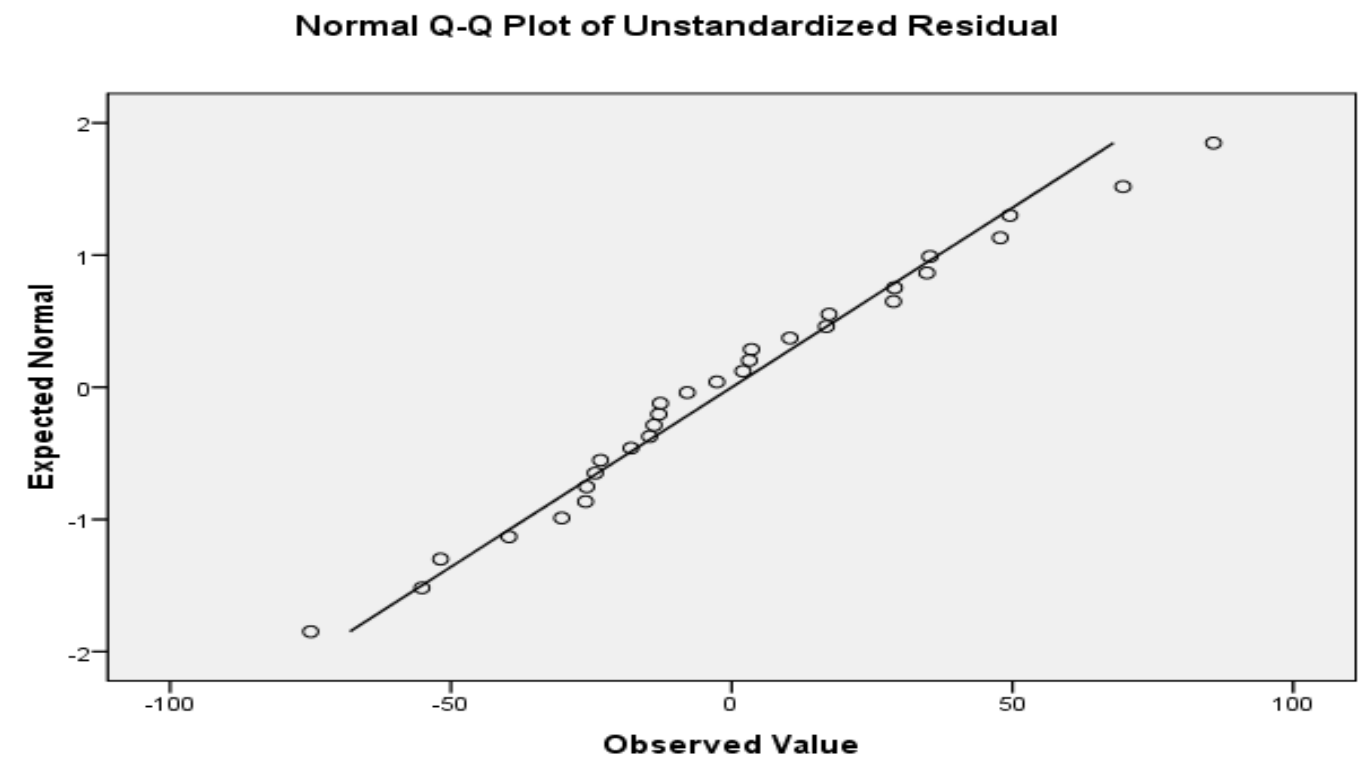

Table 4-6 QQ plot of unstandardized residual for primary data

\section{Histogram}

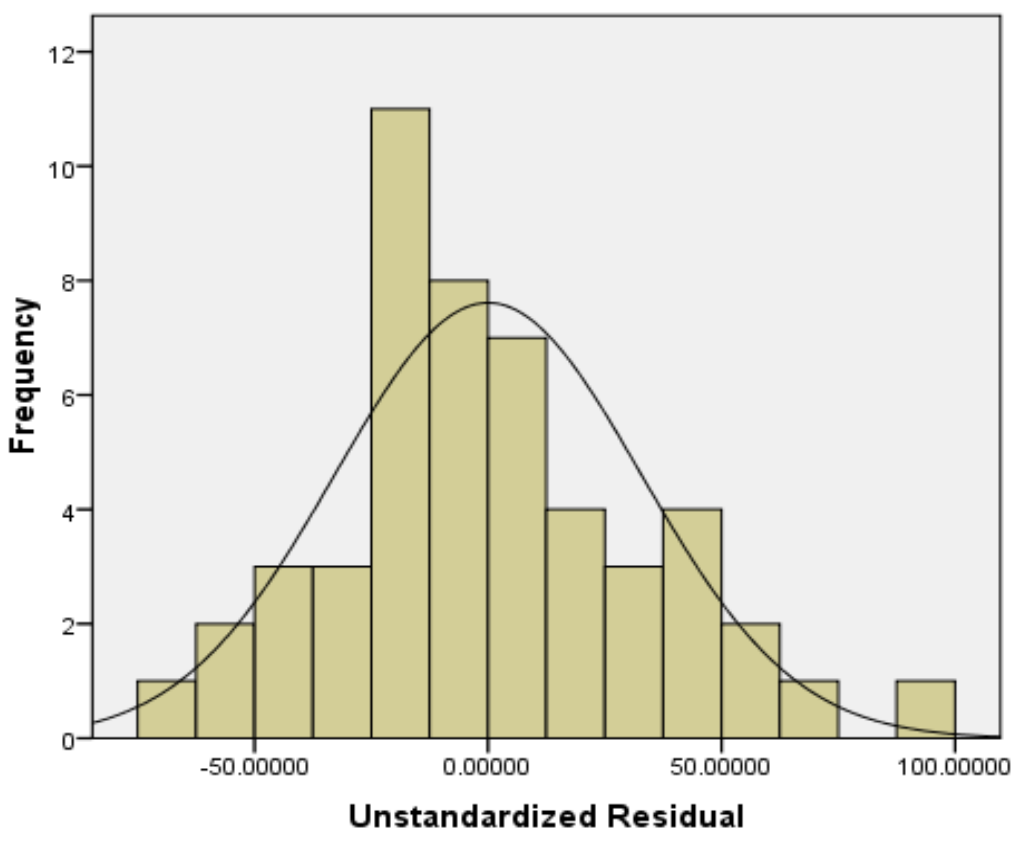

Mean $=4.76 \mathrm{E}-13$ Std. Dev. $=32.753$

Table 4-7 Histogram plot of unstandardized residual for combined data 
Normal Q-Q Plot of Unstandardized Residual

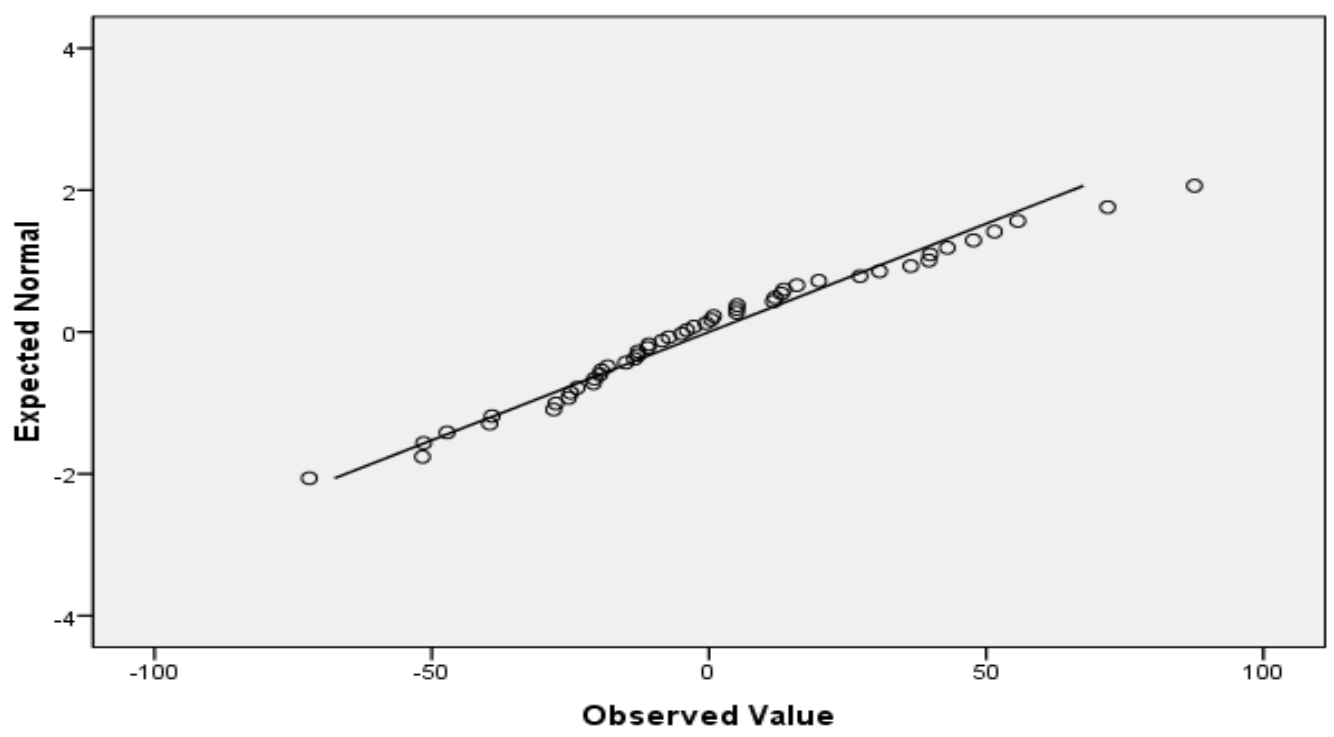

Table 4-8 QQ plot of unstandardized residual for combined data

\subsubsection{Discussion on normality test result}

From the above table and figure, the normality test result for unstandardized residual is partially fulfill the basic assumption of normally test. the mean and median is not the same, also the graphical test result basically the histogram and QQ plot result shows the data is not symmetrical as well as not perfectly close to the line because of some outliers. This shows the the data is not normally distributed but the value of skewness over its standard error as well as kurtosis over its standard error is between the range of -1.96 to +1.96 . This shows the data fulfill normality test. the kolmogrov-smirnova and shapiro-wilk test shows The significance levels $(\alpha)$ greater than 0.05 , this shows the sample data are not significantly different than a normal population or We want to accept the null hypothesis

Ho: The sample data are not significantly different than a normal population.

Ha: The sample data are significantly different than a normal population

so that the shapiro-wilk and kolmogrov-smirnova test results fulfill assumption for normally distributed data. 
In general, the test results fullfil the basic requirement of normally probability distribution data. the histogram and QQ plot gives better result for larger sample size. And also according to [25] if you are comparing means and your sample size (for each group) is "large" (say, $>=30$ ), you can invoke the central limit theorem (CLT) to justify using parametric procedures even when the data are not normally distributed. Briefly, the CLT states that sample means are approximately normal for sufficiently large sample sizes even when the original populations are non-normal.

So that we use parametric statistical test for evaluation of the hypothesis test. The independent ttest is used for parametric statistical test. The reason for selecting independent t-test is based on the data is continuous, fulfill normality test and it compares the means of two independent variables.

\subsubsection{Independent t-test result}

Ho: =there is no difference between the mean of each variable

$\mathrm{H} 1:=$ There is a difference between the mean of each variable

Table 4-9: Independent t-test result for primary data

\begin{tabular}{|l|l|c|r|r|r|}
\hline \multicolumn{7}{|c|}{ Group Statistics } \\
\hline & MDD\&OMC & $\mathrm{N}$ & \multicolumn{1}{c|}{ Mean } & \multicolumn{1}{c|}{ Std. Deviation } & \multicolumn{1}{c|}{ Std. Error Mean } \\
\hline \multirow{2}{*}{ VALUE } & 1 & 30 & 1.3324 & .01916 & .00350 \\
\cline { 2 - 7 } & 2 & 30 & $3.5569 \mathrm{E} 2$ & 89.81079 & 16.39713 \\
\hline
\end{tabular}




\begin{tabular}{|c|c|c|c|c|c|c|c|c|c|c|}
\hline \multicolumn{11}{|c|}{ Independent Samples Test } \\
\hline & & \multicolumn{2}{|c|}{\begin{tabular}{|c|} 
Levene's \\
Test for \\
Equality of \\
Variances \\
\end{tabular}} & \multicolumn{7}{|c|}{ t-test for Equality of Means } \\
\hline & & \multirow[b]{2}{*}{$\mathrm{F}$} & \multirow[b]{2}{*}{ Sig. } & \multirow[b]{2}{*}{$\mathrm{t}$} & \multirow[b]{2}{*}{ df } & \multirow{2}{*}{$\begin{array}{c}\text { Sig. } \\
(2- \\
\text { tailed }\end{array}$} & \multirow{2}{*}{$\begin{array}{c}\text { Mean } \\
\text { Difference }\end{array}$} & \multirow{2}{*}{$\begin{array}{l}\text { Std. Error } \\
\text { Difference }\end{array}$} & \multicolumn{2}{|c|}{$\begin{array}{c}\begin{array}{c}95 \% \text { Confidence } \\
\text { Interval of the } \\
\text { Difference }\end{array} \\
\end{array}$} \\
\hline & & & & & & & & & Lower & Upper \\
\hline \multirow[t]{2}{*}{ VALUE } & \begin{tabular}{|l|} 
Equal \\
variance \\
assumed
\end{tabular} & 57.578 & .000 & 21.611 & 58 & .000 & 354.35913 & 16.397 & 387.181 & 321.53671 \\
\hline & $\begin{array}{l}\text { Equal } \\
\text { variances } \\
\text { not } \\
\text { assumed }\end{array}$ & & & 21.611 & 29.00 & .000 & 354.35913 & 16.397 & 387.895 & 320.82323 \\
\hline
\end{tabular}

Table 4-10: Independent t-test result for combined data

\begin{tabular}{|l|l|c|c|r|r|}
\hline \multicolumn{7}{|c|}{ Group Statistics } \\
\hline & MDD\&OMC & $\mathrm{N}$ & \multicolumn{1}{c|}{ Mean } & \multicolumn{1}{c|}{ Std. Deviation } & \multicolumn{1}{c|}{ Std. Error Mean } \\
\hline \multirow{2}{*}{ Value } & 1 & 50 & 1.3293 & .01609 & .00228 \\
\cline { 2 - 7 } & 2 & 50 & 31.3793 & 1.29855 & .18364 \\
\hline
\end{tabular}




\begin{tabular}{|c|c|c|c|c|c|c|c|c|c|c|}
\hline \multicolumn{11}{|c|}{ Independent Samples Test } \\
\hline & & \multicolumn{2}{|c|}{$\begin{array}{c}\text { Levene's } \\
\text { Test for } \\
\text { Equality of } \\
\text { Variances } \\
\end{array}$} & \multicolumn{7}{|c|}{ t-test for Equality of Means } \\
\hline & & \multirow[b]{2}{*}{$\mathrm{F}$} & \multirow[b]{2}{*}{ Sig. } & \multirow[b]{2}{*}{$\mathrm{t}$} & \multirow[b]{2}{*}{$\mathrm{df}$} & \multirow{2}{*}{$\begin{array}{c}\text { Sig. } \\
\text { (2- } \\
\text { tailed) }\end{array}$} & \multirow{2}{*}{$\begin{array}{c}\text { Mean } \\
\text { Difference }\end{array}$} & \multirow{2}{*}{$\begin{array}{l}\text { Std. Error } \\
\text { Difference }\end{array}$} & \multicolumn{2}{|c|}{$\begin{array}{l}95 \% \text { Confidence } \\
\text { Interval of the } \\
\text { Difference }\end{array}$} \\
\hline & & & & & & & & & Lower & Upper \\
\hline Value & $\begin{array}{l}\text { Equal } \\
\text { variances } \\
\text { assumed }\end{array}$ & 124.990 & .000 & 163.621 & 98 & .000 & -30.05004 & 18366 & 30.41450 & 29.68558 \\
\hline & \begin{tabular}{|l} 
Equal \\
variances \\
not \\
assumed
\end{tabular} & & & 163.621 & 49.015 & .000 & -30.05004 & .18366 & 30.41911 & 29.68097 \\
\hline
\end{tabular}

\subsubsection{Discussion on independent t-test result}

The result of independent $t$-test shows the $t$-value is greater than the critical $t$-value which is \pm 1.96 and the level of significance is less than 0.05 in both primary and combined data. this result shows reject the null hypothesis or there is difference between the mean of each variable.[25]

\subsubsection{Multicollinearity (interdependency) test result}

The following table shows the result of collinearity test between independent variable of primary and combined (primary and secondary) data.

Table 4-11 : Multicollinearity test result of primary data

\begin{tabular}{|l|l|c|c|}
\hline \multicolumn{3}{|c|}{ Coefficients $^{\mathbf{a}}$} \\
\cline { 3 - 4 } \multicolumn{2}{|c|}{} & \multicolumn{2}{c|}{ Collinearity Statistics } \\
\cline { 3 - 4 } \multicolumn{2}{|c|}{} & Tolerance & VIF \\
\hline \multirow{2}{*}{1} & MDD & .498 & 2.010 \\
\cline { 2 - 4 } & OMC & .498 & 2.010 \\
\hline \hline
\end{tabular}

a. Dependent Variable: UCS 
Table 4-12 Multicollinearity test result of combined data

\begin{tabular}{|c|c|c|c|}
\hline \multicolumn{4}{|c|}{ Coefficients $^{\mathrm{a}}$} \\
\hline \multirow{2}{*}{\multicolumn{2}{|c|}{ Model }} & \multicolumn{2}{|c|}{ Collinearity Statistics } \\
\hline & & Tolerance & VIF \\
\hline \multirow[t]{2}{*}{1} & MDD & .520 & 1.924 \\
\hline & $\mathrm{OMC}$ & .520 & 1.924 \\
\hline
\end{tabular}

\subsubsection{Discussion on multicollinearity test result}

The variation influence factor(VIF) is less than 10. this result shows there is no interdependency or collinearity between the independent variable (MDD and OMC) for both primary and combined data.[28]

\subsubsection{Scatter Plots (univariate analysis) result}

To study the correlation of the study parameters, the UCS value is taken as dependent variable(response) whereas MDD and OMC are treated as regressor(predictor) variables for the tested soils. The scatter plot of the dependent variable UCS with the regressor variable for individual independent variable for primary and combined (primary and secondary) data presented in the figure below.

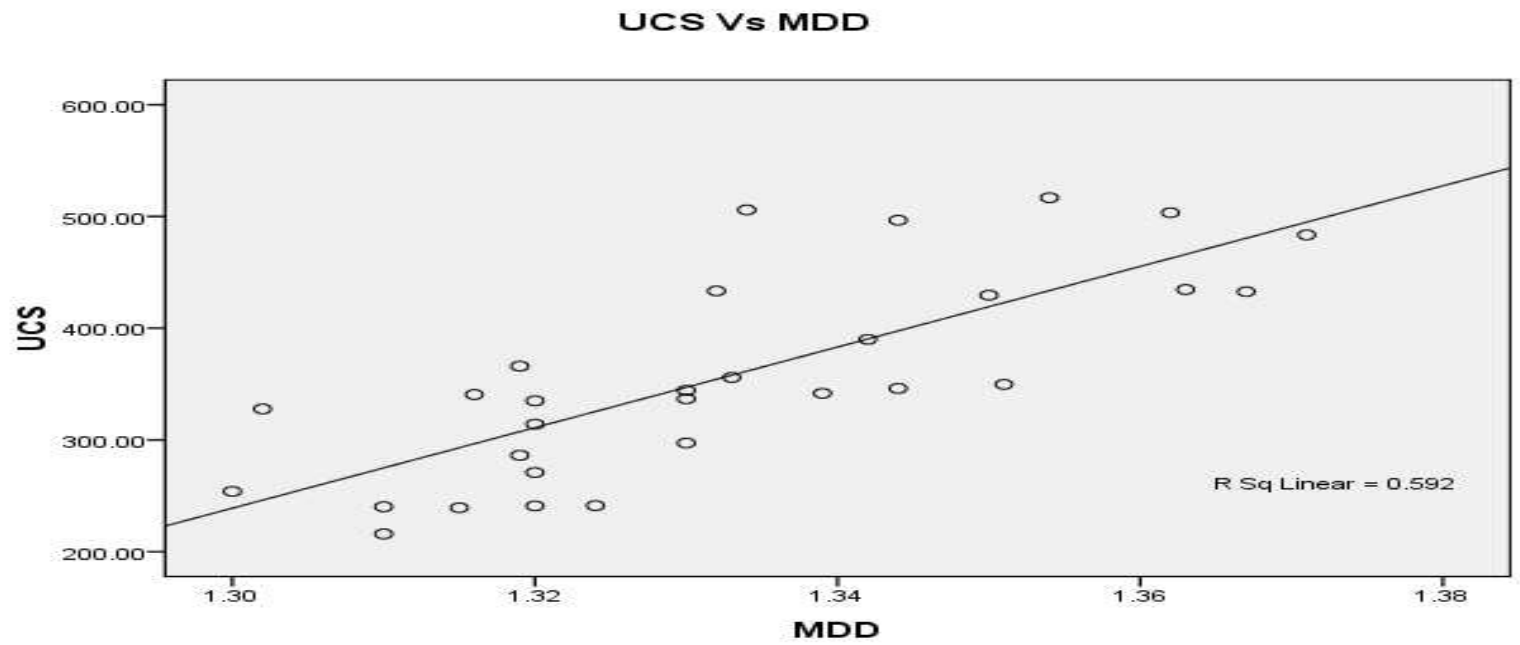

Figure 4-3:Scatter diagram of UCS versus MDD of primary data 


\section{UCS Vs OMC}

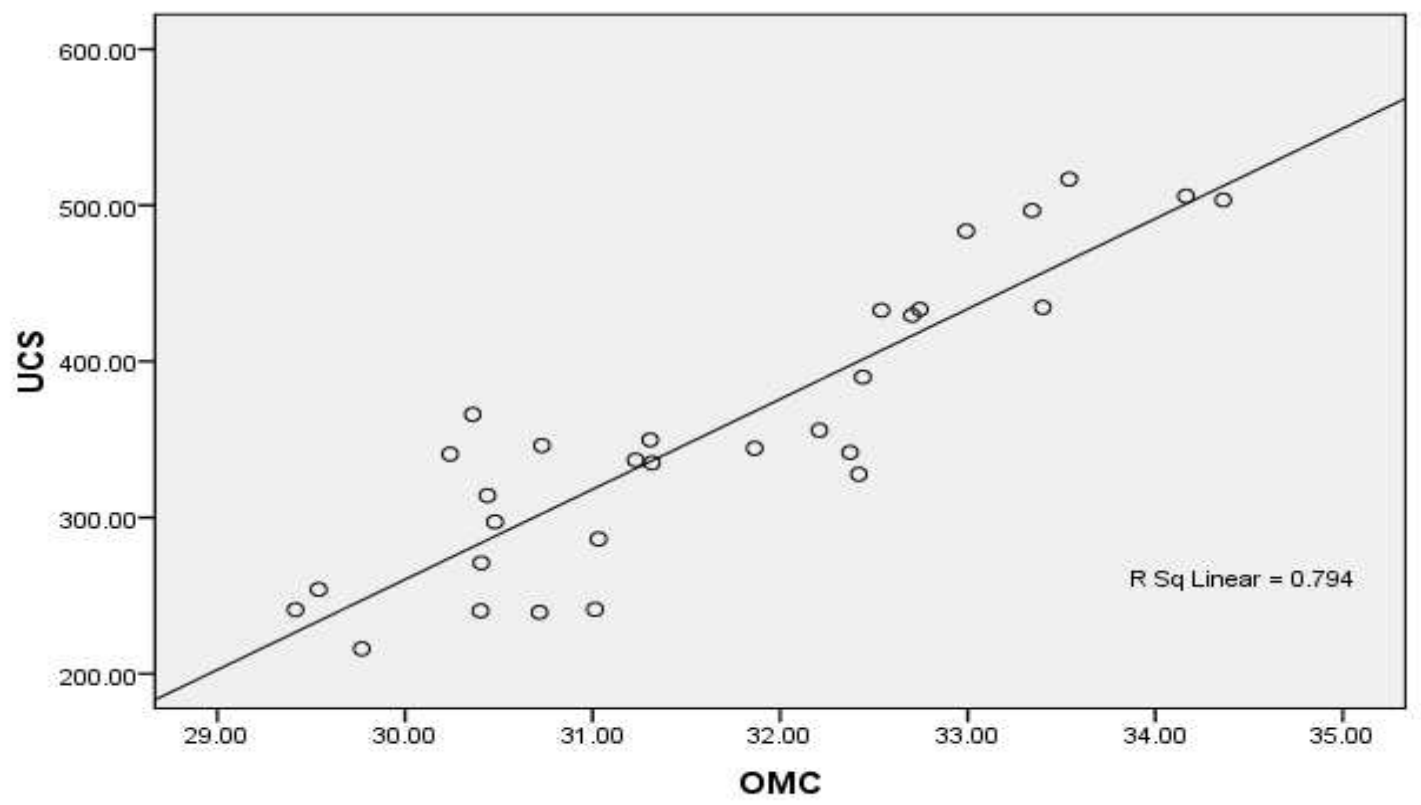

Figure 4-4: Scatter diagram of UCS versus OMC of primary data

\section{UCS Vs MDD}

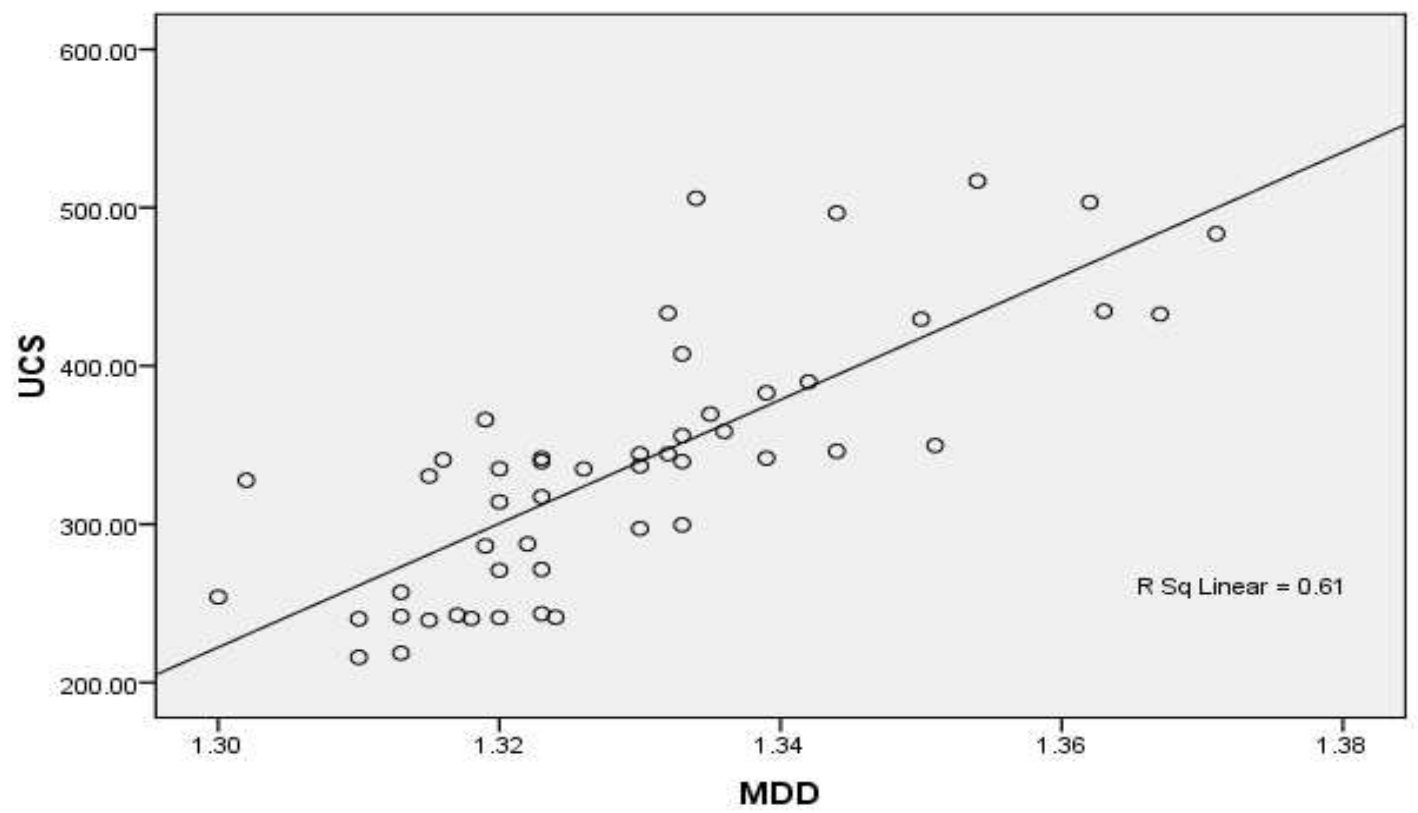

Figure 4-5:Scatter diagram of UCS versus MDD of combined data 


\section{UCS Vs OMC}

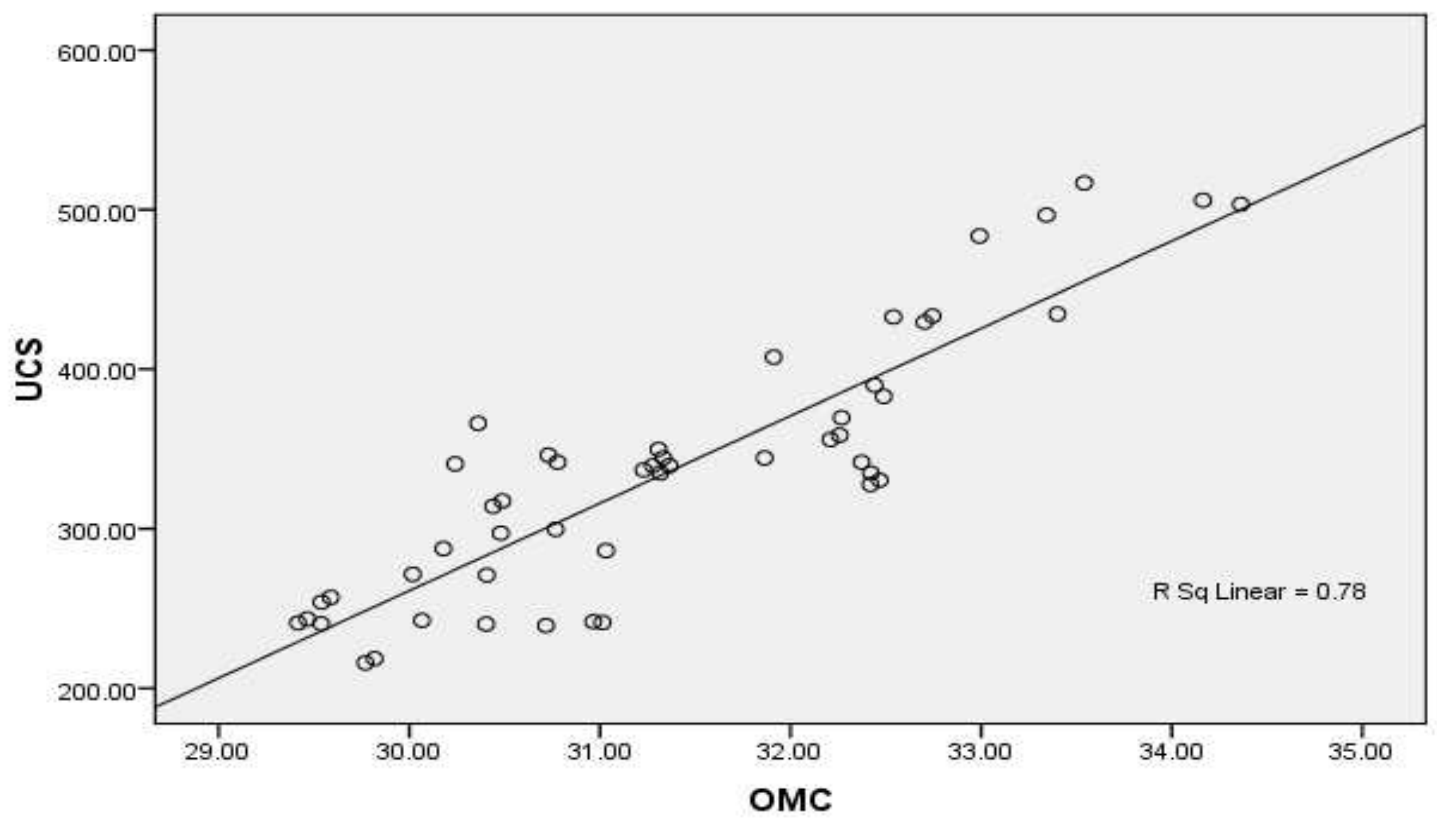

Figure 4-6:Scatter diagram of UCS versus OMC of combined data

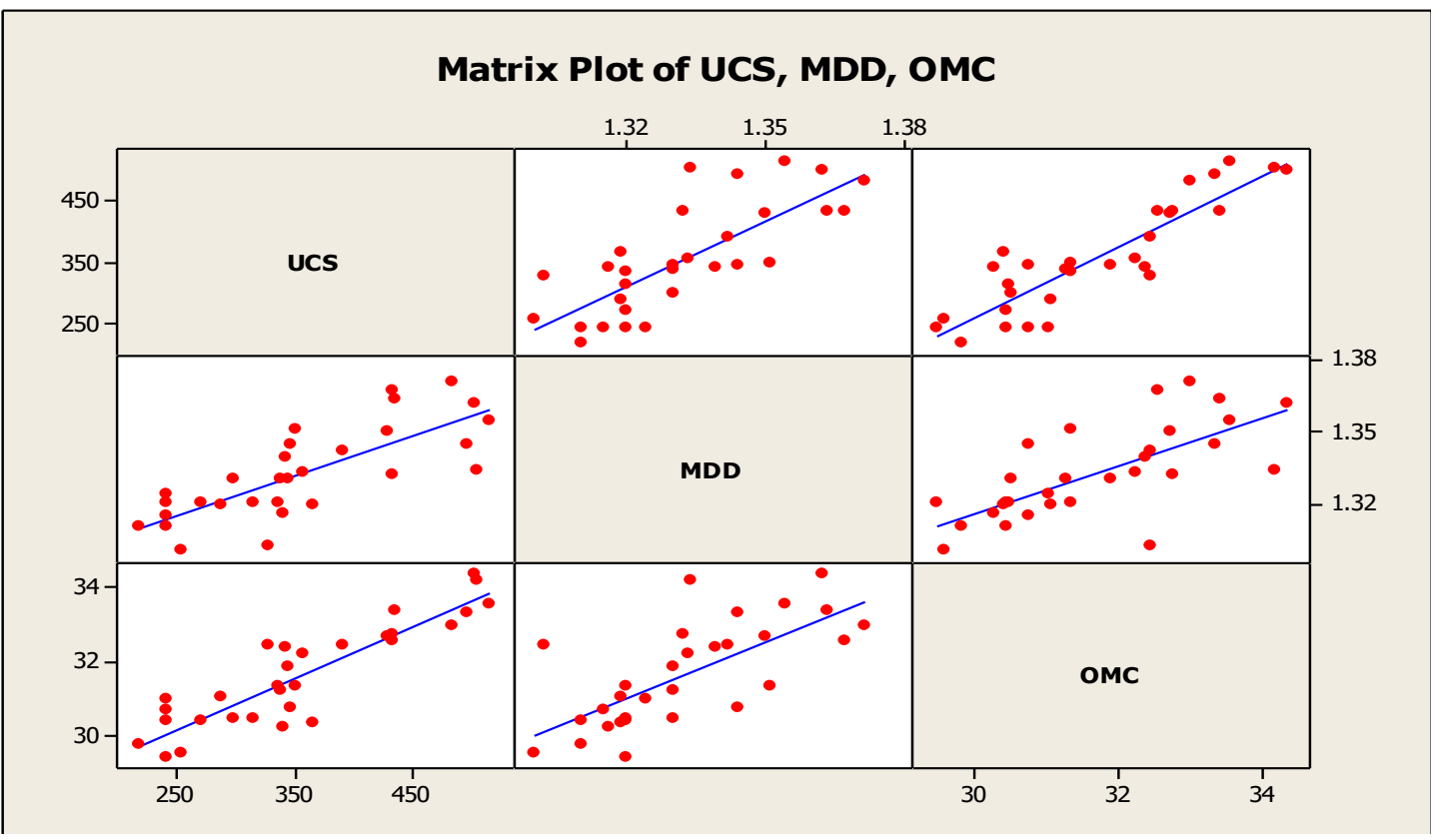

Figure 4-7:Matrix plot of dependent and independent variable for primary data 


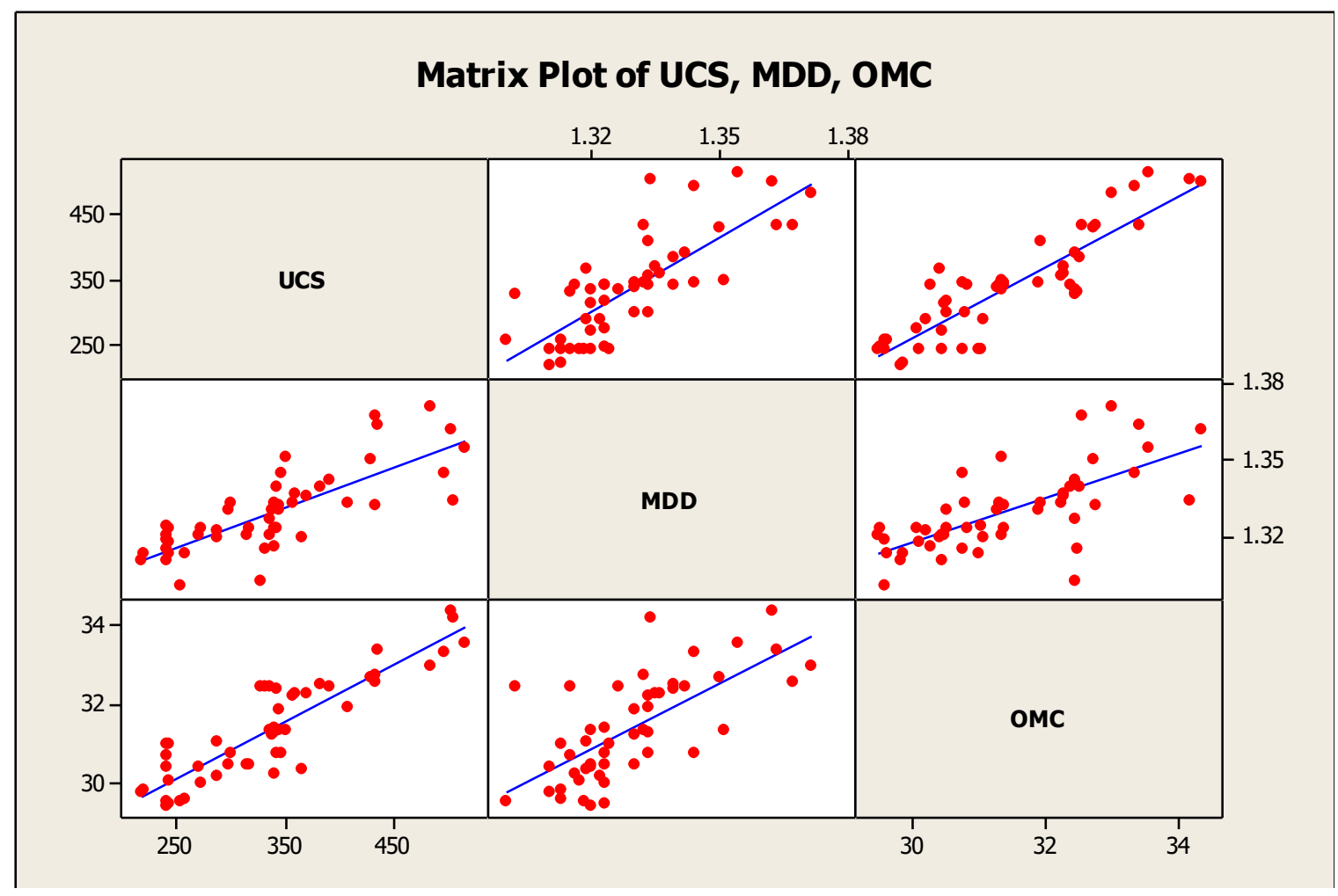

Figure 4-8: Matrix plot of dependent and independent variable for combined data

\subsubsection{Descriptive statistics results}

The statistical information's of the test results are presented in table 4.13 and table 4.14 
Table 4-13: Statistical Information of Dependent and Independent Variables for primary data

\begin{tabular}{|c|c|c|c|c|c|c|c|c|c|c|c|}
\hline \multicolumn{12}{|c|}{ Descriptive Statistics } \\
\hline & $\mathrm{N}$ & $\begin{array}{c}\text { Minimu } \\
\mathrm{m}\end{array}$ & $\begin{array}{c}\text { Maximu } \\
\mathrm{m}\end{array}$ & \multicolumn{2}{|c|}{ Mean } & \begin{tabular}{|c} 
Std. \\
Deviatio \\
$\mathrm{n}$
\end{tabular} & $\begin{array}{c}\text { Varianc } \\
\mathrm{e}\end{array}$ & \multicolumn{2}{|c|}{ Skewness } & \multicolumn{2}{|c|}{ Kurtosis } \\
\hline & $\begin{array}{c}\text { Statisti } \\
\mathrm{c}\end{array}$ & Statistic & Statistic & $\begin{array}{c}\text { Statisti } \\
\text { c }\end{array}$ & $\begin{array}{l}\text { Std. } \\
\text { Error }\end{array}$ & Statistic & Statistic & $\begin{array}{c}\text { Statisti } \\
\mathrm{c}\end{array}$ & \begin{tabular}{|c|} 
Std. \\
Erro \\
$\mathrm{r}$
\end{tabular} & $\begin{array}{c}\text { Statist } \\
\mathrm{c}\end{array}$ & $\begin{array}{c}\text { Std. } \\
\text { Erro } \\
r\end{array}$ \\
\hline UCS & 30 & 215.94 & 516.79 & $\begin{array}{c}355.69 \\
1\end{array}$ & $\begin{array}{c}16.39 \\
7\end{array}$ & 89.810 & $\begin{array}{c}8065.97 \\
8\end{array}$ & .325 & .427 & -.894 & .833 \\
\hline MDD & 30 & 1.30 & 1.37 & 1.332 & .003 & .01916 & .000 & .386 & .427 & -.636 & .833 \\
\hline $\mathrm{OMC}$ & 30 & 29.42 & 34.36 & 31.65 & .2529 & 1.3851 & 1.919 & .255 & .427 & -.957 & .833 \\
\hline $\begin{array}{c}\text { Valid } \\
\mathrm{N}(\text { listwis } \\
\mathrm{e})\end{array}$ & 30 & & & & & & & & & & \\
\hline
\end{tabular}

Table 4-14: Statistical Information of Dependent and Independent Variables for combined data

\begin{tabular}{|c|c|c|c|c|c|c|c|c|c|c|c|}
\hline \multicolumn{12}{|c|}{ Descriptive Statistics } \\
\hline & $\mathrm{N}$ & $\begin{array}{c}\text { Minimu } \\
\mathrm{m}\end{array}$ & $\begin{array}{c}\text { Maximu } \\
\mathrm{m}\end{array}$ & Mea & & $\begin{array}{c}\text { Std. } \\
\text { Deviatio } \\
\mathrm{n}\end{array}$ & $\begin{array}{c}\text { Varianc } \\
\mathrm{e}\end{array}$ & Skewn & ness & Kurto & sis \\
\hline & $\begin{array}{c}\text { Statisti } \\
\text { c }\end{array}$ & Statistic & Statistic & $\begin{array}{c}\text { Statisti } \\
\mathrm{c}\end{array}$ & \begin{tabular}{|c|} 
Std. \\
Erro \\
$\mathrm{r}$ \\
\end{tabular} & Statistic & Statistic & $\begin{array}{c}\text { Statisti } \\
\text { c }\end{array}$ & \begin{tabular}{|c|} 
Std. \\
Erro \\
$\mathrm{r}$ \\
\end{tabular} & $\begin{array}{c}\text { Statisti } \\
\text { c }\end{array}$ & $\begin{array}{c}\text { Std. } \\
\text { Erro } \\
\mathrm{r} \\
\end{array}$ \\
\hline UCS & 50 & 215.94 & 516.79 & $\begin{array}{c}336.79 \\
3\end{array}$ & \begin{tabular}{|c|}
11.3 \\
9
\end{tabular} & 80.5844 & $\begin{array}{c}6493.86 \\
8\end{array}$ & .581 & .337 & -.266 & .662 \\
\hline MDD & 50 & 1.30 & 1.37 & 1.329 & .002 & .01609 & .000 & .784 & .337 & .389 & .662 \\
\hline $\mathrm{OMC}$ & 50 & 29.42 & 34.36 & 31.379 & .183 & 1.2985 & 1.686 & .378 & .337 & -.701 & .662 \\
\hline $\begin{array}{l}\text { Valid } \\
\text { N(listwis } \\
\text { e) }\end{array}$ & 50 & & & & & & & & & & \\
\hline
\end{tabular}

\subsubsection{Discussion on the descriptive statistics result}

From the above two tables, the result of skewness over its standard error as well as kurtosis over its standard error is between \pm 2 . In appendix A and B the histogram and QQ plot of each variable 
is shown. The overall result shows each dependent and independent variable is normally distributed.

\subsubsection{Correlation matrix result of data}

For determining the influence of one variable on the other, a stepwise linear regression both forward selection and backward methods using both MINITAB and SPSS software has been used and the following correlation coefficients and level of significance determined.

Ho: $=$ there is relation between dependent and independent variable

$\mathrm{H} 1:=$ There is no relation between dependent and independent variable

If there is a relationship between dependent and independent variable $\alpha$ value is less than 0.05 if not $\alpha>0.05$. Here under, the Pearson correlation coefficient matrix is shown in Table 4-15 and Table 4-16 for primary and combined data.

Table 4-15 Correlation Matrix of Pearson Correlation Coefficient for primary data

\begin{tabular}{|l|l|c|c|c|}
\hline \multicolumn{5}{|c|}{ Correlations } \\
\hline \multirow{3}{*}{ UCS } & Pearson Correlation & UCS & MDD & OMC \\
\cline { 2 - 5 } & Sig. (2-tailed) & 1 & $.769^{* *}$ & $.891^{* *}$ \\
\cline { 2 - 5 } & $\mathrm{N}$ & 30 & .000 & .000 \\
\hline \multirow{3}{*}{ MDD } & Pearson Correlation & $.769^{* *}$ & 1 & $.709^{* *}$ \\
\cline { 2 - 5 } & Sig. (2-tailed) & .000 & & .000 \\
\cline { 2 - 5 } & $\mathrm{N}$ & 30 & 30 & 30 \\
\hline \multirow{3}{*}{ OMC } & Pearson Correlation & $.891^{* *}$ & $.709^{* *}$ & 1 \\
\cline { 2 - 5 } & Sig. (2-tailed) & .000 & .000 & 30 \\
\cline { 2 - 5 } & $\mathrm{N}$ & 30 & 30 & \\
\hline \multirow{2}{*}{ **. Correlation is significant at the 0.01 level (2-tailed). } \\
\hline \multicolumn{5}{|l}{} \\
\hline
\end{tabular}


Table 4-16: Correlation Matrix of Pearson Correlation Coefficient for combined data

\begin{tabular}{|l|l|c|c|c|}
\hline \multicolumn{5}{|c|}{ Correlations } \\
\hline \multirow{3}{*}{ UCS } & Pearson Correlation & UCS & MDD & OMC \\
\cline { 2 - 5 } & Sig. (2-tailed) & 1 & $.781^{* *}$ & $.883^{* *}$ \\
\cline { 2 - 5 } & $\mathrm{N}$ & 50 & .000 & .000 \\
\hline \multirow{3}{*}{ MDD } & Pearson Correlation & $.781^{* *}$ & 1 & $.693^{* *}$ \\
\cline { 2 - 5 } & Sig. (2-tailed) & .000 & & .000 \\
\cline { 2 - 5 } & $\mathrm{N}$ & 50 & 50 & 50 \\
\hline \multirow{3}{*}{ OMC } & Pearson Correlation & $.883^{* *}$ & $.693^{* *}$ & 1 \\
\cline { 2 - 5 } & Sig. (2-tailed) & .000 & .000 & \\
\cline { 2 - 5 } & $\mathrm{N}$ & 50 & 50 & 50 \\
\hline **. Correlation is significant at the 0.01 level (2-tailed). \\
\hline
\end{tabular}

\subsubsection{Discussion of the correlation matrix result}

To determine the correlation matrix, Pearson correlation coefficient is selected rather than spearman correlation coefficient. The reason for this is, the data is continuous as well as the dependent variable full fill the normality test assumption for both primary and combined data. Based on the above correlation result, $\alpha$ value is less than 0.05 and Pearson correlation coefficient value is close to 1 . These shows, the data accept null hypothesis and there is a linear relationship between UCS with maximum dry density and optimum moisture content.

\subsubsection{Single Linear Regression Analysis}

\section{Model A- 3: Correlation Between UCS and optimum moisture content (OMC)}

After correlating UCS with OMC, the following correlation developed.

$\mathrm{UCS}=-1473+57.8 \mathrm{OMC}$ with $\mathrm{R}-\mathrm{Sq}=79.4 \% \quad \mathrm{R}-\mathrm{Sq}(\mathrm{adj})=78.7 \% \quad N=30$

$\mathrm{UCS}=-1383+54.8 \mathrm{OMC}$ with $\mathrm{R}-\mathrm{Sq}=78.0 \% \mathrm{R}-\mathrm{Sq}(\operatorname{adj})=77.6 \% \quad \mathrm{~N}=50$

The details of the statistical out-put indicates that the relationship developed between OMC and UCS is significant $(\alpha<0.05)$ and the detail shown on Appendix D and F

Model A- 4: Correlation Between UCS and maximum dry density (MDD) 
Based on the resulting regression analysis for correlating UCS with MDD, it is observed that the best fit between UCS and MDD is using linear regression and the result obtained is Presented below

$\mathrm{UCS}=-4449+3606 \mathrm{MDD}$ with $\mathrm{R}-\mathrm{Sq}=59.2 \% \quad \mathrm{R}-\mathrm{Sq}(\operatorname{adj})=57.7 \% \quad \mathrm{~N}=30$

$\mathrm{UCS}=-4861+3910 \mathrm{MDD}$ with $\mathrm{R}-\mathrm{Sq}=61.0 \% \quad \mathrm{R}-\mathrm{Sq}(\operatorname{adj})=60.1 \% \quad \mathrm{~N}=50$

The details of the statistical out-put indicates that the relationship developed between UCS and MDD is significant $(\alpha<0.05)$ as shown in Appendix $C$ and $E$.

\subsubsection{Multiple Linear Regression Analysis}

In order to develop multiple linear regression model for the subject study, regression analysis is conducted by using commercially available softwares MINITAB, SPSS and MICROSOFT EXCEL (Analysis tool pack VBA), the following correlation results are obtained as presented below.

\section{Model B-1 Correlation Between UCS with compaction characteristics}

$\mathrm{UCS}=-2796+1295 \mathrm{MDD}+45.1 \mathrm{OMC}$ with $\mathrm{R}-\mathrm{Sq}=83.2 \% \quad \mathrm{R}-\mathrm{Sq}(\operatorname{adj})=82.0 \% \mathrm{~N}=30$

$\mathrm{UCS}=-3105+1625 \mathrm{MDD}+40.9 \mathrm{OMC}$ with $\mathrm{R}-\mathrm{Sq}=83.5 \% \quad \mathrm{R}-\mathrm{Sq}(\operatorname{adj})=82.8 \% \mathrm{~N}=50$

The details of the statistical out-put indicates that the relationship developed between UCS and compaction characteristics is significant $(\alpha<0.05)$ as shown in Appendix $\mathrm{G}$ and $\mathrm{H}$

\subsubsection{Discussion on single linear regression}

After carefully studying the data on the scatter plot and different models, this analysis discovered that UCS is highly influenced by OMC by achieving a coefficient of determination value $\left(\mathrm{R}^{2}\right)$ of 0.787 and 0.776 in primary and primary plus secondary data respectively. And UCS have a fair correlation with MDD with a coefficient of determination of 0.577 and 0.601 in primary and primary plus secondary data respectively. This category also shows that correlation of UCS has good correlation with $\mathrm{OMC}$ in this group gave good correlation result.

\subsubsection{Discussion on multiple linear regression}

From summary of multiple linear regressions one can say there is a good correlation between UCS with MDD and OMC rather than correlating with each of them. coefficient of determination value 
$\left(R^{2}\right)$ is 0.82 and 0.828 in primary and primary plus secondary data respectively. Generally, the difference in the equation and on the values of coefficient of determination that were obtained from primary and from primary plus secondary data is because of the number of samples, the factors that affect the compaction efforts and workmanship. This study however indicates the existence of a relatively good correlation UCS and compaction characteristics (OMC and MDD).

From the regression analysis it is observed that multiple linear regressions have fairly good coefficient of determination than single linear regression analysis. Because of this The Two models of multiple linear regression for primary and combined data selected.

\subsubsection{Validation of the developed equations}

In this section it was tried to validate the developed equations by using ten control tests. the data that is used as a control test is found by conducting different tests such as compaction and UCS (unconfined compressive strength) on different parts of burayu soil sample. Summary of laboratory results as follows.

Table 4-16: Summary of laboratory results for control tests

\begin{tabular}{|c|c|c|c|c|}
\hline \multirow[b]{2}{*}{ NO } & \multirow[b]{2}{*}{ Sample name } & \multirow[t]{2}{*}{ UCS(Kpa) } & \multicolumn{2}{|c|}{ Compaction Characteristics } \\
\hline & & & $\mathrm{MDD}(\mathrm{g} / \mathrm{cc} 3)$ & OMC(\%) \\
\hline 1 & $\begin{array}{l}\text { Leku keta @ } 1 \mathrm{~m} \text { (control } \\
\text { test) }\end{array}$ & 275.325 & 1.31 & 30.5 \\
\hline 2 & $\begin{array}{l}\text { Gefersaguji@1m (control } \\
\text { test) }\end{array}$ & 463.273 & 1.35 & 33.8 \\
\hline 3 & $\begin{array}{l}\text { Gefersa burayu@1m(control } \\
\text { test) }\end{array}$ & 370.140 & 1.34 & 31.9 \\
\hline 4 & $\begin{array}{l}\text { Burayu Keta@1m (control } \\
\text { test }\end{array}$ & 256.293 & 1.327 & 29.623 \\
\hline 5 & $\begin{array}{l}\text { Leku keta } 2 @ 1 \mathrm{~m} \text { (control } \\
\text { test) }\end{array}$ & 334.258 & 1.311 & 32.154 \\
\hline 6 & $\begin{array}{l}\text { Gefersa Nono@1m (control } \\
\text { test) }\end{array}$ & 446.231 & 1.346 & 33.627 \\
\hline 7 & $\begin{array}{l}\text { Melka Gefersa@1m (control } \\
\text { test) }\end{array}$ & 433.265 & 1.33 & 34.168 \\
\hline 8 & $\begin{array}{l}\text { Burayu Keta } 2 @ 1 \mathrm{~m} \text { (control } \\
\text { test) }\end{array}$ & 268.344 & 1.302 & 31.012 \\
\hline 9 & $\begin{array}{l}\text { Gefersa burayu@1m(control } \\
\text { test) }\end{array}$ & 243.253 & 1.293 & 30.269 \\
\hline
\end{tabular}




\begin{tabular}{|c|l|c|c|c|}
\hline 10 & $\begin{array}{l}\text { Gefersa Nono2 @1m (control } \\
\text { test) }\end{array}$ & 344.215 & 1.324 & 31.621 \\
\hline
\end{tabular}

among the developed equations the following equation is selected for validation by higher value of coefficient of determination $\left(\mathrm{R}^{2}\right)$. The selected model is $\mathrm{UCS}=-3105+1625 \mathrm{MDD}+40.9$ OMC with $\mathrm{R}-\mathrm{Sq}=83.5 \% \mathrm{R}-\mathrm{Sq}(\operatorname{adj})=82.8 \%$ and standard error $=61.373)$.

\subsubsection{Cross Validation result}

For validation test, the selected control test covers $20 \%$ of the training data. The following table shows the percentage of average validation of controlled test.

Table 4-17: Validation result of data

\begin{tabular}{|c|c|c|c|c|c|c|}
\hline \multirow[b]{2}{*}{ NO } & \multirow[b]{2}{*}{ Sample name } & \multirow{2}{*}{$\begin{array}{l}\mathrm{UCS} \\
(\mathrm{Kpa})\end{array}$} & \multicolumn{2}{|c|}{$\begin{array}{l}\text { Compaction } \\
\text { Characteristics }\end{array}$} & \multirow[b]{2}{*}{$\begin{array}{l}\text { Predicted UCS } \\
(\mathrm{Kpa})\end{array}$} & \multirow{2}{*}{$\begin{array}{l}\text { variation } \\
\text { in } \%\end{array}$} \\
\hline & & & $\begin{array}{l}\operatorname{MDD}(g / \\
\mathrm{cc} 3)\end{array}$ & $\begin{array}{l}\mathrm{OMC}( \\
\%)\end{array}$ & & \\
\hline 1 & $\begin{array}{l}\text { Leku keta@1m (control } \\
\text { test) }\end{array}$ & $\begin{array}{c}275.3 \\
25\end{array}$ & 1.31 & 30.5 & 271.2 & 1.498 \\
\hline 2 & $\begin{array}{l}\text { Gefersa guji@1m (control } \\
\text { test) }\end{array}$ & $\begin{array}{c}463.2 \\
73 \\
\end{array}$ & 1.35 & 33.8 & 471.17 & 1.705 \\
\hline 3 & $\begin{array}{l}\text { Gefersa } \\
\text { burayu@1m(control test) }\end{array}$ & $\begin{array}{c}370.1 \\
4\end{array}$ & 1.34 & 31.9 & 377.21 & 1.910 \\
\hline 4 & $\begin{array}{l}\text { Burayu Keta@1m } \\
\text { (control test }\end{array}$ & $\begin{array}{c}256.2 \\
93\end{array}$ & 1.327 & 29.623 & 262.9557 & 2.600 \\
\hline 5 & $\begin{array}{l}\text { Leku keta2@1m (control } \\
\text { test) }\end{array}$ & $\begin{array}{c}334.2 \\
58\end{array}$ & 1.311 & 32.154 & 340.4736 & 1.860 \\
\hline 6 & $\begin{array}{l}\text { Gefersa Nono @1m } \\
\text { (control test) }\end{array}$ & $\begin{array}{c}446.2 \\
31\end{array}$ & 1.346 & 33.627 & 457.5943 & 2.547 \\
\hline 7 & $\begin{array}{l}\text { Melka Gefersa @1m } \\
\text { (control test) }\end{array}$ & $\begin{array}{c}433.2 \\
65\end{array}$ & 1.33 & 34.168 & 453.7212 & 4.721 \\
\hline 8 & $\begin{array}{l}\text { Burayu Keta } 2 @ 1 \mathrm{~m} \\
\text { (control test) }\end{array}$ & $\begin{array}{c}268.3 \\
44\end{array}$ & 1.302 & 31.012 & 279.1408 & 4.023 \\
\hline 9 & $\begin{array}{l}\text { Gefersa burayu } \\
@ 1 \mathrm{~m} \text { (control test) }\end{array}$ & $\begin{array}{c}243.2 \\
53\end{array}$ & 1.293 & 30.269 & 234.1271 & 3.752 \\
\hline 10 & $\begin{array}{l}\text { Gefersa Nono2@1m } \\
\text { (control test) }\end{array}$ & $\begin{array}{c}344.2 \\
15\end{array}$ & 1.324 & 31.621 & 339.7989 & 1.283 \\
\hline & & & & & $\begin{array}{l}\text { average } \\
\text { variation (\%) }\end{array}$ & 2.590 \\
\hline
\end{tabular}




\subsubsection{Discussion on cross validation result}

From The Above cross validation result, the total percentage of variation is $2.59 \%$. this indicate that there is a very good prediction of the values. The reason for this percentage of variation occurred is due to the location of the test pit different from the samples considered in the correlation and seasonal variations. Since the soil vary from place to place and season to season, it may have different properties. In general, we can conclude that the statistical regression analysis shows the correlation may give 97\% accuracy in determination of the UCS for controlled tests. Before using this correlation for practical purpose, it also needs modification with large number of samples and advanced methods rather than simple correlation analysis.

\subsubsection{Evaluation of the Developed and Existing Correlations}

Specifically, there is no equation developed to determine UCS from Compaction characteristics for Burayu town. But Ikeagwuani [4] develop the equation for Nigerian clay soil . This correlation is chosen because the soil type used for regression analysis is classified under tropical residual soil and it will perform well for Ethiopian soil. The table below shows the variation between the values of from current study and Ikeagwuani with actual values.

Table 4-18 Validation of UCS From Correlation Developed with The Actual Test Data

\begin{tabular}{|c|c|c|c|c|r|r|r|}
\hline $\begin{array}{c}\text { Sample } \\
\text { code }\end{array}$ & MDD & OMC & $\begin{array}{c}\text { UCS } \\
\text { actual }\end{array}$ & $\begin{array}{c}\text { Current } \\
\text { Studies }\end{array}$ & variation & $\begin{array}{c}\text { Ikeagwuani } \\
\text { studies }\end{array}$ & variation \\
\hline 1 & 1.31 & 29.77 & 215.943 & 241.343 & 11.7624 & 261.1 & 20.91154 \\
\hline 2 & 1.32 & 29.417 & 240.998 & 243.155 & 0.89515 & 300.2 & 24.56535 \\
\hline 3 & 1.3 & 29.54 & 253.955 & 215.686 & 15.0692 & 222 & 12.58294 \\
\hline 4 & 1.32 & 30.44 & 314.103 & 284.996 & 9.26671 & 300.2 & 4.426255 \\
\hline 5 & 1.316 & 30.241 & 340.637 & 270.357 & 20.632 & 284.56 & 16.46239 \\
\hline 6 & 1.319 & 30.361 & 366.051 & 280.14 & 23.4697 & 296.29 & 19.05773 \\
\hline 7 & 1.31 & 30.403 & 240.236 & 267.233 & 11.2376 & 261.1 & 8.684793 \\
\hline 8 & 1.32 & 30.407 & 270.912 & 283.646 & 4.70053 & 300.2 & 10.81089 \\
\hline 9 & 1.33 & 30.48 & 297.224 & 302.882 & 1.90361 & 339.3 & 14.15633 \\
\hline 10 & 1.315 & 30.717 & 239.291 & 288.2 & 20.4393 & 280.65 & 17.28398 \\
\hline 11 & 1.324 & 31.013 & 241.169 & 314.932 & 30.5855 & 315.84 & 30.96211 \\
\hline 12 & 1.319 & 31.032 & 286.22 & 307.584 & 7.46412 & 296.29 & 3.518273 \\
\hline 13 & 1.33 & 31.23 & 336.84 & 333.557 & 0.97465 & 339.3 & 0.730317 \\
\hline
\end{tabular}




\begin{tabular}{|r|c|c|c|c|c|r|r|}
\hline 14 & 1.302 & 32.42 & 327.745 & 336.728 & 2.74085 & 229.82 & 29.87841 \\
\hline 15 & 1.333 & 32.21 & 355.946 & 378.514 & 6.34029 & 351.03 & 1.381108 \\
\hline 16 & 1.32 & 31.317 & 335.023 & 320.865 & 4.22589 & 300.2 & 10.39421 \\
\hline 17 & 1.339 & 32.373 & 341.724 & 394.931 & 15.5701 & 374.49 & 9.58844 \\
\hline 18 & 1.342 & 32.441 & 389.993 & 402.587 & 3.22926 & 386.22 & 0.967453 \\
\hline 19 & 1.33 & 31.864 & 344.344 & 359.488 & 4.39781 & 339.3 & 1.464814 \\
\hline 20 & 1.344 & 30.73 & 346.119 & 335.857 & 2.96488 & 394.04 & 13.84524 \\
\hline 21 & 1.351 & 31.307 & 349.74 & 370.831 & 6.03057 & 421.41 & 20.49237 \\
\hline 22 & 1.334 & 34.164 & 505.929 & 460.058 & 9.06677 & 354.94 & 29.84391 \\
\hline 23 & 1.354 & 33.541 & 516.787 & 467.077 & 9.61907 & 433.14 & 16.18597 \\
\hline 24 & 1.362 & 34.362 & 503.365 & 513.656 & 2.0444 & 464.42 & 7.73693 \\
\hline 25 & 1.367 & 32.54 & 432.729 & 447.261 & 3.35822 & 483.97 & 11.84136 \\
\hline 26 & 1.332 & 32.745 & 433.398 & 398.771 & 7.98977 & 347.12 & 19.90734 \\
\hline 27 & 1.344 & 33.343 & 496.635 & 442.729 & 10.8543 & 394.04 & 20.65803 \\
\hline 28 & 1.35 & 32.703 & 429.519 & 426.303 & 0.74881 & 417.5 & 2.798246 \\
\hline 29 & 1.363 & 33.4 & 434.613 & 475.935 & 9.50777 & 468.33 & 7.757936 \\
\hline 30 & 1.371 & 32.992 & 483.557 & 472.248 & 2.33875 & 499.61 & 3.319774 \\
\hline
\end{tabular}

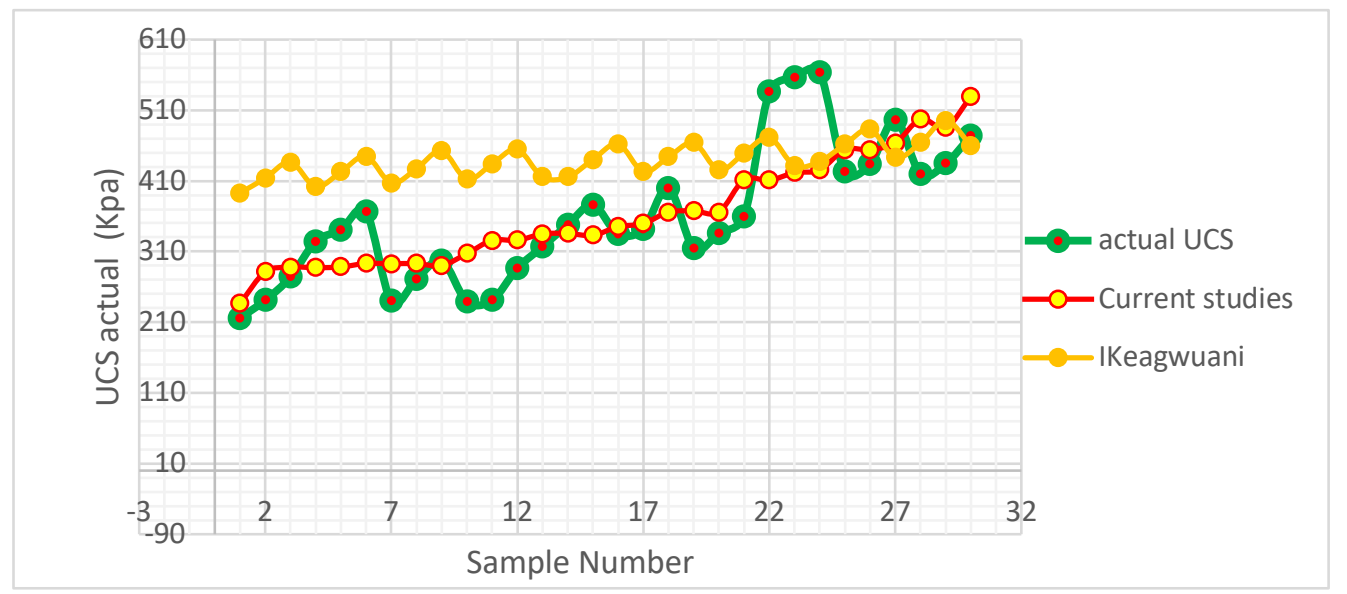

Figure 4-9 Graphical comparison of the developed model with previous correlations

From table and figure above, one can see that there is variation of UCS by $0.7 \%$ to $30 \%$ using Ikeagwuani soil. This indicate that correlation developed for a certain soil is not applicable for other soil. The reason for this variation is may be due to the difference in test procedures and also the unique properties of the geological material where this correlation was developed. 


\section{CHAPTER -FIVE \\ 5 CONCLUSION AND RECOMMENDATION}

\subsection{Conclusions}

The research was conducted to study correlation between Unconfined compression test or undrained shear strength (UCS) value and Compaction characteristics. About thirty samples extracted from the town and laboratory tests were carried out. Using this test results, statistical analysis was carried out. A single and multiple linear regressions were conducted for both primary and combined ( 30 primary and 20 secondary) data and a relationship was developed that predict the UCS values of a soil in terms of MDD, and OMC

From the results of this study the following conclusions are drawn:

$>\quad$ The data results fulfil the basic assumption of normality test and statistical test to conduct hypothesis testing.

$>\quad$ The independent variable maximum dry density and optimum moisture content have less interdependency between them. The result of multicollinearity is very minimum

$>\quad$ From the single linear regression, it is observed that the effect of maximum dry density and optimum moisture content have positive effect on UCS. That means if maximum dry density and optimum moisture content tends to increase, the UCS value tends to increase. Therefore, from this it can be concluded that the increment of dry density and optimum moisture content increase the strength of undrained shear strength (UCS) soil.

$>\quad$ From the single linear regression analysis, the correlation between UCS and optimum moisture content (OMC) as well as UCS and maximum Dry density (MDD) have fulfil the objective of thesis by created strong relationship between each other. which was expressed in the following relationship:

$$
\begin{array}{lll}
\text { UCS }=-1473+57.8 \text { OMC with R-Sq }=79.4 \% & \text { R-Sq }(\text { adj })=78.7 \% & \mathrm{~N}=30 \\
\text { UCS }=-1383+54.8 \text { OMC with R-Sq }=78.0 \% & \text { R-Sq(adj) }=77.6 \% & \mathrm{~N}=50 \\
\text { UCS }=-4449+3606 \mathrm{MDD} \text { with R-Sq }=59.2 \% & \mathrm{R}-\mathrm{Sq}(\text { adj })=57.7 \% & \mathrm{~N}=30 \\
\mathrm{UCS}=-4861+3910 \mathrm{MDD} \text { with R-Sq }=61.0 \% & \mathrm{R}-\mathrm{Sq}(\operatorname{adj})=60.1 \% & \mathrm{~N}=50
\end{array}
$$


From the multiple regression analysis, the correlation between UCS and compaction parameters is used as given below:

$\mathrm{UCS}=-2796+1295 \mathrm{MDD}+45.1 \mathrm{OMC}$ with R-Sq $=83.2 \%$ R-Sq(adj) $=82.0 \% \mathrm{~N}=30$

$\mathrm{UCS}=-3105+1625 \mathrm{MDD}+40.9$ OMC with R-Sq $=83.5 \% \quad \mathrm{R}-\mathrm{Sq}(\operatorname{adj})=82.8 \% \mathrm{~N}=50$

From the result combined data gives better correlation than primary data.

From control tests the predicted UCS have an average variation of $2.59 \%$ compared to the actual UCS. This indicates the correlation gives better results. to minimize this variation, use large number of samples and advanced methods rather than simple correlation analysis.

5. From existing correlations Ikeagwuani [4] estimation of the actual UCS value has over estimated.

\subsection{Recommendations for the future}

The following points are some of the recommendations given by the researcher in relation to the subject study:

1. It is advisable to conduct frequent researches in the soil, due to the fact that soil property vary from place to place and seasonally

2. Further detailed laboratory analysis carried out on a number of additional disturbed and undisturbed samples from different locations of the town to prepare a reliable correlation and regression analysis.

3. Finally, it is important to study Ethiopian soil using advanced other than using simple regression analysis by collecting different soil property data's available in to national database system for further study. 


\section{REFERENCE}

1. Blahova, K., Influence of water content on the shear strength parameters of clayey soil in relation to stability analysis of a hillside in brno region. 2013. 81(6).

2. Budhu, M., Soil mechanics and foundations. 3rd ed. 2011, United States of America: John Wiley \& Sons, Inc. .

3. Addis, K., Correlation between standard penetration test with unconfined compressive strength and index properties of fine-grained soil, in Civil Engineering. 2016, Addis Ababa University: Addis Ababa.

4. Ikeagwuani, c.e.a., Correlation between maximum dry density and cohesion of remoulded nsukka clays. Nigerian Journal of Technology, 2018. 37.

5. Arora, k.R., soil mechanics and foundation engineering. 2003, Delhi: standard publishers distributors.

6. Sorensen, K.K.a.O., N. , Correlation between drained shear strength and plasticity index of undisturbed over consolidated clays, in 18th International Conference on Soil Mechanics and Geotechnical Engineering. 2013: Paris.

7. Dino, A., A Study on Correlation of California Bearing Ratio (CBR) With Index Properties of Soils on Welkite -Arekit-Hossana Road., in School of Civil and Environmental Engineering. 2016: Jimma University.

8. Das, B., Principles of Geotechnical Engineering. 7th ed. 2010: Stamford: Cengage Learning.

9. Murthy, V.N.S., Soil Mechanics and Foundation Engineering. 5th ed. 2001, new york: UBS Publishers Distributors Ltd.

10. Bowels, J., Foundation Analysis And Design. 5th ed. 1997, Singapore: McGraw-Hill.

11. Teferra, A.a.L., M, Soil Mechanics. 1999, Addis Ababa Addis Ababa University.

12. Briaud, J.L., Geotechnical Engineering: Unsaturated and Saturated Soils. 2013, United States of America: John Wiley \& Sons, Inc.

13. Das, B., Advanced Soil Mechanics. 3rd ed. 2008., new York, USA: Taylor \& Francis eLibrary, 
14. Tesfamichael, T., correlation between compaction characteristics and atterberg limits of fine grained soil found in Addis Ababa. International Journal of Scientific \& Engineering Research, 2017. 8(6).

15. Raju , V., Srimurali, M. and Prasad ,K., Functional Correlations between Compaction Characteristics, Un-drained Shear Strength and Atterberg Limits. IOSR Journal of Mechanical and Civil Engineering, 2014. 11(3).

16. Persson, E., Empirical correlation between undrained shear strength and preconsolidation pressure in Swedish soft clays, in Civil and Architectural Engineering. 2017, Royal Institute of Technology: Stockholm.

17. Obasi, N.L., Anyaegbunam, A. J., correlation of the undrained shear strength and plasticity index of tropical clays Nigerian Journal of Technology, 2005. 24(2).

18. Dirriba, A., Developing Correlation between Dynamic Cone Penetration Index (DCPI) and Unconfined Compression Strength (UCS) of the Soils in Alem Gena Town, in Civil Engineering (Geotechnical Engineering). 2017, Addis Ababa University.

19. ASTM, Standard Test Method for Laboratory Determination of Water (Moisture) Content of Soil and Rock by Mass, in D 2216 - 98. 1998: West Conshohocken.

20. Krishna, R., Engineering Properties of Soils Based on Laboratory Testing. UIC, 2002.

21. Hirpassa, W., Investigation on the engineering properties of soil found in burayu town in Civil Engineering. 2015, Addis Ababa University.

22. Baecher, G.B., Christian,J.T, Reliability and Statistics in Geotechnical Engineering. 2003, England: John Wiley \& Sons Ltd.

23. patel, J.K., Read,C.B, Handbook of the Normal Distribution 1982, New York: Marcel Dekker, Inc.

24. Berkman, E.T., Reise,S.P, A conceptual guide to statistics using SPSS. 2012, United States of America: SAGE Publications, Inc.

25. Elliott, A.C., Woodward,W.A, Statistical analysis quick reference guidebook. 2007.

26. Graybill, F., Iyer, H.k., Regression analysis concepts and application. 1962, California: wadsworth publishing company. 
27. Yan, X., Su, G.X., Linear Regression Analysis: Theory and Computing. 2009, Singapore: World Scientific Publishing Co. Pte. Ltd.

28. Stevens , P., Applied Multivariate Statistics For The Social Sciences. 2009, New York: Taylor \& Francis.

29. Montgomery, D.C., Runger, G.C., Applied Statistics and Probability for Engineers. 2002, United States of America: John Wiley \& Sons, Inc.

30. Draper, N.R., Smith, H, Applied Regression Analysis. 1998, United States of America: John Wiley \& Sons.inc.

31. James, G., Witten,D., Hastei,T., Tibshirnai,T, An Introduction to Statistical Learning. 2013, United States of America. 


\section{APPENDIX A:}

Normality Test Result of Each Variable and Residual for Primary Data

Case Processing Summary

\begin{tabular}{|c|c|c|c|c|c|c|}
\hline & \multicolumn{6}{|c|}{ Cases } \\
\hline & \multicolumn{2}{|c|}{ Valid } & \multicolumn{2}{|c|}{ Missing } & \multicolumn{2}{|c|}{ Total } \\
\hline & $\mathrm{N}$ & Percent & $\mathrm{N}$ & Percent & $\mathrm{N}$ & Percent \\
\hline UCS & 30 & $100.0 \%$ & 0 & $.0 \%$ & 30 & $100.0 \%$ \\
\hline MDD & 30 & $100.0 \%$ & 0 & $.0 \%$ & 30 & $100.0 \%$ \\
\hline OMC & 30 & $100.0 \%$ & 0 & $.0 \%$ & 30 & $100.0 \%$ \\
\hline Unstandardized Residual & 30 & $100.0 \%$ & 0 & $.0 \%$ & 30 & $100.0 \%$ \\
\hline
\end{tabular}

\begin{tabular}{|c|c|c|c|c|}
\hline \multicolumn{5}{|c|}{ Descriptives } \\
\hline & & & Statistic & $\begin{array}{c}\text { Std. } \\
\text { Error }\end{array}$ \\
\hline \multirow{13}{*}{ UCS } & \multicolumn{2}{|l|}{ Mean } & $3.56 \mathrm{E}+02$ & 16.39713 \\
\hline & \multirow{2}{*}{$\begin{array}{l}95 \% \text { Confidence Interval for } \\
\text { Mean }\end{array}$} & $\begin{array}{l}\text { Lower } \\
\text { Bound }\end{array}$ & $3.22 \mathrm{E}+02$ & \\
\hline & & $\begin{array}{l}\text { Upper } \\
\text { Bound }\end{array}$ & $3.89 \mathrm{E}+02$ & \\
\hline & \multicolumn{2}{|l|}{$5 \%$ Trimmed Mean } & $3.54 \mathrm{E}+02$ & \\
\hline & \multicolumn{2}{|l|}{ Median } & $3.43 \mathrm{E}+02$ & \\
\hline & \multicolumn{2}{|l|}{\begin{tabular}{|l|} 
Variance \\
\end{tabular}} & $8.07 \mathrm{E}+03$ & \\
\hline & \multicolumn{2}{|l|}{ Std. Deviation } & $8.98 \mathrm{E}+01$ & \\
\hline & \multicolumn{2}{|l|}{ Minimum } & 215.94 & \\
\hline & \multicolumn{2}{|l|}{\begin{tabular}{|l|} 
Maximum \\
\end{tabular}} & 516.79 & \\
\hline & \multicolumn{2}{|l|}{ Range } & 300.84 & \\
\hline & \multicolumn{2}{|l|}{ Interquartile Range } & 150.5 & \\
\hline & \multicolumn{2}{|l|}{ Skewness } & 0.325 & 0.427 \\
\hline & \multicolumn{2}{|l|}{ Kurtosis } & -0.894 & 0.833 \\
\hline \multirow{4}{*}{ MDD } & \multicolumn{2}{|l|}{ Mean } & 1.3324 & 0.0035 \\
\hline & \multirow{2}{*}{$\begin{array}{l}\text { 95\% Confidence Interval for } \\
\text { Mean }\end{array}$} & \begin{tabular}{|l|} 
Lower \\
Bound
\end{tabular} & 1.3252 & \\
\hline & & $\begin{array}{l}\text { Upper } \\
\text { Bound }\end{array}$ & 1.3395 & \\
\hline & \multicolumn{2}{|l|}{ 5\% Trimmed Mean } & 1.3321 & \\
\hline
\end{tabular}




\begin{tabular}{|c|c|c|c|c|}
\hline & \multicolumn{2}{|l|}{ Median } & 1.33 & \\
\hline & \multicolumn{2}{|l|}{ Variance } & 0 & \\
\hline & \multicolumn{2}{|l|}{\begin{tabular}{|l|} 
Std. Deviation \\
\end{tabular}} & 0.01916 & \\
\hline & \multicolumn{2}{|l|}{ Minimum } & 1.3 & \\
\hline & \multicolumn{2}{|l|}{ Maximum } & 1.37 & \\
\hline & \multicolumn{2}{|l|}{ Range } & 0.07 & \\
\hline & \multicolumn{2}{|l|}{ Interquartile Range } & 0.03 & \\
\hline & \multicolumn{2}{|l|}{\begin{tabular}{|l|} 
Skewness \\
\end{tabular}} & 0.386 & 0.427 \\
\hline & \multicolumn{2}{|l|}{ Kurtosis } & -0.636 & 0.833 \\
\hline \multirow{13}{*}{$\mathrm{OMC}$} & \multicolumn{2}{|l|}{ Mean } & 31.6501 & 0.2529 \\
\hline & \multirow{2}{*}{$\begin{array}{l}\text { 95\% Confidence Interval for } \\
\text { Mean }\end{array}$} & $\begin{array}{l}\text { Lower } \\
\text { Bound }\end{array}$ & 31.1329 & \\
\hline & & $\begin{array}{l}\text { Upper } \\
\text { Bound }\end{array}$ & 32.1673 & \\
\hline & \multicolumn{2}{|l|}{ 5\% Trimmed Mean } & 31.6249 & \\
\hline & \multicolumn{2}{|l|}{ Median } & 31.312 & \\
\hline & \multicolumn{2}{|l|}{ Variance } & 1.919 & \\
\hline & \multicolumn{2}{|l|}{\begin{tabular}{|l} 
Std. Deviation \\
\end{tabular}} & 1.38519 & \\
\hline & \multicolumn{2}{|l|}{\begin{tabular}{|l|} 
Minimum \\
\end{tabular}} & 29.42 & \\
\hline & \multicolumn{2}{|l|}{ Maximum } & 34.36 & \\
\hline & \multicolumn{2}{|l|}{ Range } & 4.94 & \\
\hline & \multicolumn{2}{|l|}{ Interquartile Range } & 2.28 & \\
\hline & \multicolumn{2}{|l|}{\begin{tabular}{|l|} 
Skewness \\
\end{tabular}} & 0.255 & 0.427 \\
\hline & \multicolumn{2}{|l|}{ Kurtosis } & -0.957 & 0.833 \\
\hline \multirow{11}{*}{$\begin{array}{l}\text { Unstandardized } \\
\text { Residual }\end{array}$} & \multicolumn{2}{|l|}{ Mean } & $\begin{array}{r}-6.17 \mathrm{E}- \\
13\end{array}$ & $6.72 \mathrm{E}+00$ \\
\hline & \multirow{2}{*}{$\begin{array}{l}\text { 95\% Confidence Interval for } \\
\text { Mean }\end{array}$} & $\begin{array}{l}\text { Lower } \\
\text { Bound } \\
\end{array}$ & $1.37 \mathrm{E}+01$ & \\
\hline & & $\begin{array}{l}\text { Upper } \\
\text { Bound }\end{array}$ & $1.37 \mathrm{E}+01$ & \\
\hline & \multicolumn{2}{|l|}{ 5\% Trimmed Mean } & $\begin{array}{r}-6.70 \mathrm{E}- \\
01\end{array}$ & \\
\hline & \multicolumn{2}{|l|}{ Median } & $5.28 \mathrm{E}+00$ & \\
\hline & \multicolumn{2}{|l|}{ Variance } & $1.35 \mathrm{E}+03$ & \\
\hline & \multicolumn{2}{|l|}{\begin{tabular}{|l|} 
Std. Deviation \\
\end{tabular}} & $3.68 \mathrm{E}+01$ & \\
\hline & \multicolumn{2}{|l|}{ Minimum } & $7.50 \mathrm{E}+01$ & \\
\hline & Maximum & & $8.58 \mathrm{E}+01$ & \\
\hline & Range & & $1.61 \mathrm{E}+02$ & \\
\hline & Interquartile Range & & $5.35 \mathrm{E}+01$ & \\
\hline
\end{tabular}




\begin{tabular}{|l|l|r|r|}
\hline & Skewness & 0.334 & 0.427 \\
\cline { 2 - 4 } & Kurtosis & 0.062 & 0.833 \\
\hline
\end{tabular}

Tests of Normality

\begin{tabular}{|l|r|r|r|r|r|r|}
\hline \multirow{2}{*}{} & \multicolumn{3}{|c|}{ Kolmogorov-Smirnov $^{\mathrm{a}}$} & \multicolumn{3}{c|}{ Shapiro-Wilk } \\
\cline { 2 - 7 } & \multicolumn{1}{|c|}{ Statistic } & df & \multicolumn{1}{c|}{ Sig. } & Statistic & df & Sig. \\
\hline UCS & .132 & 30 & .191 & .937 & 30 & .077 \\
MDD & .141 & 30 & .134 & .962 & 30 & .342 \\
OMC & .128 & 30 & $.200^{*}$ & .957 & 30 & .253 \\
Unstandardized Residual & .102 & 30 & $.200^{*}$ & .984 & 30 & .918 \\
\hline
\end{tabular}

a. Lilliefors Significance Correction

*. This is a lower bound of the true significance.

\section{Histogram}

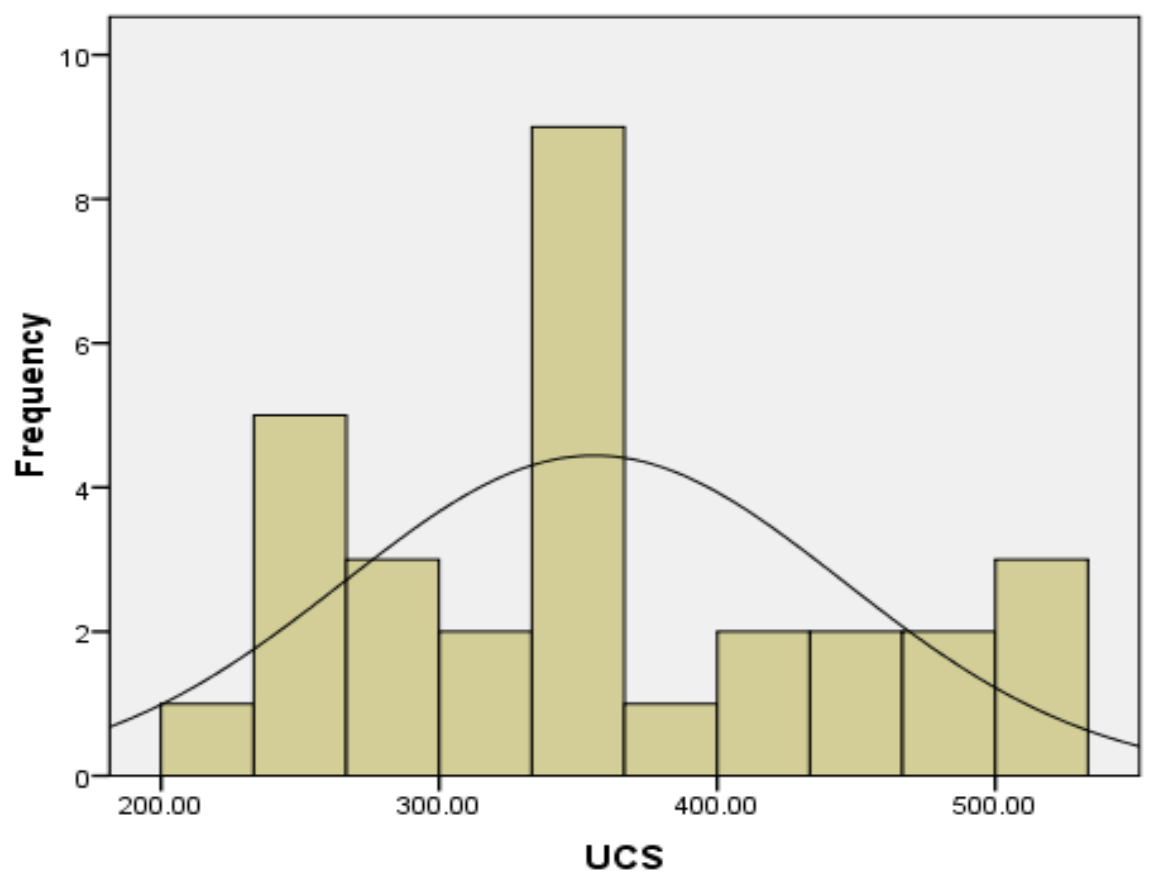

Mean $=355.69$
Std. Dev. $=89.811$

$\mathrm{N}=30$ 
Normal Q-Q Plot of UCS

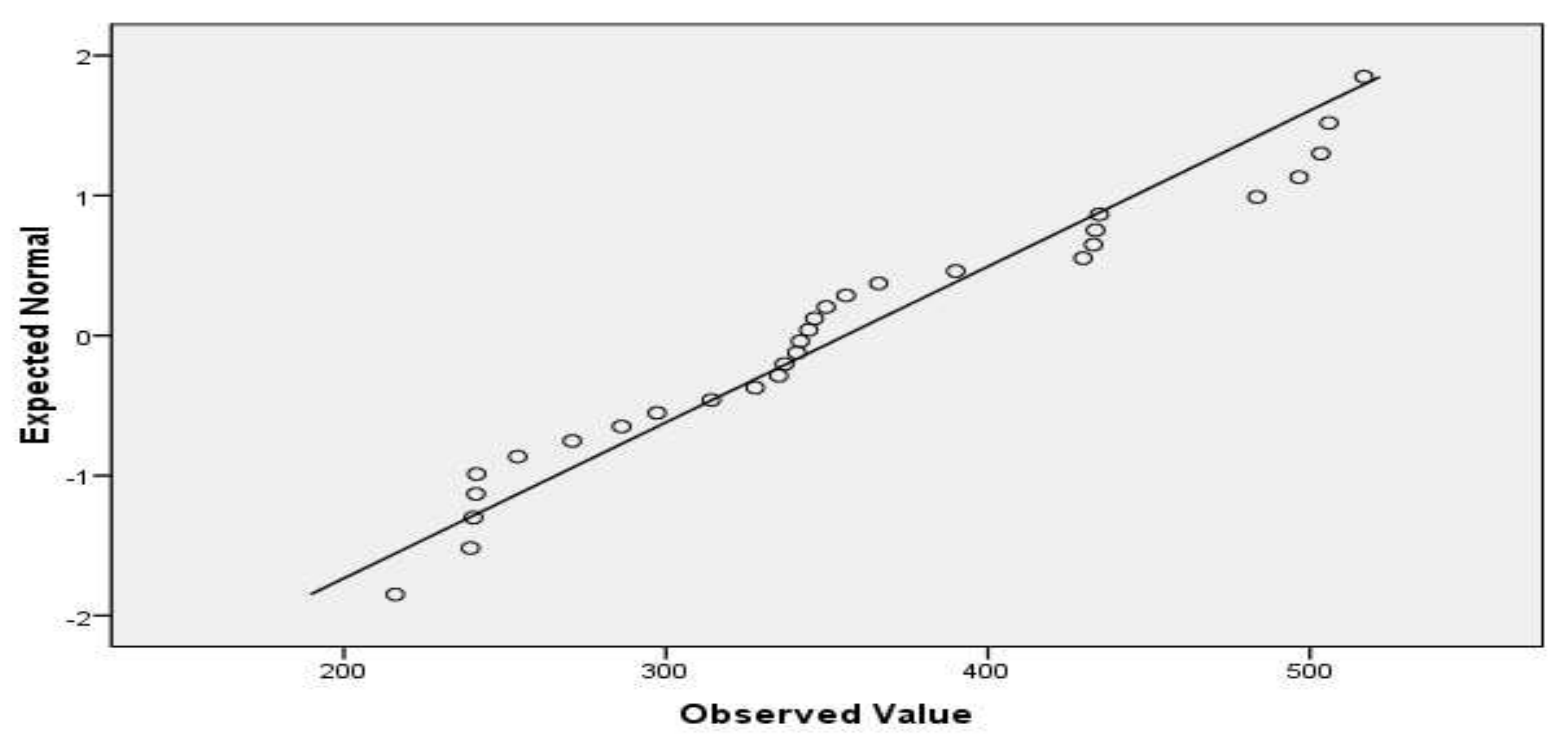

- Normal

\section{Histogram}

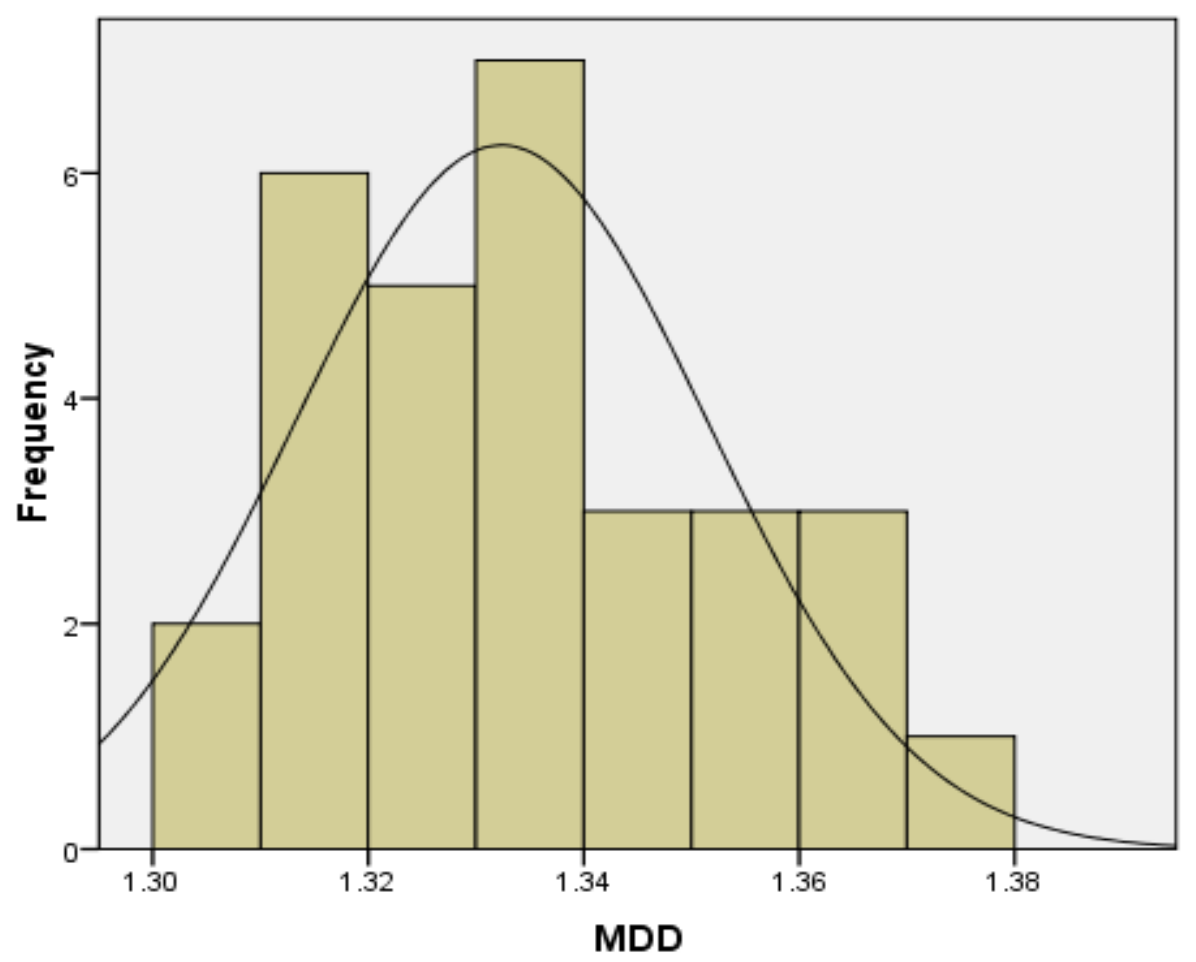

Mean $=1.33$

Std. Dev. $=0.019$

$\mathrm{N}=30$ 
Normal Q-Q Plot of MDD

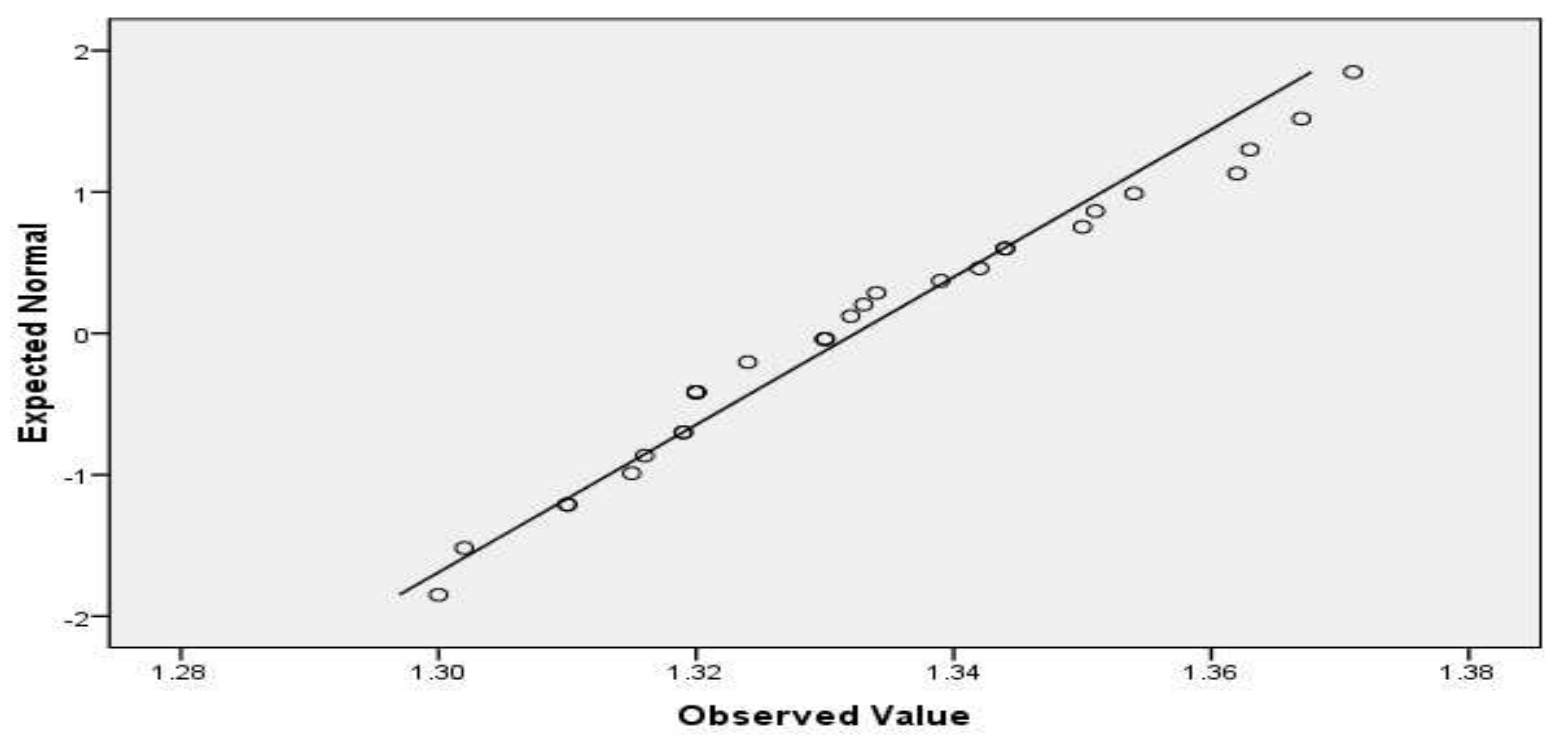

— Normal

Histogram

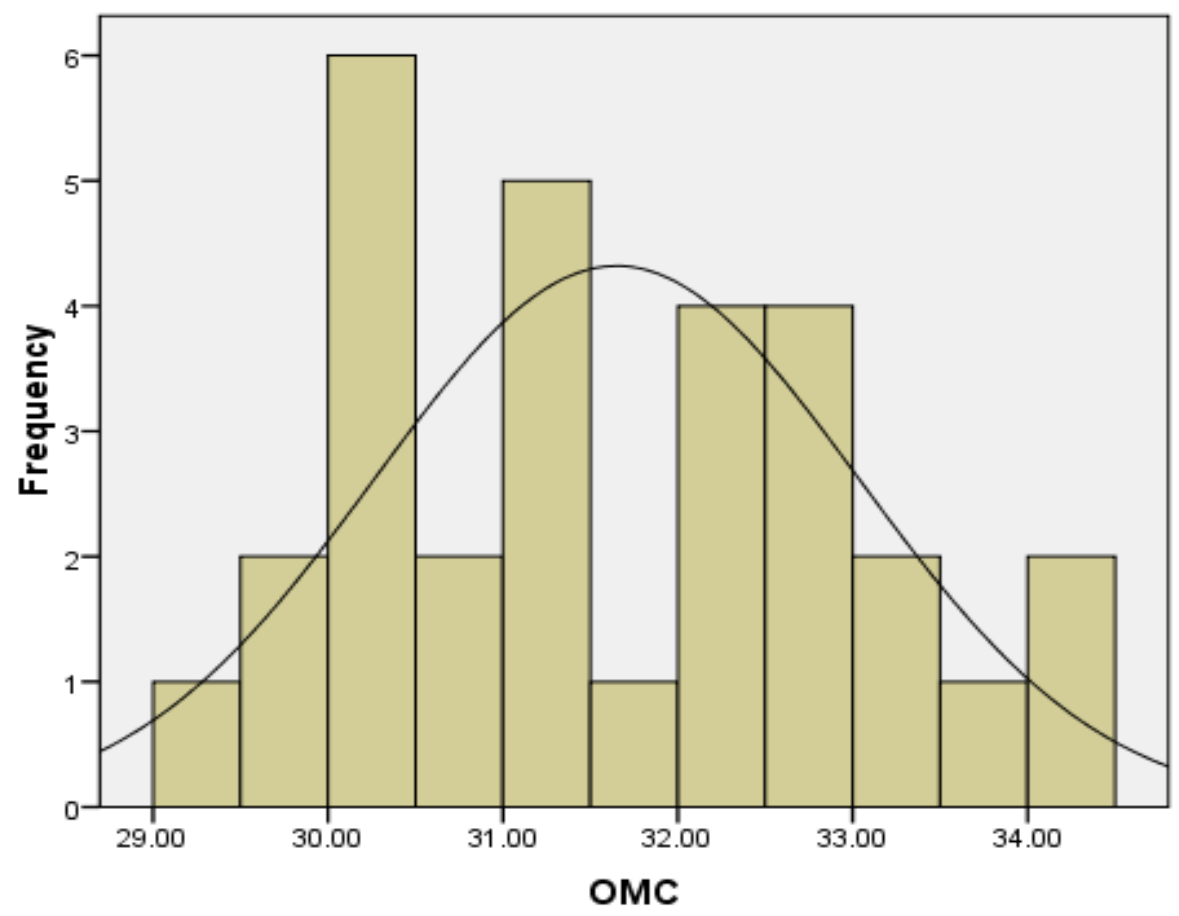

Mean $=31.65$

Std. Dev. $=1.385$ 
Normal Q-Q Plot of OMC

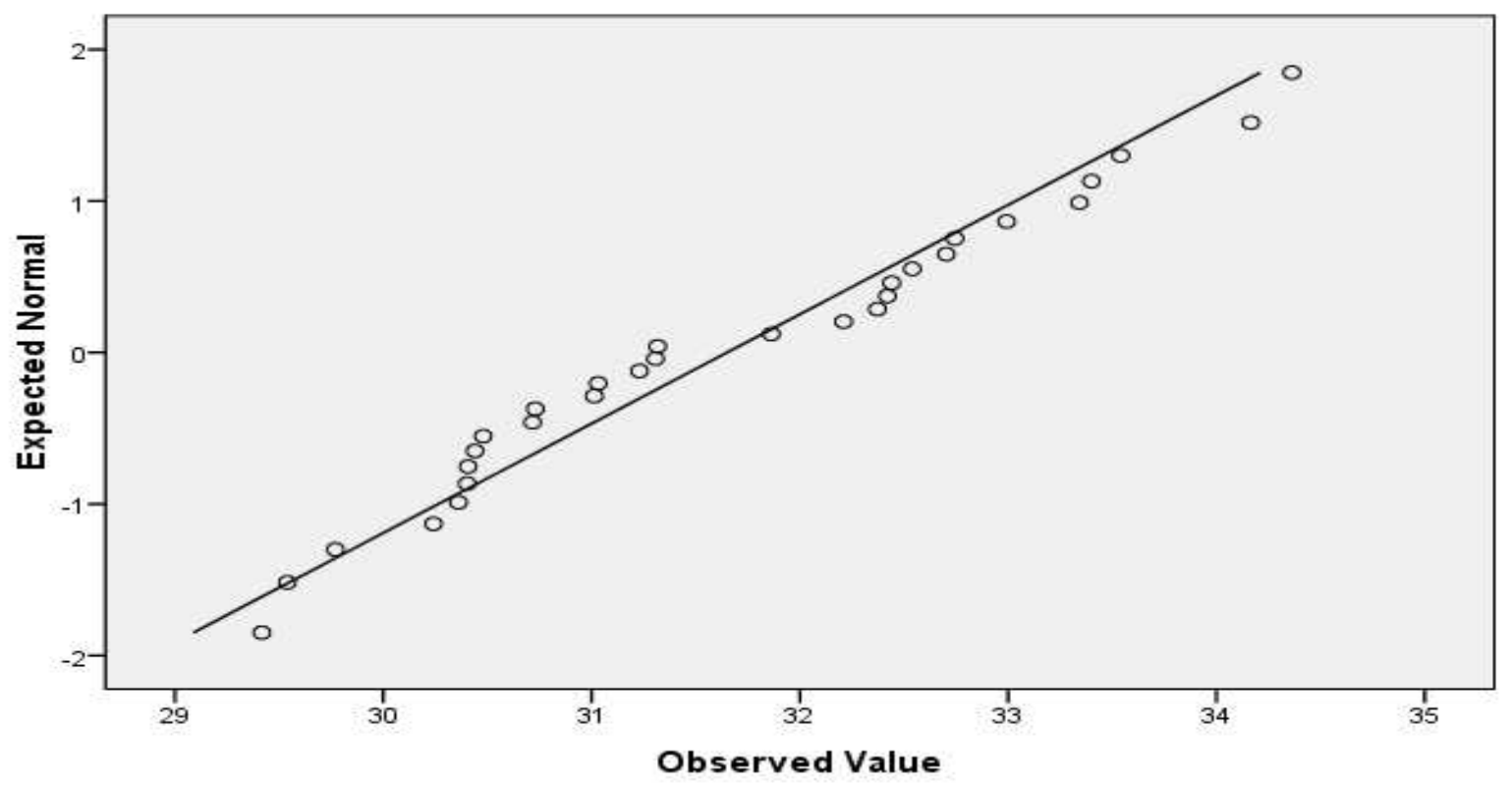

- Normal

\section{Histogram}

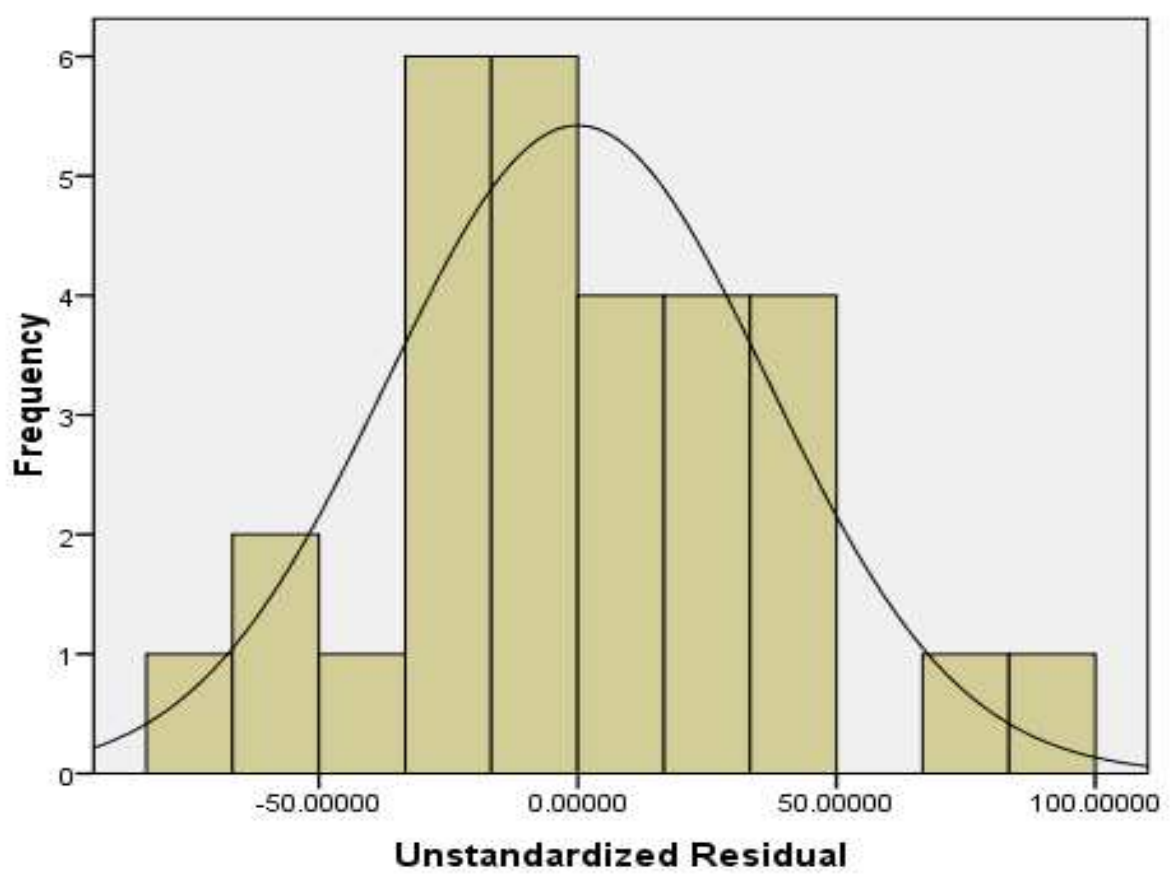

Mean $=-6.21 \mathrm{E}-13$

Std. Dev. $=36.786$

$N=30$ 
APPENDIX B:

Normality Test Result of Each Variable and Residual for combined Data

\begin{tabular}{|c|c|c|c|c|c|c|}
\hline \multicolumn{7}{|c|}{ Case Processing Summary } \\
\hline & \multicolumn{6}{|c|}{ Cases } \\
\hline & \multicolumn{2}{|c|}{ Valid } & \multicolumn{2}{|c|}{ Missing } & \multicolumn{2}{|c|}{ Total } \\
\hline & $\mathrm{N}$ & Percent & $\mathrm{N}$ & Percent & $\mathrm{N}$ & Percent \\
\hline ucs & 50 & $100.0 \%$ & 0 & $.0 \%$ & 50 & $100.0 \%$ \\
\hline mdd & 50 & $100.0 \%$ & 0 & $.0 \%$ & 50 & $100.0 \%$ \\
\hline omc & 50 & $100.0 \%$ & 0 & $.0 \%$ & 50 & $100.0 \%$ \\
\hline Unstandardized Residual & 50 & $100.0 \%$ & 0 & $.0 \%$ & 50 & $100.0 \%$ \\
\hline
\end{tabular}

Descriptives

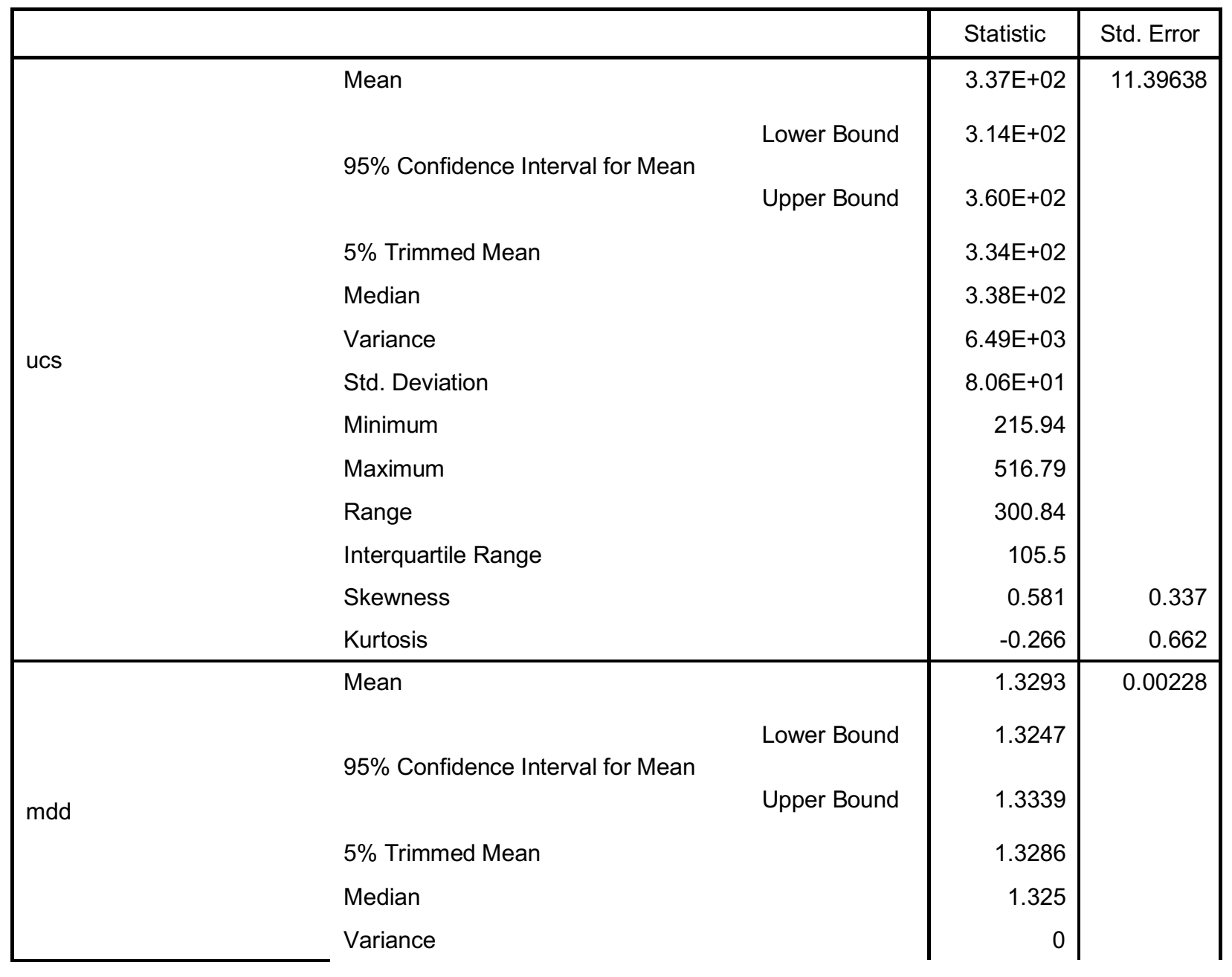




\begin{tabular}{|c|c|c|c|c|}
\hline & Std. Deviation & & 0.01609 & \\
\hline & Minimum & & 1.3 & \\
\hline & Maximum & & 1.37 & \\
\hline & Range & & 0.07 & \\
\hline & Interquartile Range & & 0.02 & \\
\hline & Skewness & & 0.784 & 0.337 \\
\hline & Kurtosis & & 0.389 & 0.662 \\
\hline & Mean & & 31.3793 & 0.18364 \\
\hline & & Lower Bound & 31.0103 & \\
\hline & 95\% Confidence Interval tor IMean & Upper Bound & 31.7484 & \\
\hline & $5 \%$ Trimmed Mean & & 31.3337 & \\
\hline & Median & & 31.254 & \\
\hline 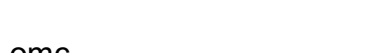 & Variance & & 1.686 & \\
\hline (Tit & Std. Deviation & & 1.29855 & \\
\hline & Minimum & & 29.42 & \\
\hline & Maximum & & 34.36 & \\
\hline & Range & & 4.94 & \\
\hline & Interquartile Range & & 2.03 & \\
\hline & Skewness & & 0.378 & 0.337 \\
\hline & Kurtosis & & -0.701 & 0.662 \\
\hline & Mean & & 0 & $4.63 E+00$ \\
\hline & & Lower Bound & $-9.31 E+00$ & \\
\hline & $95 \%$ Confidence Interval tor Mean & Unner Round & $931 \mathrm{~F}+00$ & \\
\hline & $5 \%$ Trimmed Mean & & $-8.41 \mathrm{E}-01$ & \\
\hline & Median & & $-4.48 \mathrm{E}+00$ & \\
\hline Inctandardized Pasidual & Variance & & $1.07 \mathrm{E}+03$ & \\
\hline 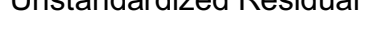 & Std. Deviation & & $3.28 \mathrm{E}+01$ & \\
\hline & Minimum & & $-7.21 \mathrm{E}+01$ & \\
\hline & Maximum & & $8.76 \mathrm{E}+01$ & \\
\hline & Range & & $1.60 \mathrm{E}+02$ & \\
\hline & Interquartile Range & & $3.75 \mathrm{E}+01$ & \\
\hline & Skewness & & 0.465 & 0.337 \\
\hline & Kurtosis & & 0.285 & 0.662 \\
\hline
\end{tabular}


Tests of Normality

\begin{tabular}{|c|c|c|c|c|c|c|}
\hline & \multicolumn{3}{|c|}{ Kolmogorov-Smirnov } & \multicolumn{3}{|c|}{ Shapiro-Wilk } \\
\hline & Statistic & $\mathrm{df}$ & Sig. & Statistic & $\mathrm{df}$ & Sig. \\
\hline ucs & .116 & 50 & .089 & .935 & 50 & .008 \\
\hline mdd & .132 & 50 & .030 & .946 & 50 & .023 \\
\hline omc & .104 & 50 & $.200^{*}$ & .957 & 50 & .069 \\
\hline Unstandardized Residual & .098 & 50 & $.200^{*}$ & .978 & 50 & .471 \\
\hline
\end{tabular}

a. Lilliefors Significance Correction

*. This is a lower bound of the true significance.

\section{Histogram}

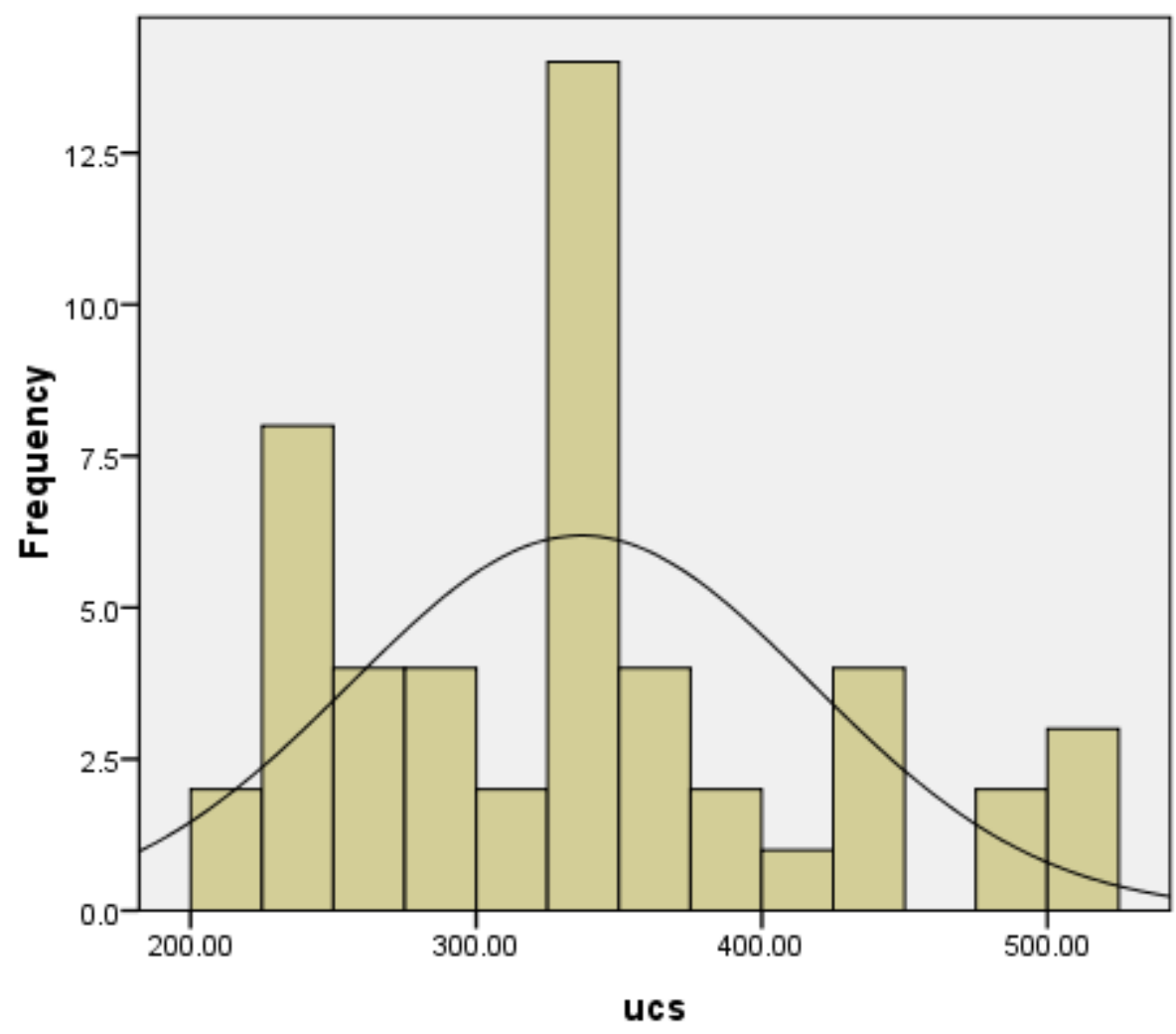

Mean $=336.79$

Std. Dev. $=80.585$ 
Normal Q-Q Plot of ucs

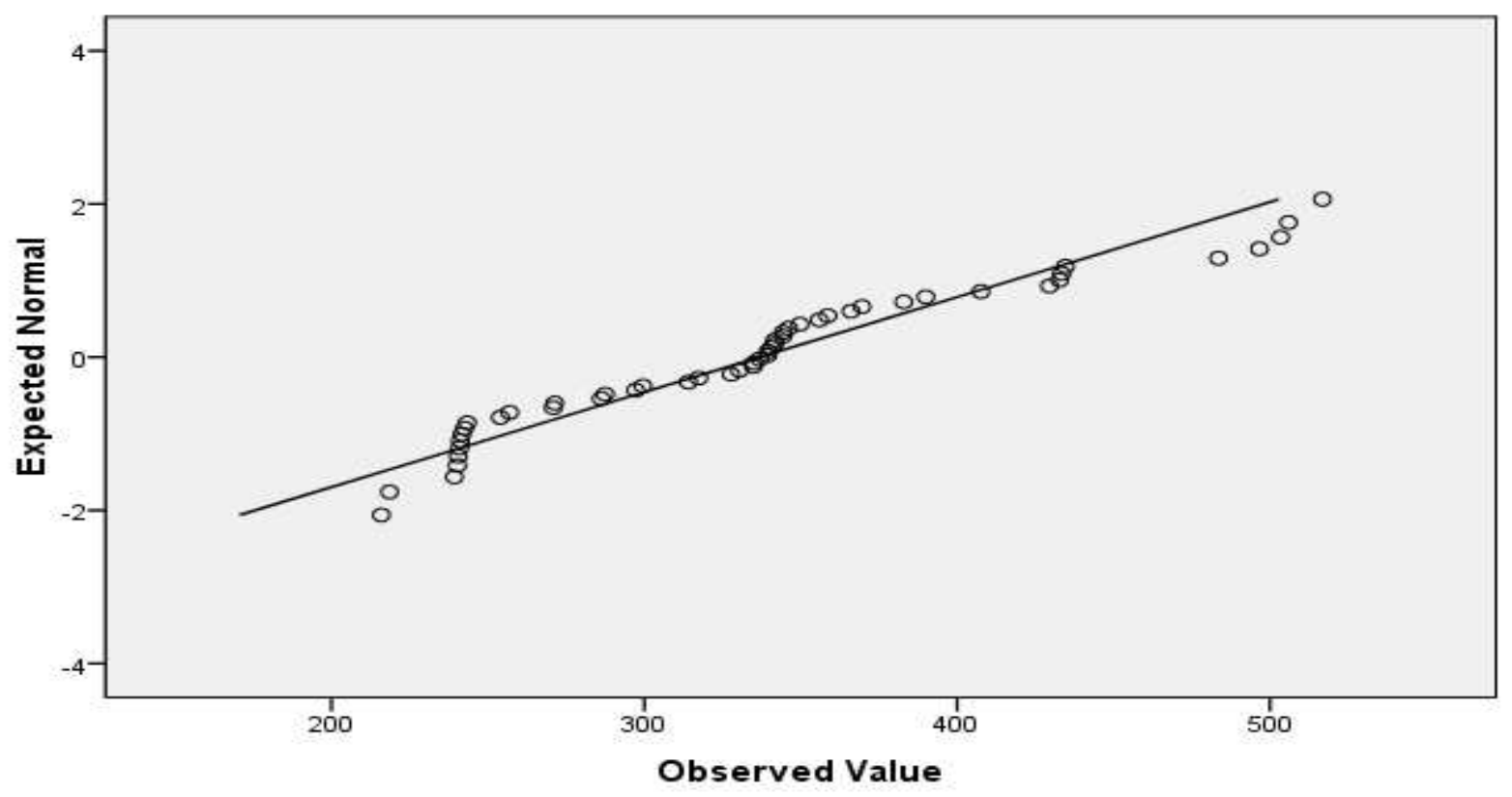

- Normal

Histogram

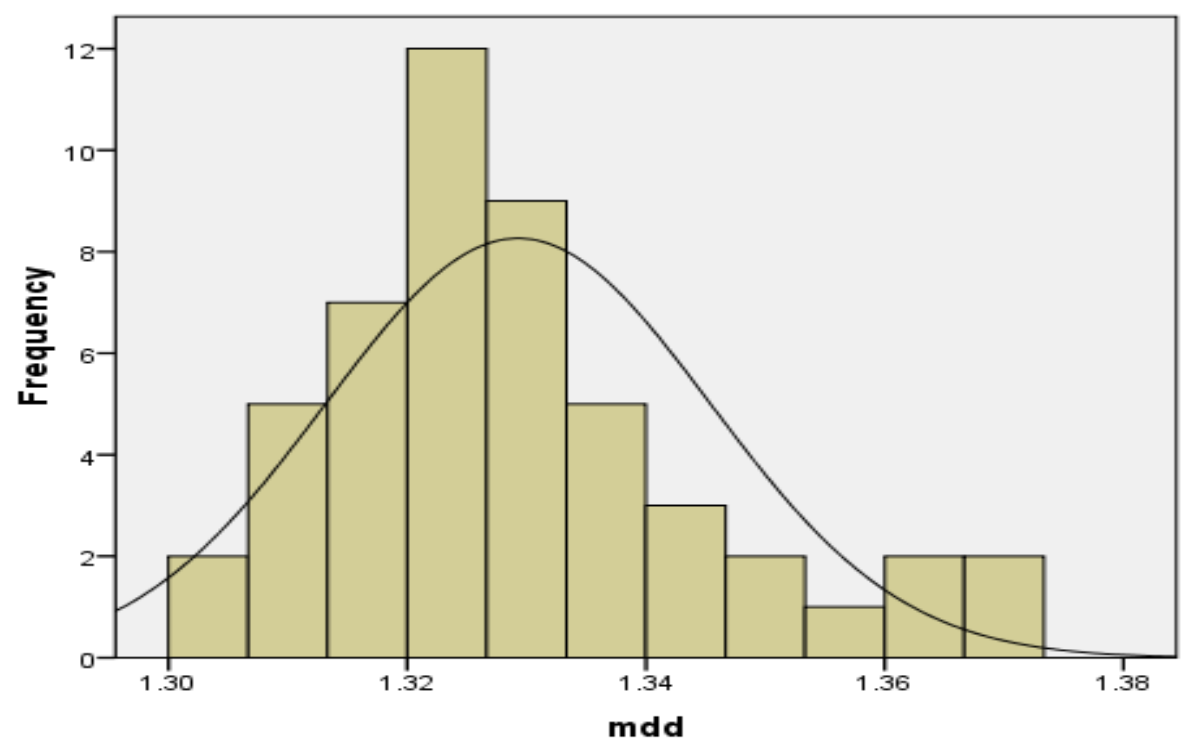

Mean $=1.33$ std. $D$ ev $=50.016$ 


\section{Normal Q-Q Plot of mdd}

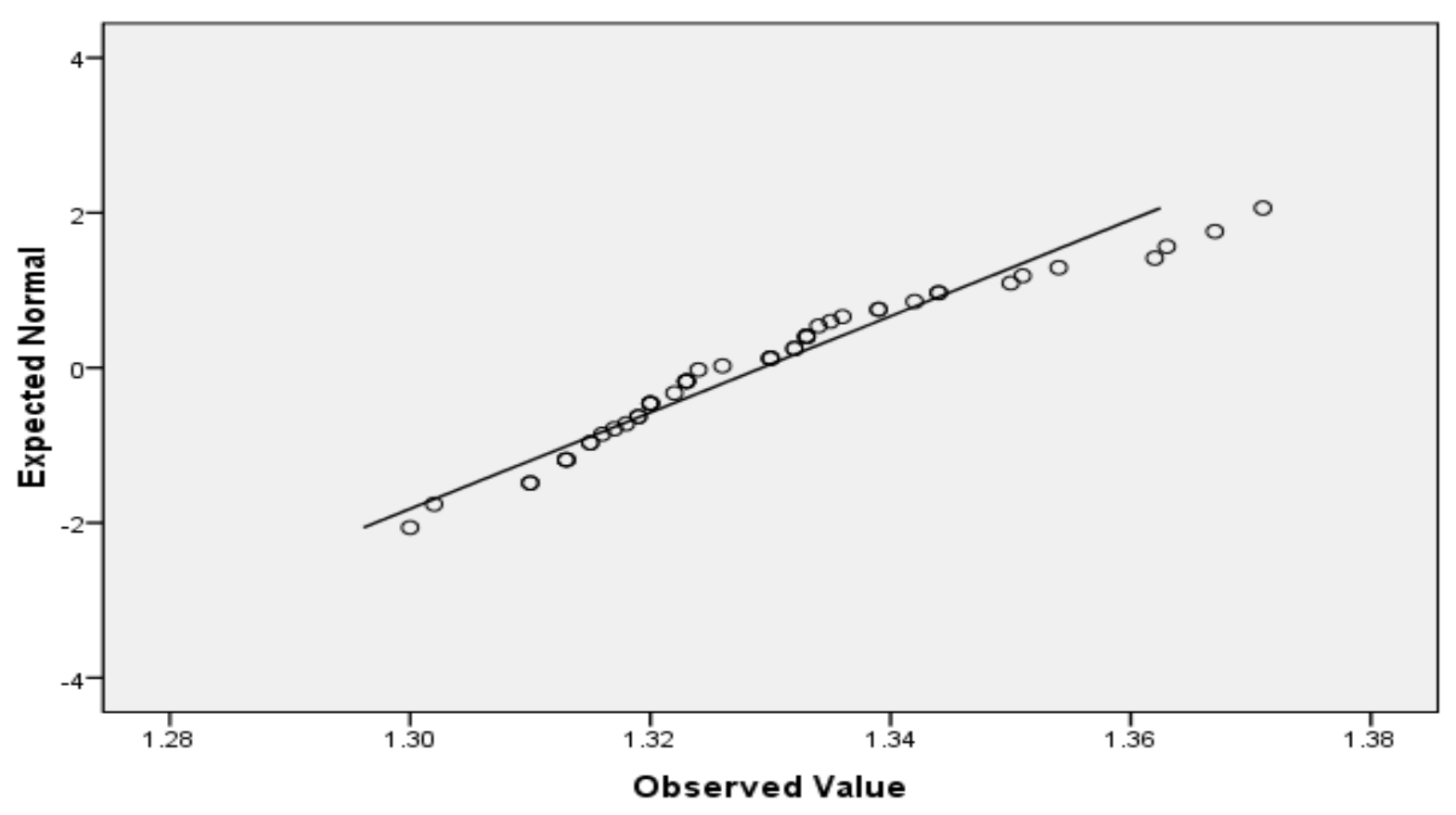

\section{Histogram}

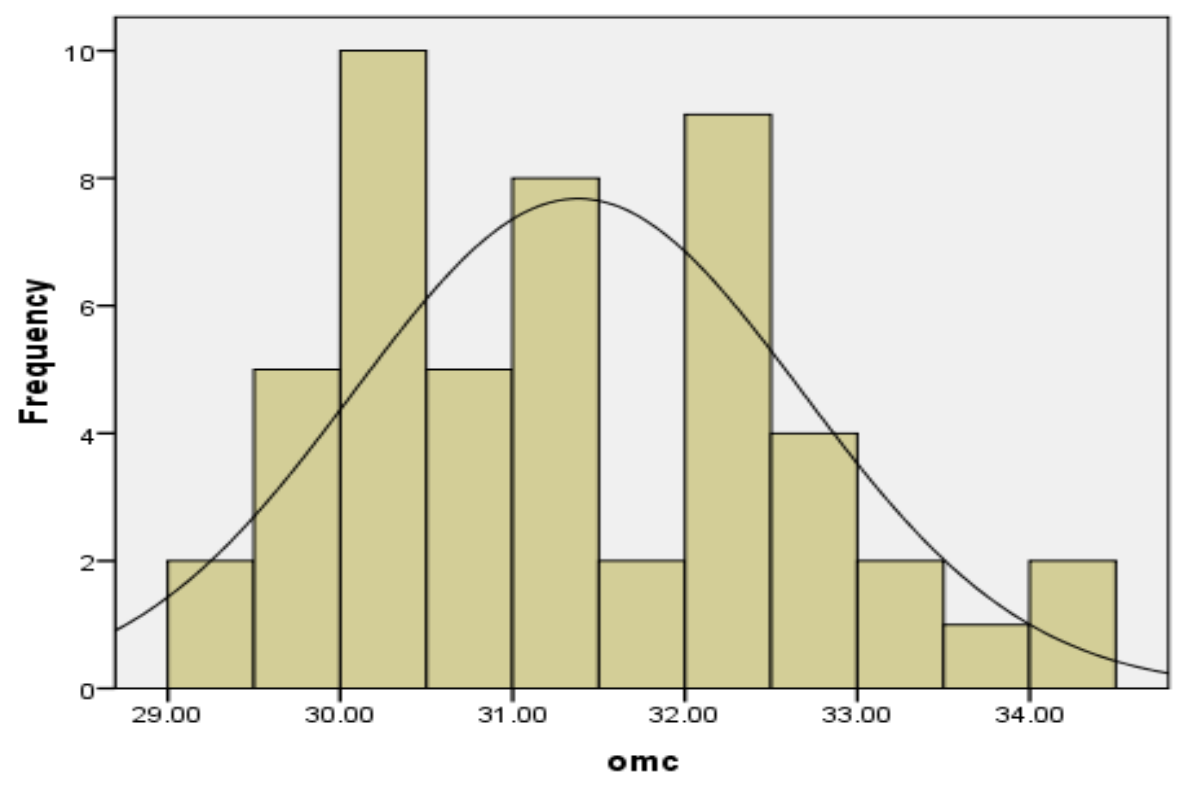

Mean $=31.38$ Std. $\operatorname{Dev}_{N=50}=1.299$ 


\section{Normal Q-Q Plot of omc}

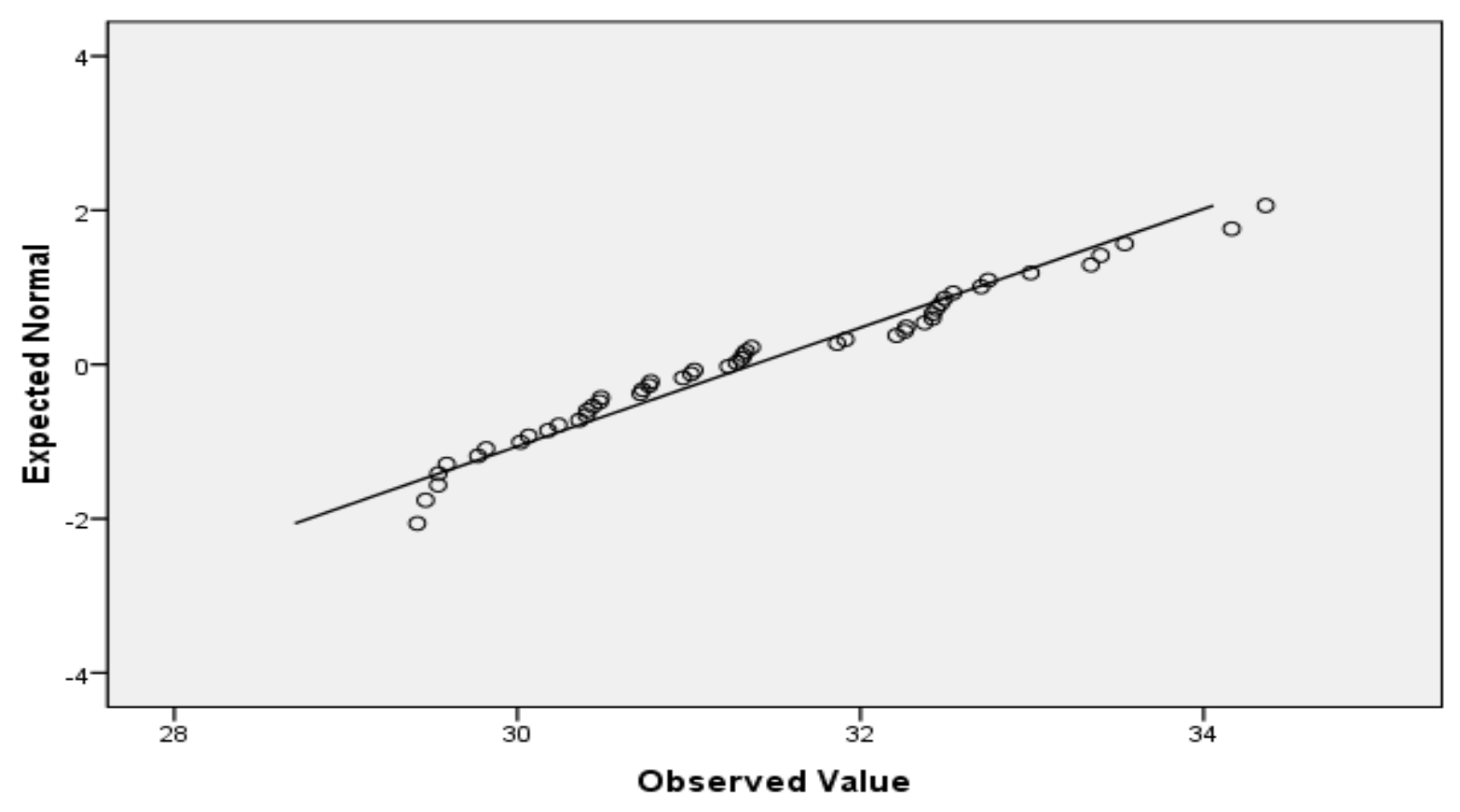

- Normal

\section{Histogram}

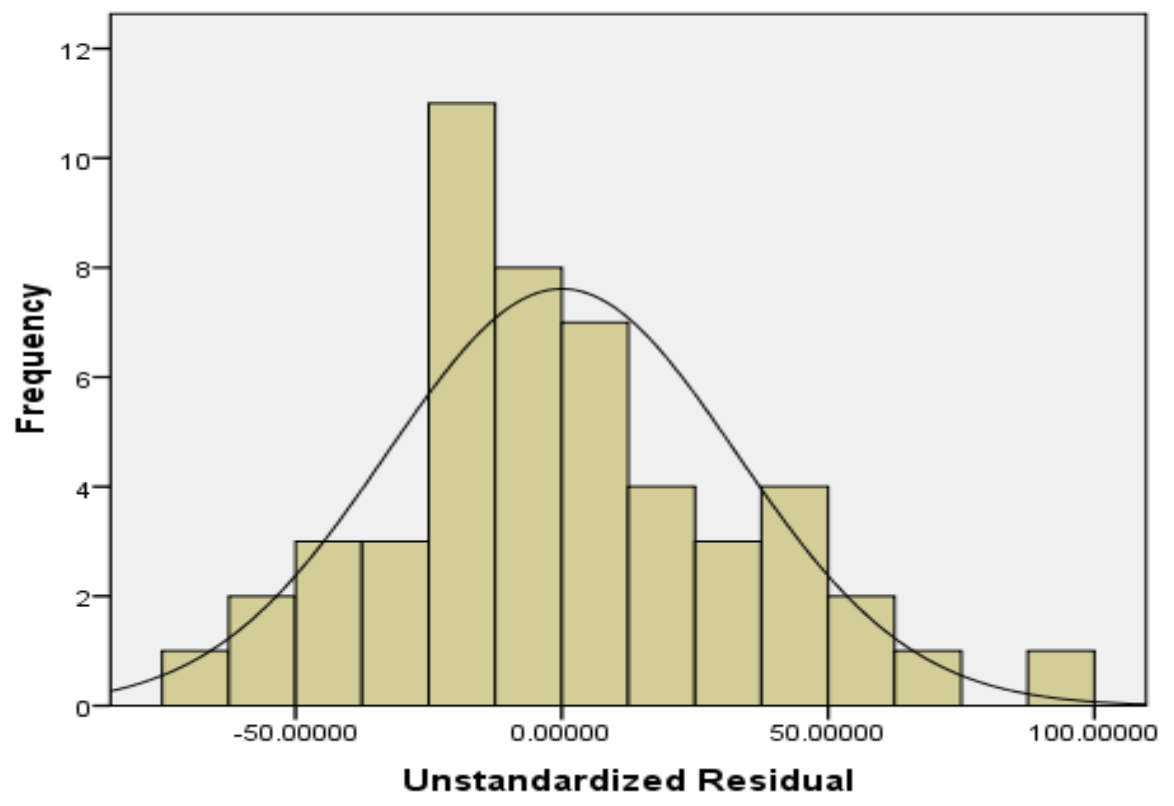

Mean $=4.76 \mathrm{E}-13$ Std. Dev. $=32.753$ 
Normal Q-Q Plot of Unstandardized Residual

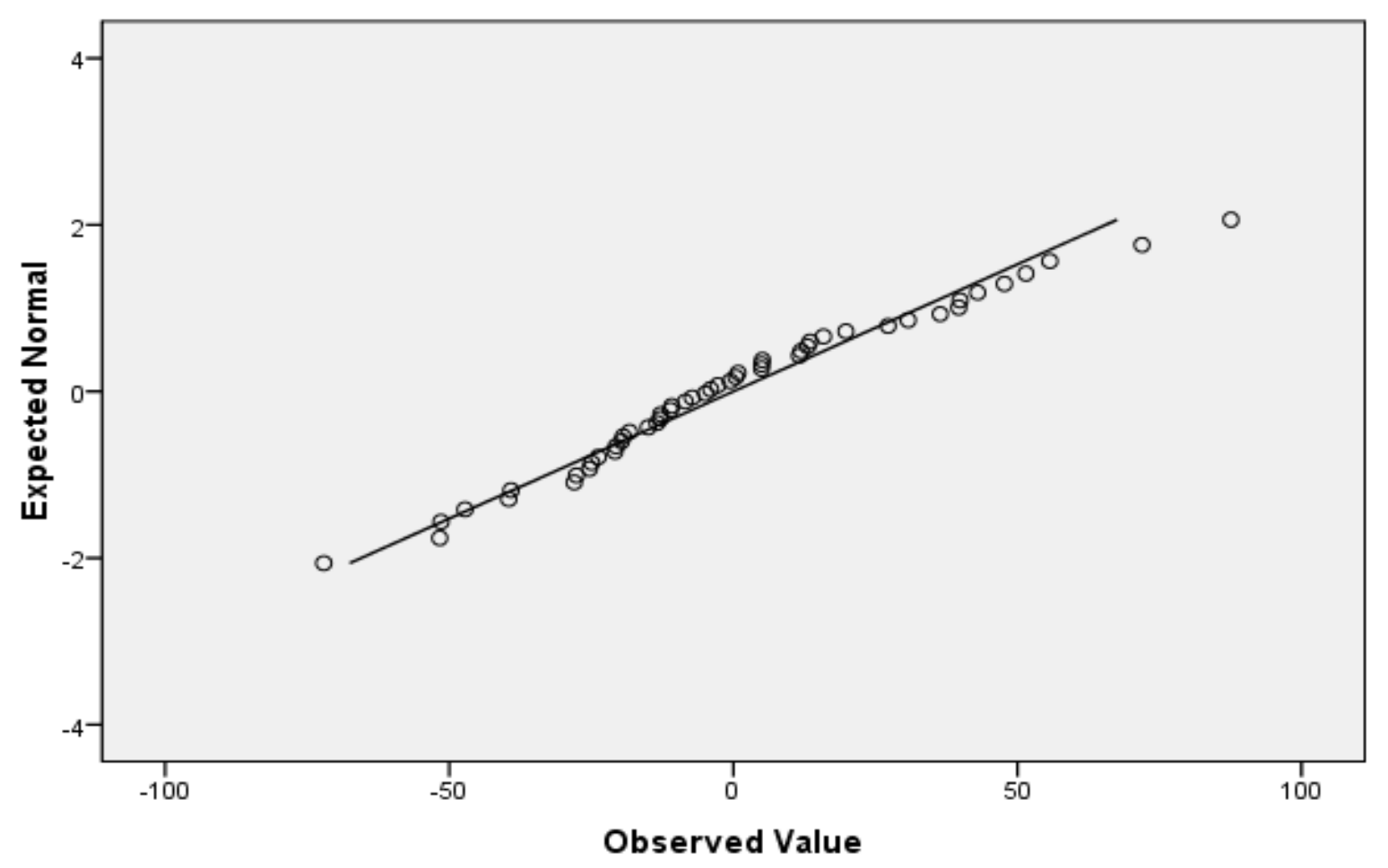




\section{APPENDIX C:
Single linear regression analysis result between UCS with MDD for primary Data

\begin{tabular}{|l|l|l|l|}
\hline \multicolumn{2}{|c|}{ Variables Entered/Removed $^{\mathbf{b}}$} & \\
\hline Model & \multicolumn{1}{|c|}{ Variables Entered } & Variables Removed & Method \\
\hline 1 & MDD $^{\text {a }}$ & & . Enter \\
\hline
\end{tabular}

a. All requested variables entered.

b. Dependent Variable: UCS

Model Summary

\begin{tabular}{|c|c|c|c|c|c|}
\hline Model & $\mathrm{R}$ & R Square & Adjusted R Square & $\begin{array}{c}\text { Std. Error of the } \\
\text { Estimate }\end{array}$ & Durbin-Watson \\
\hline 1 & $.769^{a}$ & .592 & .577 & 58.41172 & 1.410 \\
\hline
\end{tabular}

a. Predictors: (Constant), MDD

b. Dependent Variable: UCS

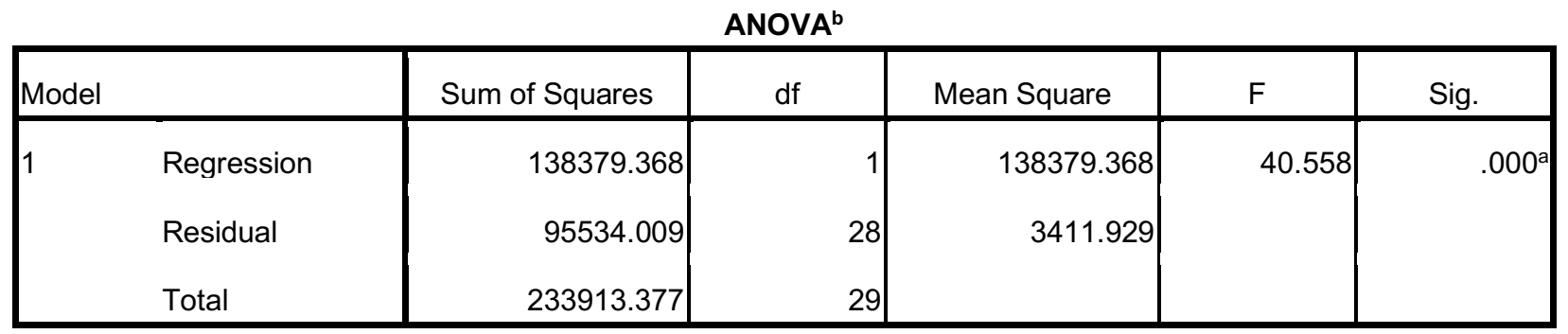
a. Predictors: (Constant), MDD
b. Dependent Variable: UCS 


\section{Coefficients $^{a}$}

\begin{tabular}{|c|c|c|c|c|c|c|c|c|c|}
\hline \multirow[b]{2}{*}{ Model } & \multicolumn{2}{|c|}{$\begin{array}{c}\text { Unstandardized } \\
\text { Coefficients }\end{array}$} & $\begin{array}{l}\text { Standardized } \\
\text { Coefficients }\end{array}$ & \multirow[b]{2}{*}{$\mathrm{t}$} & \multirow[b]{2}{*}{ Sig. } & \multicolumn{2}{|c|}{$\begin{array}{l}\text { 95\% Confidence Interval } \\
\text { for B }\end{array}$} & \multicolumn{2}{|c|}{$\begin{array}{l}\text { Collinearity } \\
\text { Statistics }\end{array}$} \\
\hline & B & Std. Error & Beta & & & $\begin{array}{l}\text { Lower } \\
\text { Bound }\end{array}$ & $\begin{array}{l}\text { Upper } \\
\text { Bound }\end{array}$ & Tolerance & VIF \\
\hline 1 (Constant) & -4449.037 & 754.530 & & 5.896 & .000 & -5994.622 & -2903.452 & & \\
\hline MDD & 3606.161 & 566.252 & .769 & 6.368 & .000 & 2446.247 & 4766.075 & 1.000 & 1.000 \\
\hline
\end{tabular}

a. Dependent Variable:

UCS

Residuals Statistics ${ }^{a}$

\begin{tabular}{|c|c|c|c|c|c|}
\hline & Minimum & Maximum & Mean & Std. Deviation & $\mathrm{N}$ \\
\hline Predicted Value & 238.9721 & 495.0095 & 3.5569E2 & 69.07751 & 30 \\
\hline Residual & $-8.43510 \mathrm{E} 1$ & 1.44347E2 & .00000 & 57.39579 & 30 \\
\hline Std. Predicted Value & -1.690 & 2.017 & .000 & 1.000 & 30 \\
\hline Std. Residual & -1.444 & 2.471 & .000 & .983 & 30 \\
\hline
\end{tabular}

a. Dependent Variable: UCS

Histogram

\section{Dependent Variable: UCS}

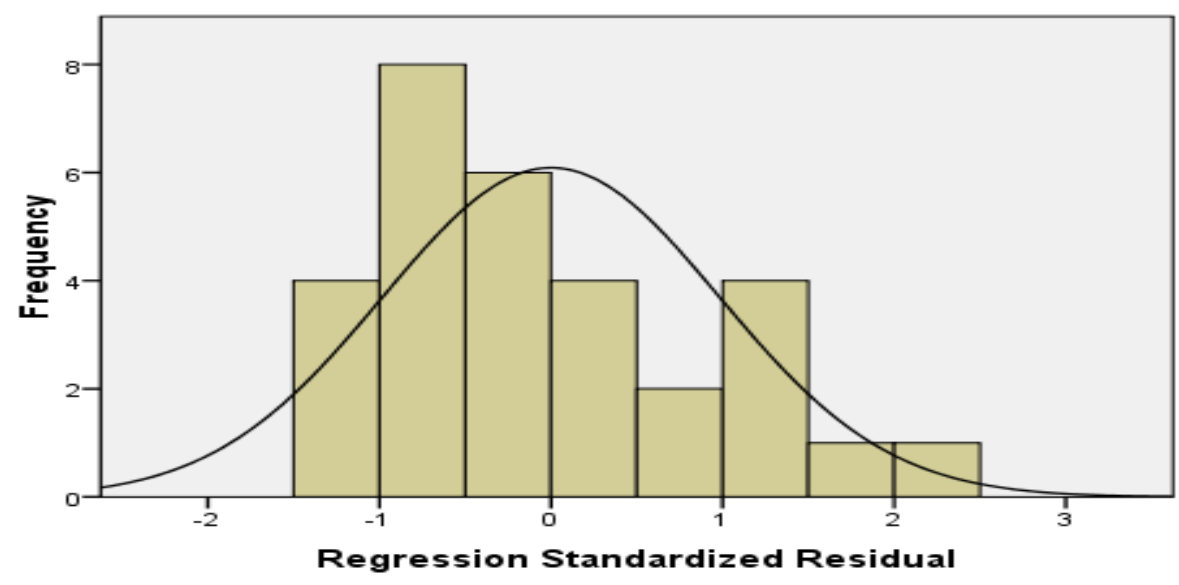

Mean $=-1.24 \mathrm{E}-14$ Std. $\mathrm{Dev}=0.983$ 
Normal P-P Plot of Regression Standardized Residual

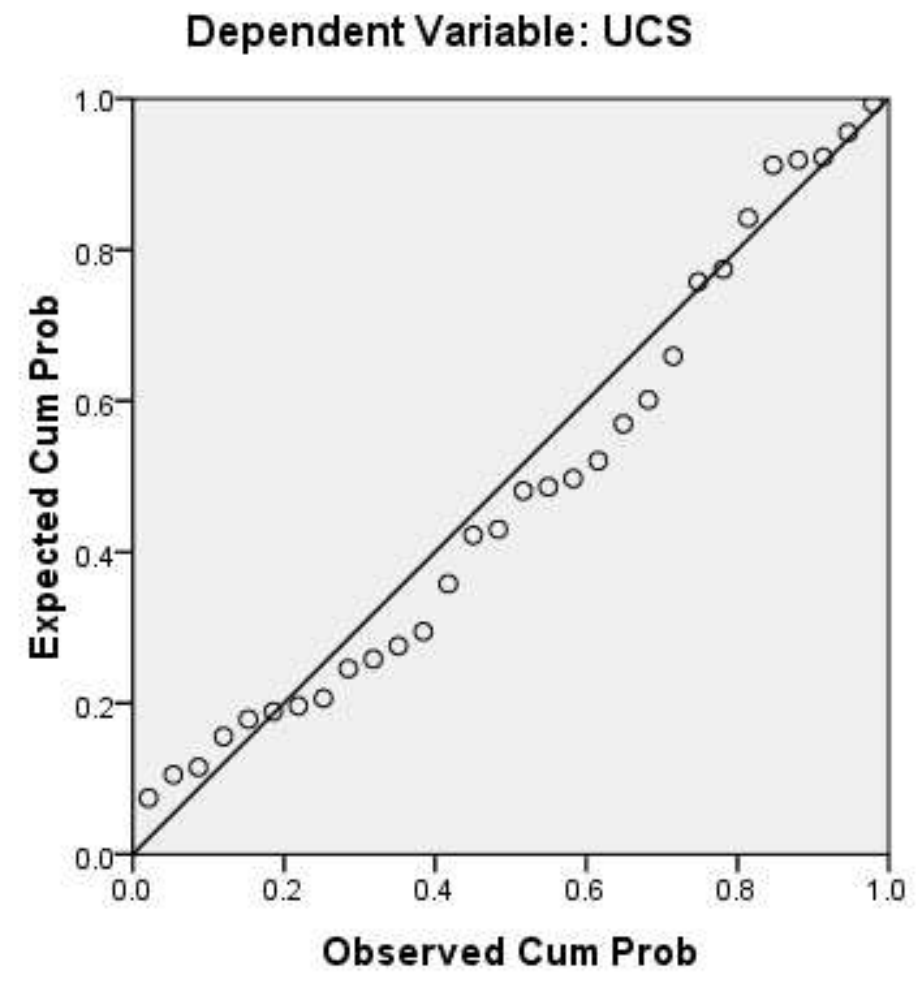




\section{APPENDIX D: \\ Single linear regression analysis result between UCS with OMC for primary Data}

\begin{tabular}{|l|l|c|l|}
\hline Model & \multicolumn{1}{|c|}{ Variables Entered } & Variables Removed & Method \\
\hline 1 & OMC $^{\text {a }}$ & & Enter \\
\hline
\end{tabular}

a. All requested variables entered.

b. Dependent Variable: UCS

Model Summaryb

\begin{tabular}{|c|c|c|c|c|c|}
\hline Model & $\mathrm{R}$ & R Square & Adjusted R Square & $\begin{array}{l}\text { Std. Error of the } \\
\text { Estimate }\end{array}$ & Durbin-Watson \\
\hline 1 & $.891^{\mathrm{a}}$ & .794 & .787 & 41.45385 & 1.357 \\
\hline
\end{tabular}

a. Predictors: (Constant), OMC

b. Dependent Variable: UCS

ANOVA $^{b}$

\begin{tabular}{|ll|r|r|r|r|r|}
\hline Model & & Sum of Squares & df & Mean Square & F & Sig. \\
\hline 1 & Regression & 185797.572 & 1 & 185797.572 & 108.121 & $.000^{\mathrm{a}}$ \\
Residual & 48115.804 & 28 & 1718.422 & \\
& 233913.377 & 29 & & & \\
\hline
\end{tabular}

a. Predictors: (Constant), OMC

b. Dependent Variable: UCS 


\section{Coefficients $^{\mathrm{a}}$}

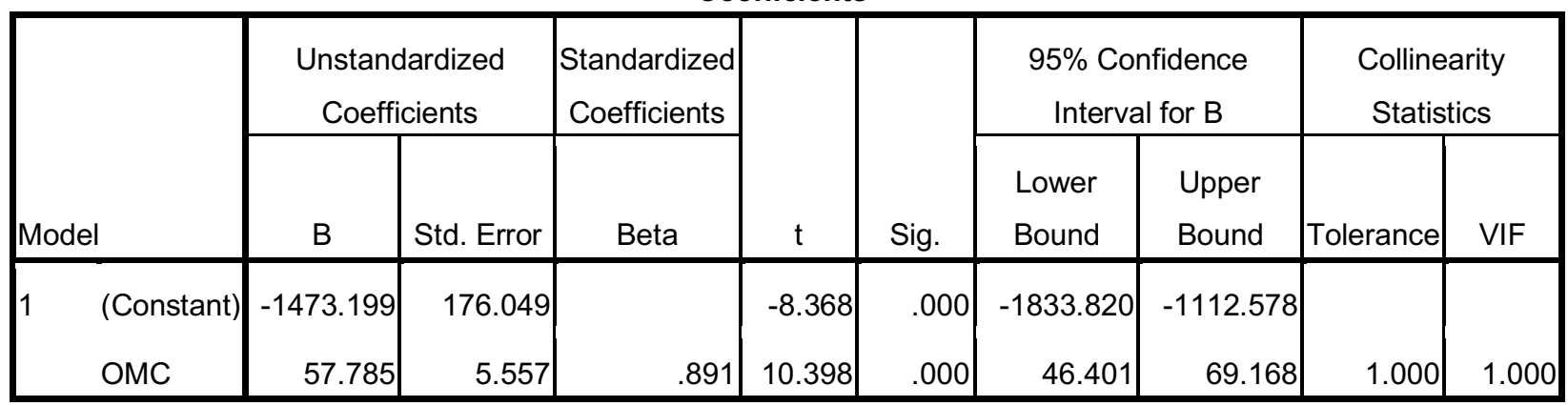

a. Dependent Variable: UCS

\section{Residuals Statistics}

\begin{tabular}{|c|c|c|c|c|c|c|}
\hline & Minimum & Maximum & Mean & Std. Deviation & $\mathrm{N}$ & \\
\hline Predicted Value & 226.6526 & 512.3978 & 3.5569E2 & 80.04257 & & 30 \\
\hline Residual & $-7.77079 \mathrm{E} 1$ & 84.84972 & .00000 & 40.73286 & & 30 \\
\hline Std. Predicted Value & -1.612 & 1.958 & .000 & 1.000 & & 30 \\
\hline Std. Residual & -1.875 & 2.047 & .000 & .983 & & 30 \\
\hline
\end{tabular}

a. Dependent Variable: UCS

Histogram

Dependent Variable: UCS

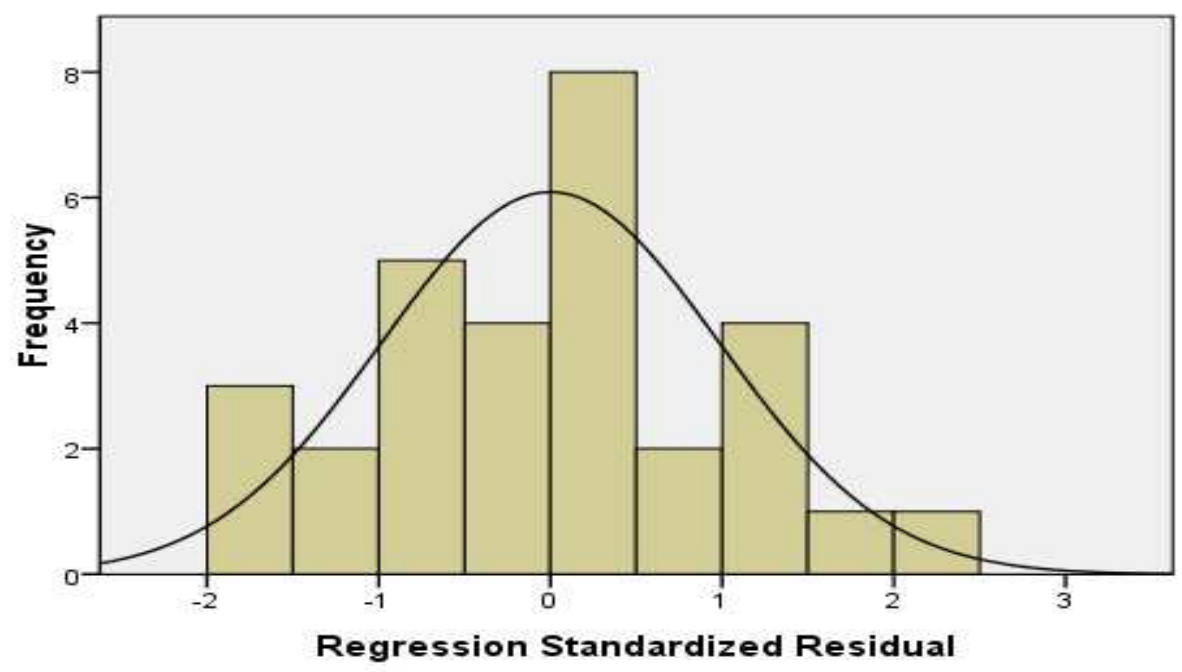

Mean $=-1.60 \mathrm{E}-14$ Std. Dev. $=0.983$ 
Normal P-P Plot of Regression Standardized Residual

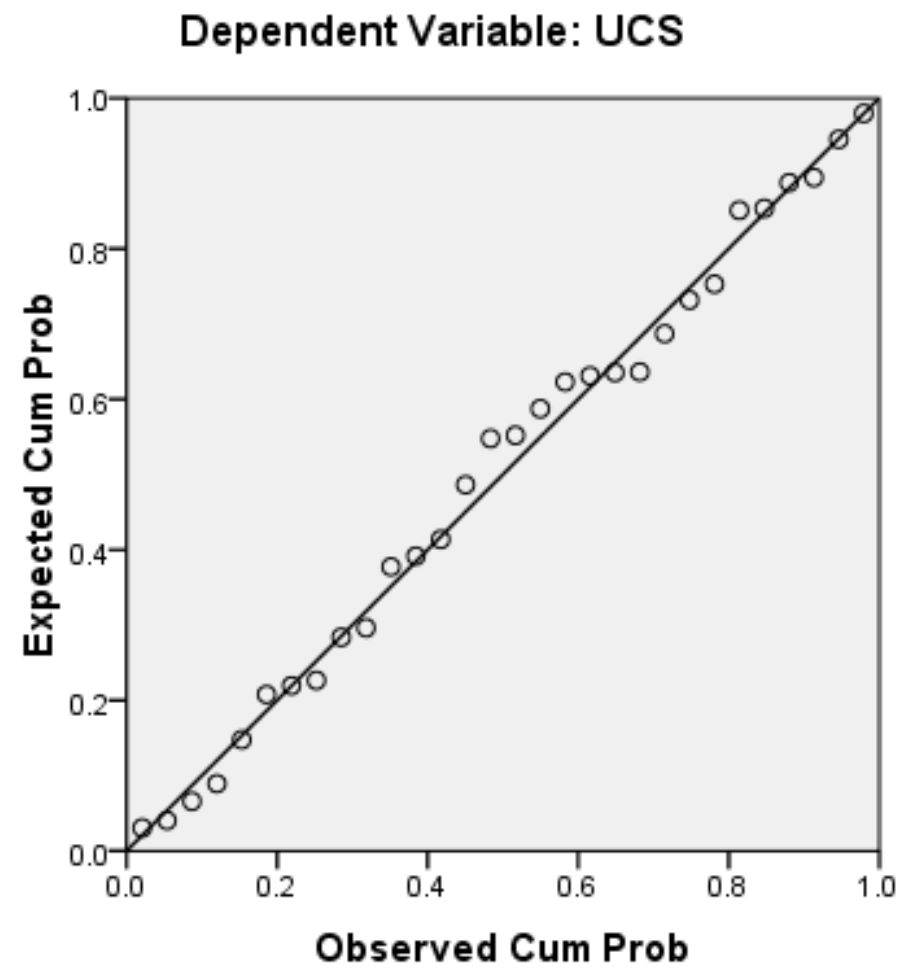




\section{APPENDIX E: \\ Single linear regression analysis result between UCS with MDD for Combined Data}

\begin{tabular}{|l|r|r|r|}
\hline & \multicolumn{2}{|c|}{ Descriptive Statistics } \\
\hline Mean & Std. Deviation & \multicolumn{1}{|c|}{$\mathrm{N}$} \\
\hline mdd & $3.3679 \mathrm{E} 2$ & 80.58454 & 50 \\
\hline
\end{tabular}

\begin{tabular}{|ll|r|r|}
\hline \multicolumn{1}{|c|}{ Correlations } & ucs & \multicolumn{1}{c|}{ mdd } \\
\hline Pearson Correlation & & 1.000 & .781 \\
& ucs & .781 & 1.000 \\
\hline Sig. (1-tailed) & mdd &. & .000 \\
& ucs & .000 & 50 \\
\hline N & mdd & 50 & 50 \\
\hline
\end{tabular}

\section{Variables Entered/Removed ${ }^{\mathrm{b}}$}

\begin{tabular}{|l|l|c|l|}
\hline Model & \multicolumn{1}{|c|}{ Variables Entered } & Variables Removed & \\
\hline 1 & mdd $^{a}$ & & Method \\
\hline
\end{tabular}
a. All requested variables entered.
b. Dependent Variable: ucs

\begin{tabular}{|l|r|r|r|r|r|}
\hline & & & & \multicolumn{2}{c|}{ Model Summary } \\
Model & $\mathrm{R}$ & R Square & Adjusted R Square & Est. Error of the & \\
\hline 1 & $.781^{\mathrm{a}}$ & .610 & .601 & 50.87485 & Durbin-Watson \\
\hline
\end{tabular}

a. Predictors: (Constant), mdd 
Model Summary ${ }^{b}$

\begin{tabular}{|l|r|r|r|r|r|}
\hline & & & & \multicolumn{2}{c|}{$\begin{array}{c}\text { Std. Error of the } \\
\text { Model }\end{array}$} \\
\hline 1 & $\mathrm{R}$ & $\mathrm{R}$ Square & Adjusted R Square & Estimate & Durbin-Watson \\
\hline & $.781^{\mathrm{a}}$ & .610 & .601 & 50.87485 & 1.339 \\
\hline
\end{tabular}

b. Dependent Variable: ucs

ANOVA $^{b}$

\begin{tabular}{|c|c|c|c|c|c|c|}
\hline \multicolumn{2}{|c|}{ Model } & Sum of Squares & df & Mean Square & $\mathrm{F}$ & Sig. \\
\hline \multirow[t]{3}{*}{1} & Regression & 193963.531 & 1 & 193963.531 & 74.940 & $.000^{\mathrm{a}}$ \\
\hline & Residual & 124236.039 & 48 & 2588.251 & & \\
\hline & Total & 318199.570 & 49 & & & \\
\hline
\end{tabular}

a. Predictors: (Constant), mdd

b. Dependent Variable: ucs

Coefficients $^{\mathrm{a}}$

\begin{tabular}{|c|c|c|c|c|c|c|c|c|c|}
\hline \multirow[b]{2}{*}{ Model } & \multicolumn{2}{|c|}{$\begin{array}{c}\text { Unstandardized } \\
\text { Coefficients }\end{array}$} & \multirow{2}{*}{\begin{tabular}{|c|}
$\begin{array}{c}\text { Standardize } \\
\mathrm{d} \\
\text { Coefficients }\end{array}$ \\
\\
Beta
\end{tabular}} & \multirow[b]{2}{*}{$\mathrm{t}$} & \multirow[b]{2}{*}{ Sig. } & \multicolumn{2}{|c|}{$\begin{array}{c}95 \% \text { Confidence Interval } \\
\text { for B }\end{array}$} & \multicolumn{2}{|c|}{$\begin{array}{l}\text { Collinearity } \\
\text { Statistics }\end{array}$} \\
\hline & $B$ & Std. Error & & & & $\begin{array}{l}\text { Lower } \\
\text { Bound }\end{array}$ & $\begin{array}{l}\text { Upper } \\
\text { Bound }\end{array}$ & $\begin{array}{c}\text { Toleranc } \\
\mathrm{e}\end{array}$ & VIF \\
\hline $\begin{array}{ll}1 & \text { (Constant } \\
& \text { ) }\end{array}$ & -4860.926 & 600.464 & & -8.095 & .000 & -6068.240 & -3653.612 & & \\
\hline mdd & 3910.176 & 451.689 & .781 & 8.657 & .000 & 3001.995 & 4818.358 & 1.000 & 1.000 \\
\hline
\end{tabular}

a. Dependent Variable: ucs

Residuals Statistics ${ }^{a}$

\begin{tabular}{|l|r|r|r|r|r|}
\hline & \multicolumn{1}{|c|}{ Minimum } & Maximum & Mean & Std. Deviation & $\mathrm{N}$ \\
\hline Predicted Value & 222.3031 & 499.9256 & $3.3679 \mathrm{E} 2$ & 62.91613 & 50 \\
Residual & $-7.49783 \mathrm{E} 1$ & $1.50680 \mathrm{E} 2$ & .00000 & 50.35305 & 50 \\
Std. Predicted Value & -1.820 & 2.593 & .000 & 1.000 & .990 \\
Std. Residual & -1.474 & 2.962 & .000 & 50 \\
\hline
\end{tabular}

a. Dependent Variable: ucs 
Histogram

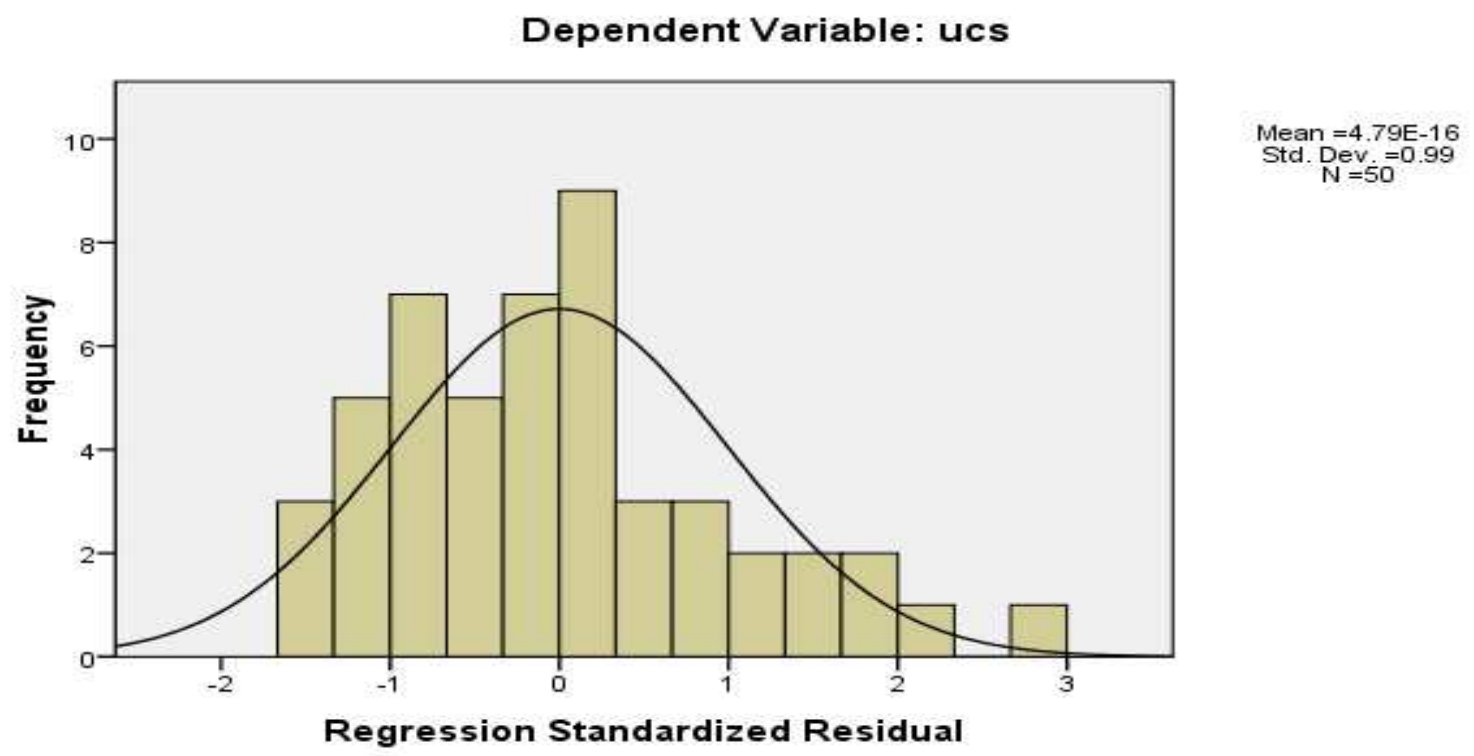

Normal P-P Plot of Regression Standardized Residual

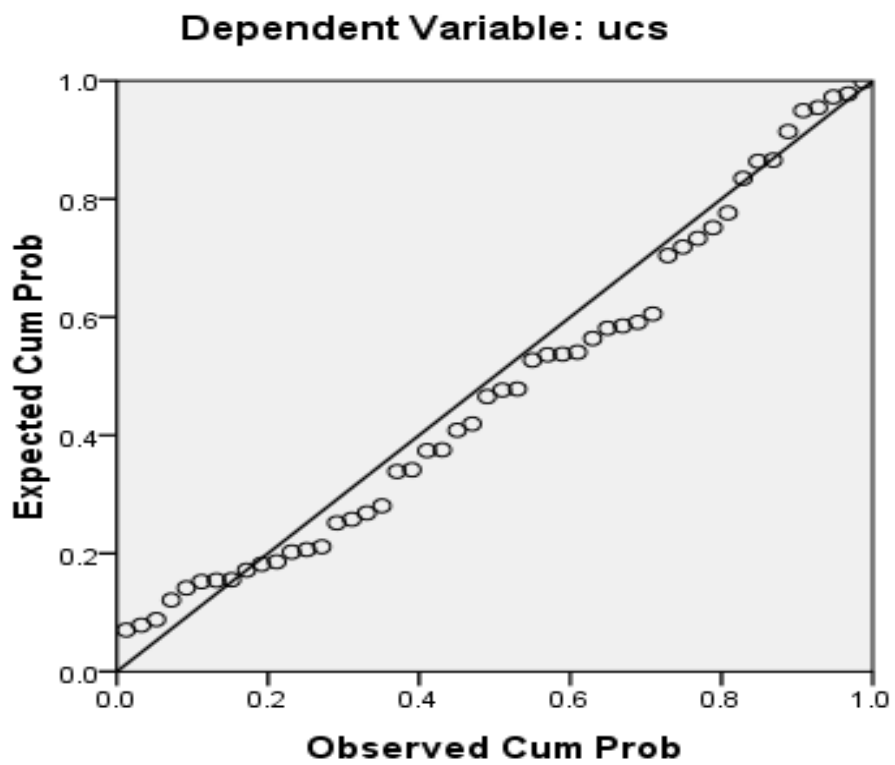




\section{APPENDIX F: \\ Single linear regression analysis result between UCS with omc for combined Data}

\begin{tabular}{|l|r|r|r|}
\hline & \multicolumn{2}{|c|}{ Descriptive Statistics } \\
\hline ucs & Mean & Std. Deviation & \multicolumn{1}{c|}{$\mathrm{N}$} \\
Omc & $3.3679 \mathrm{E} 2$ & 80.58454 & 50 \\
\hline
\end{tabular}

\begin{tabular}{|ll|r|r|}
\hline \multicolumn{2}{|c|}{ Correlations } & \multicolumn{1}{|c|}{ omc } \\
\hline Pearson Correlation & & ucs & .883 \\
& ucs & 1.000 & 1.000 \\
\hline Sig. (1-tailed) & omc & .883 & .000 \\
& ucs & .000 & 50 \\
\hline N & omc & 50 & 50 \\
\hline
\end{tabular}

Variables Entered/Removed ${ }^{b}$

\begin{tabular}{|l|l|c|l|}
\hline Model & \multicolumn{1}{|c|}{ Variables Entered } & Variables Removed & Method \\
\hline 1 & omc & & Enter \\
\hline
\end{tabular}

a. All requested variables entered.

b. Dependent Variable: ucs

\begin{tabular}{|l|r|r|r|r|r|}
\hline & & & & \multicolumn{2}{c|}{ Model Summary } \\
Model & $\mathrm{R}$ & $\mathrm{R}$ Square & Adjusted R Square & Std. Error of the & Estimate \\
\hline 1 & $.883^{\mathrm{a}}$ & .780 & .776 & 38.18204 & Durbin-Watson \\
\hline
\end{tabular}

a. Predictors: (Constant), omc 
Model Summary ${ }^{b}$

\begin{tabular}{|l|r|r|r|r|r|}
\hline Model & R & R Square & Adjusted R Square & \multicolumn{1}{c|}{$\begin{array}{c}\text { Std. Error of the } \\
\text { Estimate }\end{array}$} & \multicolumn{1}{c|}{ Durbin-Watson } \\
\hline 1 & $.883^{\mathrm{a}}$ & .780 & .776 & 38.18204 & 1.478 \\
\hline
\end{tabular}

b. Dependent Variable: ucs

ANOVA $^{b}$

\begin{tabular}{|ll|r|r|r|r|r|}
\hline Model & Sum of Squares & df & Mean Square & \multicolumn{1}{|c|}{ F } & \multicolumn{1}{c|}{ Sig. } \\
\hline 1 & Regression & 248221.899 & 1 & 248221.899 & 170.264 & $.000^{\circ}$ \\
& Residual & 69977.671 & 48 & 1457.868 & & \\
Total & 318199.570 & 49 & & & \\
\hline
\end{tabular}

a. Predictors: (Constant), omc

b. Dependent Variable: ucs

\section{Coefficients $^{\mathrm{a}}$}

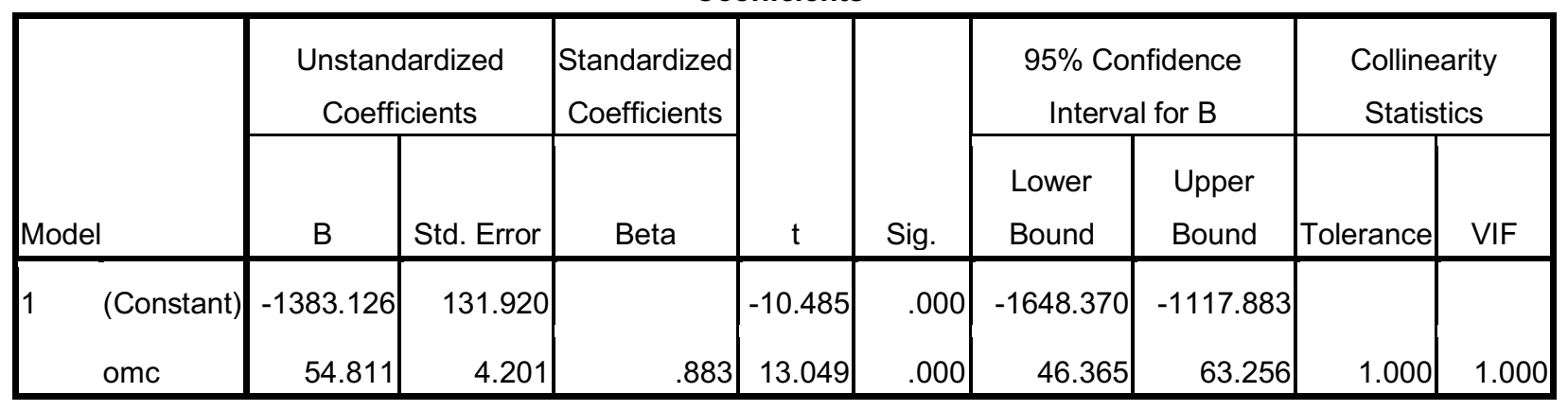

a. Dependent Variable: ucs

Residuals Statistics ${ }^{a}$

\begin{tabular}{|l|r|r|r|r|r|}
\hline & \multicolumn{1}{|c|}{ Minimum } & \multicolumn{1}{c|}{ Maximum } & \multicolumn{1}{c|}{ Mean } & Std. Deviation & $\mathrm{N}$ \\
\hline Predicted Value & 229.2371 & 500.2755 & $3.3679 \mathrm{E} 2$ & 71.17410 & 50 \\
Residual & $-7.55458 \mathrm{E} 1$ & 85.07269 & .00000 & 37.79042 & 50 \\
Std. Predicted Value & -1.511 & 2.297 & .000 & 1.000 & 50 \\
Std. Residual & -1.979 & 2.228 & .000 & .990 & 50 \\
\hline
\end{tabular}

a. Dependent Variable: ucs 


\section{Histogram}

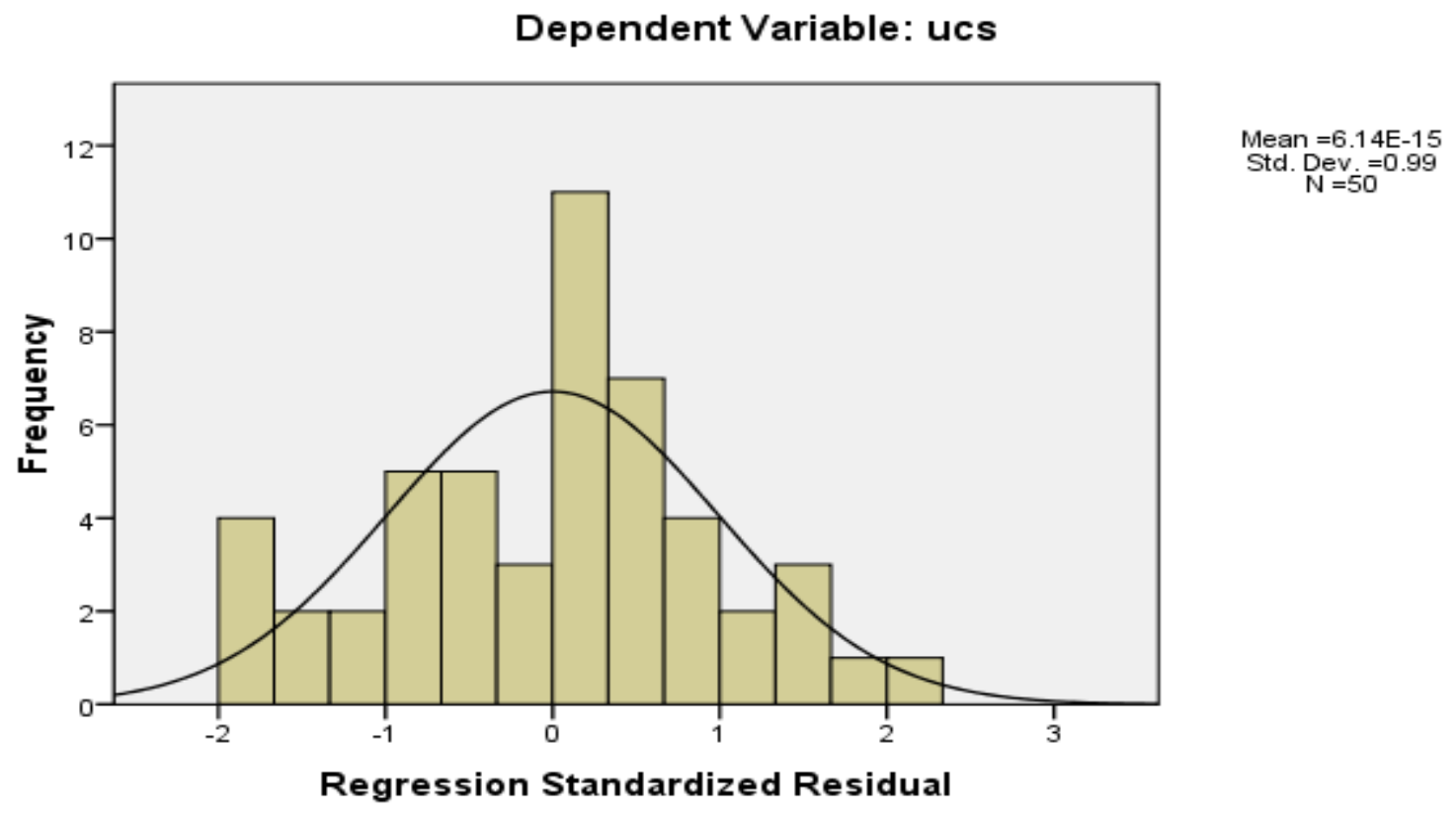

Normal P-P Plot of Regression Standardized Residual

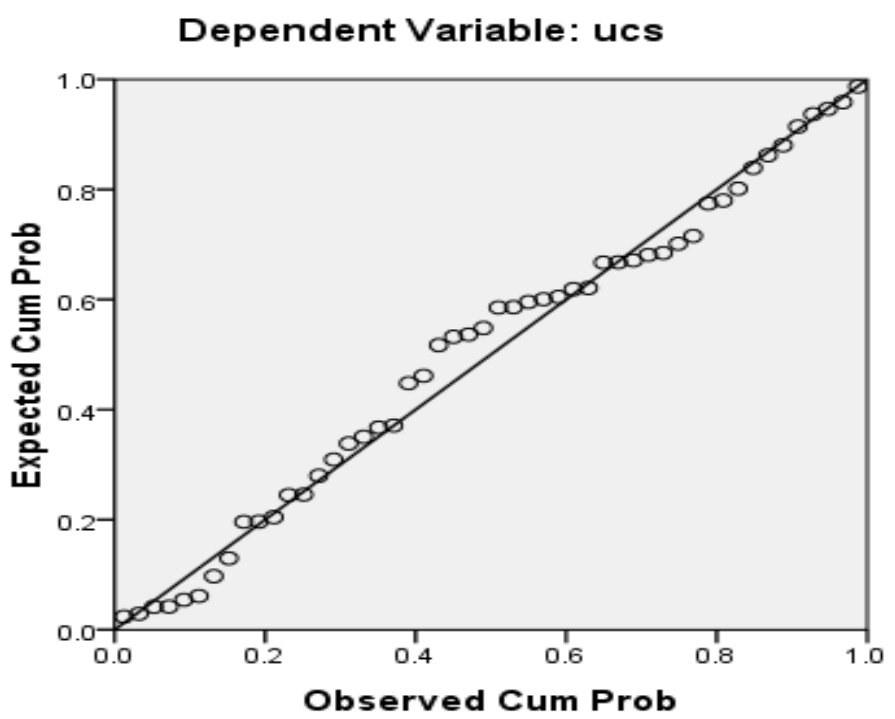




\section{APPENDIX G:}

\section{Multiple linear regression analysis result between UCS with MDD and OMC for primary Data}

\begin{tabular}{|l|c|c|c|}
\hline \multicolumn{2}{|c|}{ Variables Entered/Removed } \\
Model & Variables Entered & Variables Removed & \\
\hline 1 & OMC, MDD & Method \\
\hline
\end{tabular}
a. All requested variables entered.
b. Dependent Variable: UCS

\begin{tabular}{|l|r|r|r|r|r|}
\hline & & & & \multicolumn{1}{c|}{ Model Summary $^{\mathbf{b}}$} & \multicolumn{2}{c|}{$\begin{array}{c}\text { Std. Error of the } \\
\text { Estimate }\end{array}$} & Durbin-Watson \\
\hline 1 & $\mathrm{R}$ & R Square & Adjusted R Square & Estel \\
\hline & $.912^{\mathrm{a}}$ & .832 & .820 & 38.12366 & 1.263 \\
\hline
\end{tabular}

a. Predictors: (Constant), OMC, MDD

b. Dependent Variable: UCS

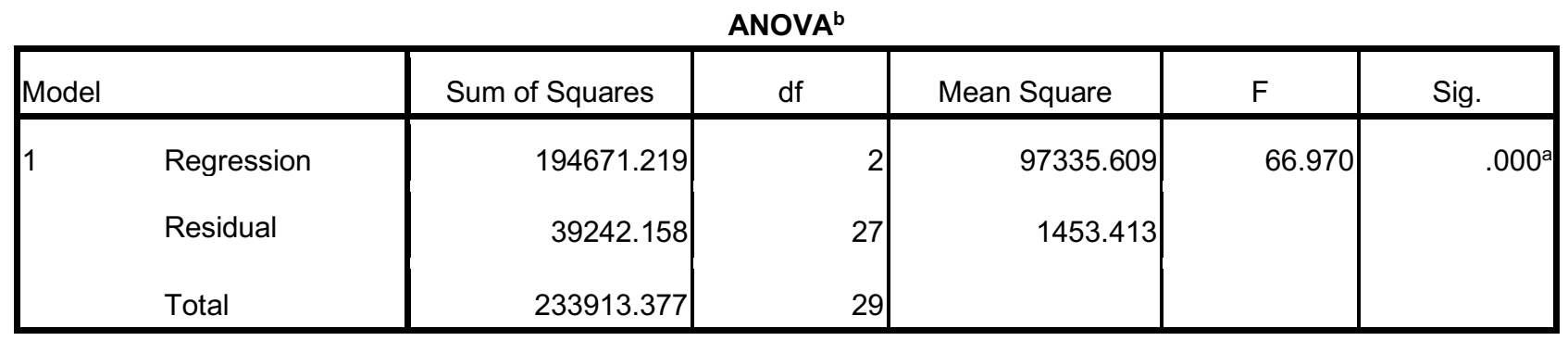

a. Predictors: (Constant), OMC, MDD

b. Dependent Variable: UCS 


\section{Coefficients $^{a}$}

\begin{tabular}{|c|c|c|c|c|c|c|c|c|c|c|}
\hline \multirow{2}{*}{\multicolumn{2}{|c|}{ Model }} & \multicolumn{2}{|c|}{$\begin{array}{l}\text { Unstandardized } \\
\text { Coefficients }\end{array}$} & \multirow{2}{*}{\begin{tabular}{|c|}
$\begin{array}{c}\text { Standardized } \\
\text { Coefficients }\end{array}$ \\
Beta \\
\end{tabular}} & \multirow[b]{2}{*}{$t$} & \multirow[b]{2}{*}{ Sig. } & \multicolumn{2}{|c|}{$\begin{array}{c}95 \% \text { Confidence } \\
\text { Interval for B }\end{array}$} & \multicolumn{2}{|c|}{$\begin{array}{c}\text { Collinearity } \\
\text { Statistics }\end{array}$} \\
\hline & & B & Std. Error & & & & $\begin{array}{l}\text { Lower } \\
\text { Bound }\end{array}$ & $\begin{array}{l}\text { Upper } \\
\text { Bound }\end{array}$ & Tolerance & VIF \\
\hline \multirow[t]{3}{*}{1} & (Constant) & -2796.492 & 559.488 & & -4.998 & .000 & -3944.467 & -1648.518 & & \\
\hline & MDD & 1294.668 & 523.965 & .276 & 2.471 & .020 & 219.582 & 2369.754 & .498 & 2.010 \\
\hline & OMC & 45.093 & 7.246 & .695 & 6.223 & .000 & 30.226 & 59.961 & .498 & 2.010 \\
\hline
\end{tabular}

a. Dependent Variable: UCS

Residuals Statistics ${ }^{a}$

\begin{tabular}{|c|c|c|c|c|c|}
\hline & Minimum & Maximum & Mean & Std. Deviation & $\mathrm{N}$ \\
\hline Predicted Value & 218.6358 & 516.3457 & $3.5569 \mathrm{E} 2$ & 81.93168 & 30 \\
\hline Residual & $-7.49614 \mathrm{E} 1$ & 85.79484 & .00000 & 36.78557 & 30 \\
\hline Std. Predicted Value & -1.673 & 1.961 & .000 & 1.000 & 30 \\
\hline Std. Residual & -1.966 & 2.250 & .000 & .965 & 30 \\
\hline
\end{tabular}

a. Dependent Variable: UCS

\section{Histogram}

\section{Dependent Variable: UCS}

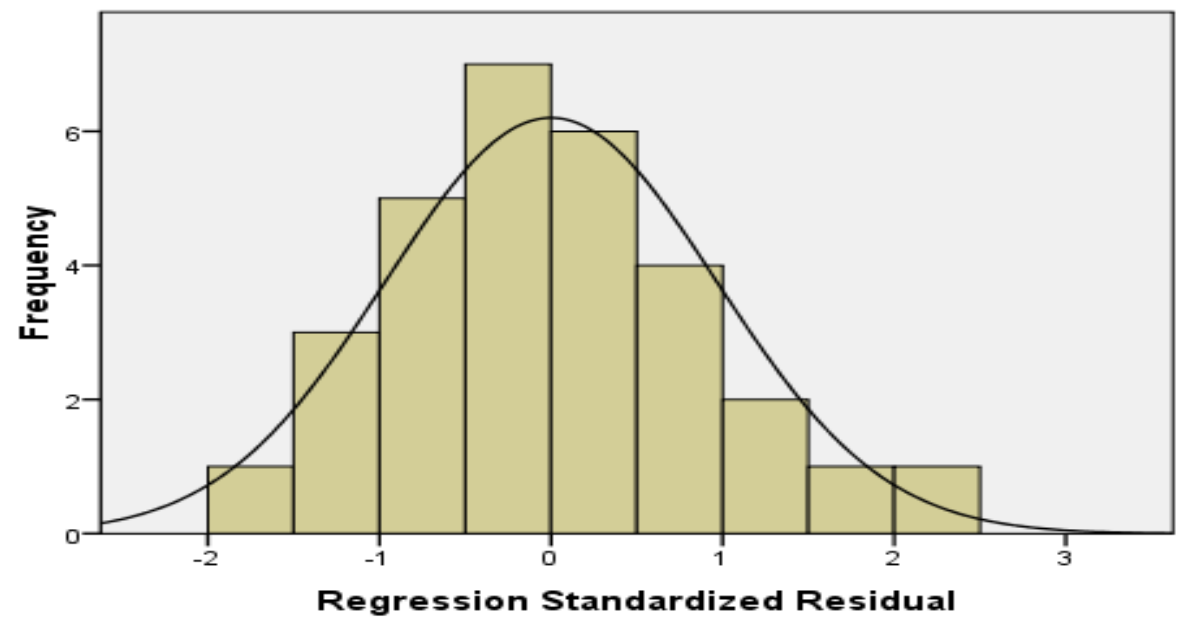

Mean $=-1.62 \mathrm{E}-14$ Std. Dev $=0.965$

Regression Standardized Residual 
Normal P-P Plot of Regression Standardized Residual

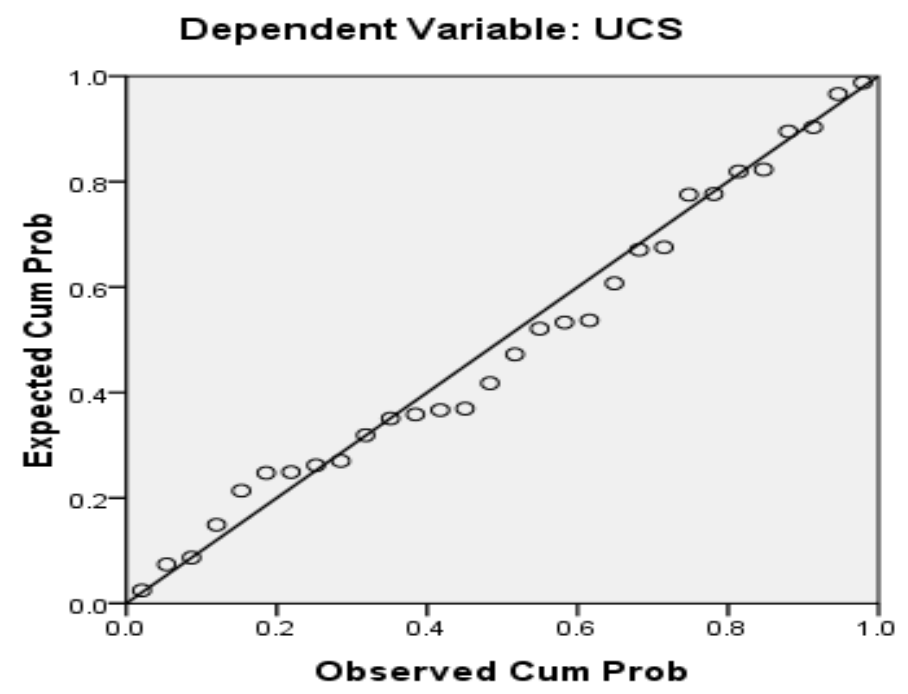




\section{APPENDIX H: \\ Multiple linear regression analysis result between UCS with MDD and OMC for combined Data}

\begin{tabular}{|ll|r|r|r|}
\hline & & & \\
& & ucs & mdd & \multicolumn{1}{c|}{ omc } \\
\hline Pearson Correlation & ucs & 1.000 & .781 & .883 \\
& mdd & .781 & 1.000 & .693 \\
& omc & .883 & .693 & 1.000 \\
\hline Sig. (1-tailed) & ucs & & .000 & .000 \\
& mdd & .000 & .000 \\
& omc & .000 & .000 & .00 \\
\hline N & ucs & 50 & 50 & 50 \\
& mdd & 50 & 50 & 50 \\
& omc & 50 & 50 & 50 \\
\hline
\end{tabular}

Variables Entered/Removed ${ }^{\mathrm{b}}$

\begin{tabular}{|l|l|c|l|}
\hline \multirow{2}{*}{ Model } & \multicolumn{1}{|c|}{ Variables Entered } & Variables Removed & Method \\
\hline 1 & omc, mdd $^{\mathrm{a}}$ & & Enter \\
\hline
\end{tabular}

a. All requested variables entered.

b. Dependent Variable: ucs

Model Summary ${ }^{b}$

\begin{tabular}{|l|r|r|r|r|r|}
\hline Model & R & R Square & Adjusted R Square & \multicolumn{1}{c|}{$\begin{array}{c}\text { Std. Error of the } \\
\text { Estimate }\end{array}$} & \multicolumn{1}{c|}{ Durbin-Watson } \\
\hline 1 & $.914^{\mathrm{a}}$ & .835 & .828 & 33.44270 & 1.328 \\
\hline
\end{tabular}

a. Predictors: (Constant), omc, mdd

b. Dependent Variable: ucs 
ANOVA $^{b}$

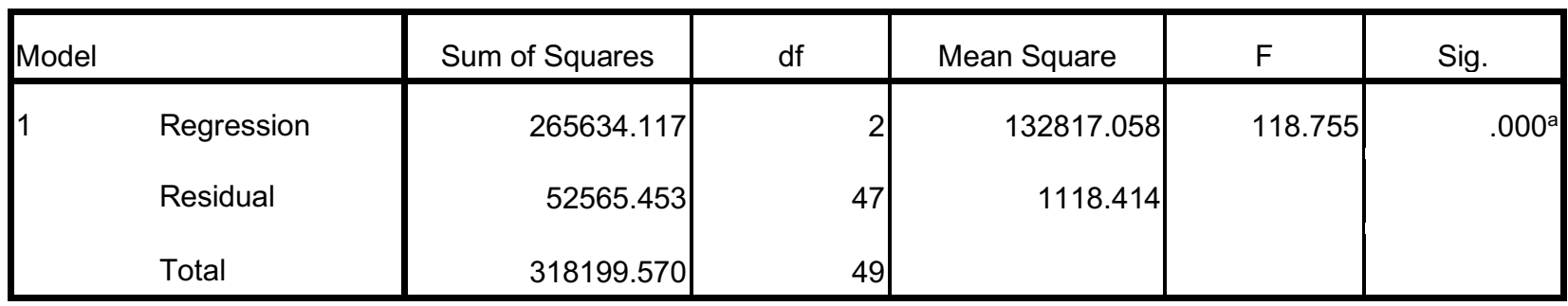

a. Predictors: (Constant), omc, mdd

b. Dependent Variable: ucs

Coefficients $^{a}$

\begin{tabular}{|c|c|c|c|c|c|c|c|c|c|}
\hline \multirow[b]{2}{*}{ Model } & \multicolumn{2}{|c|}{$\begin{array}{c}\text { Unstandardized } \\
\text { Coefficients }\end{array}$} & \multirow{2}{*}{\begin{tabular}{|c|}
$\begin{array}{c}\text { Standardize } \\
\mathrm{d} \\
\text { Coefficients }\end{array}$ \\
\\
Beta
\end{tabular}} & \multirow[b]{2}{*}{$t$} & \multirow[b]{2}{*}{ Sig. } & \multicolumn{2}{|c|}{$\begin{array}{c}95 \% \text { Confidence Interval } \\
\text { for B } \\
\end{array}$} & \multicolumn{2}{|c|}{$\begin{array}{l}\text { Collinearity } \\
\text { Statistics }\end{array}$} \\
\hline & B & Std. Error & & & & $\begin{array}{l}\text { Lower } \\
\text { Bound }\end{array}$ & $\begin{array}{l}\text { Upper } \\
\text { Bound }\end{array}$ & $\begin{array}{c}\text { Toleranc } \\
\text { e }\end{array}$ & VIF \\
\hline $\begin{array}{ll}1 \quad \text { (Constant } \\
\text { ) }\end{array}$ & -3105.463 & 451.542 & & -6.877 & .000 & -4013.847 & -2197.078 & & \\
\hline mdd & 1625.138 & 411.874 & .324 & 3.946 & .000 & 796.554 & 2453.722 & .520 & 1.924 \\
\hline omc & 40.855 & 5.104 & .658 & 8.005 & .000 & 30.588 & 51.122 & .520 & 1.924 \\
\hline
\end{tabular}

a. Dependent Variable: ucs

Residuals Statistics ${ }^{a}$

\begin{tabular}{|c|c|c|c|c|c|}
\hline & Minimum & Maximum & Mean & Std. Deviation & $\mathrm{N}$ \\
\hline Predicted Value & 214.0642 & 511.8240 & 3.3679E2 & 73.62815 & 50 \\
\hline Residual & $-7.20774 \mathrm{E} 1$ & 87.56752 & .00000 & 32.75308 & 50 \\
\hline Std. Predicted Value & -1.667 & 2.377 & .000 & 1.000 & 50 \\
\hline Std. Residual & -2.155 & 2.618 & .000 & .979 & 50 \\
\hline
\end{tabular}

a. Dependent Variable: ucs 


\section{Histogram}

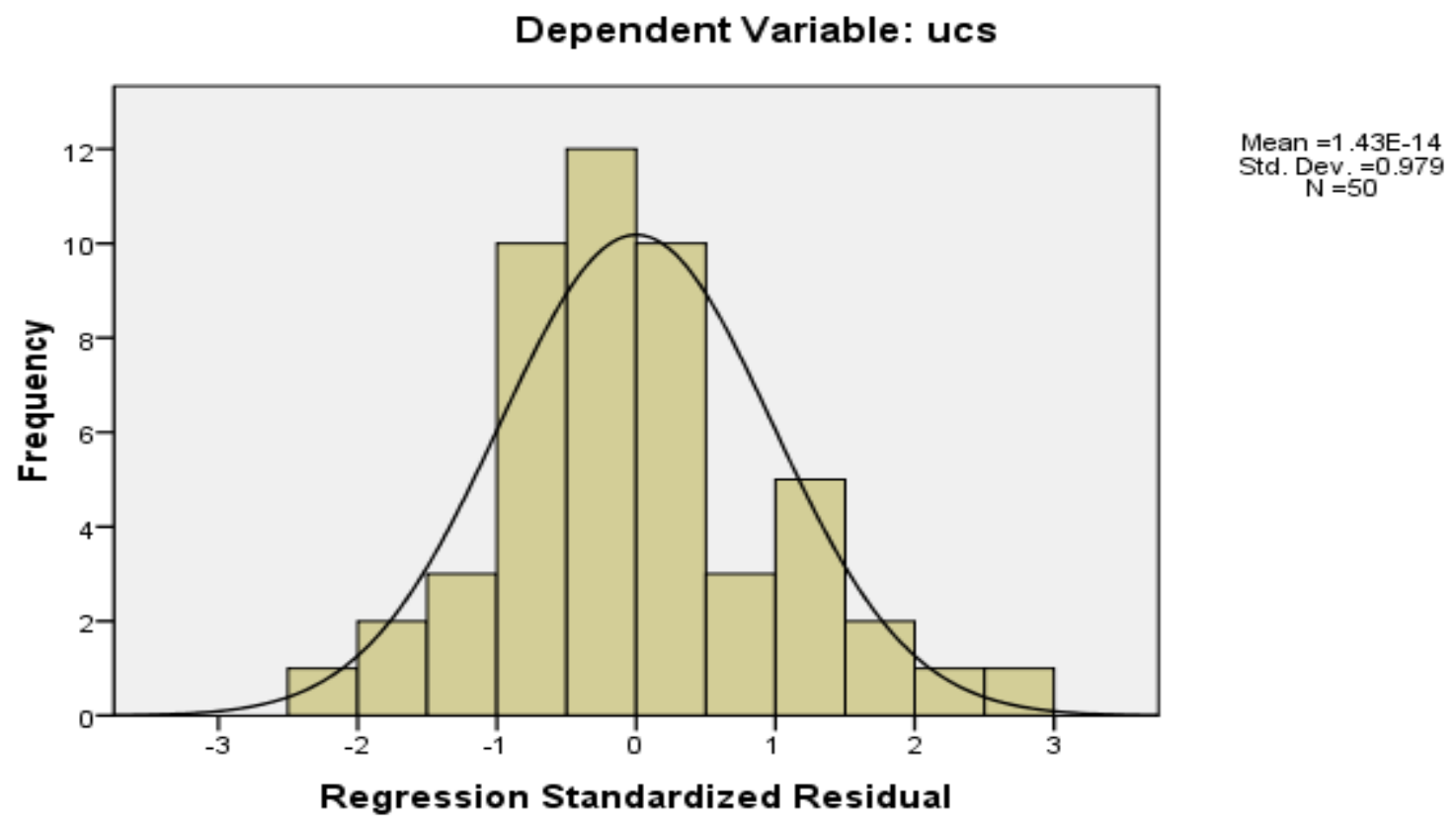

Normal P-P Plot of Regression Standardized Residual

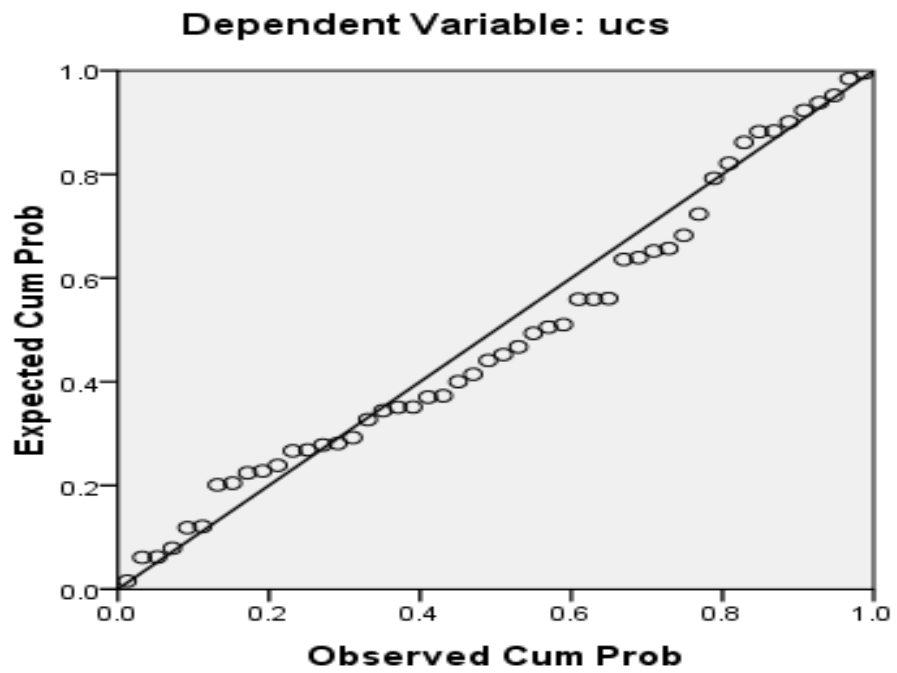


Correlations

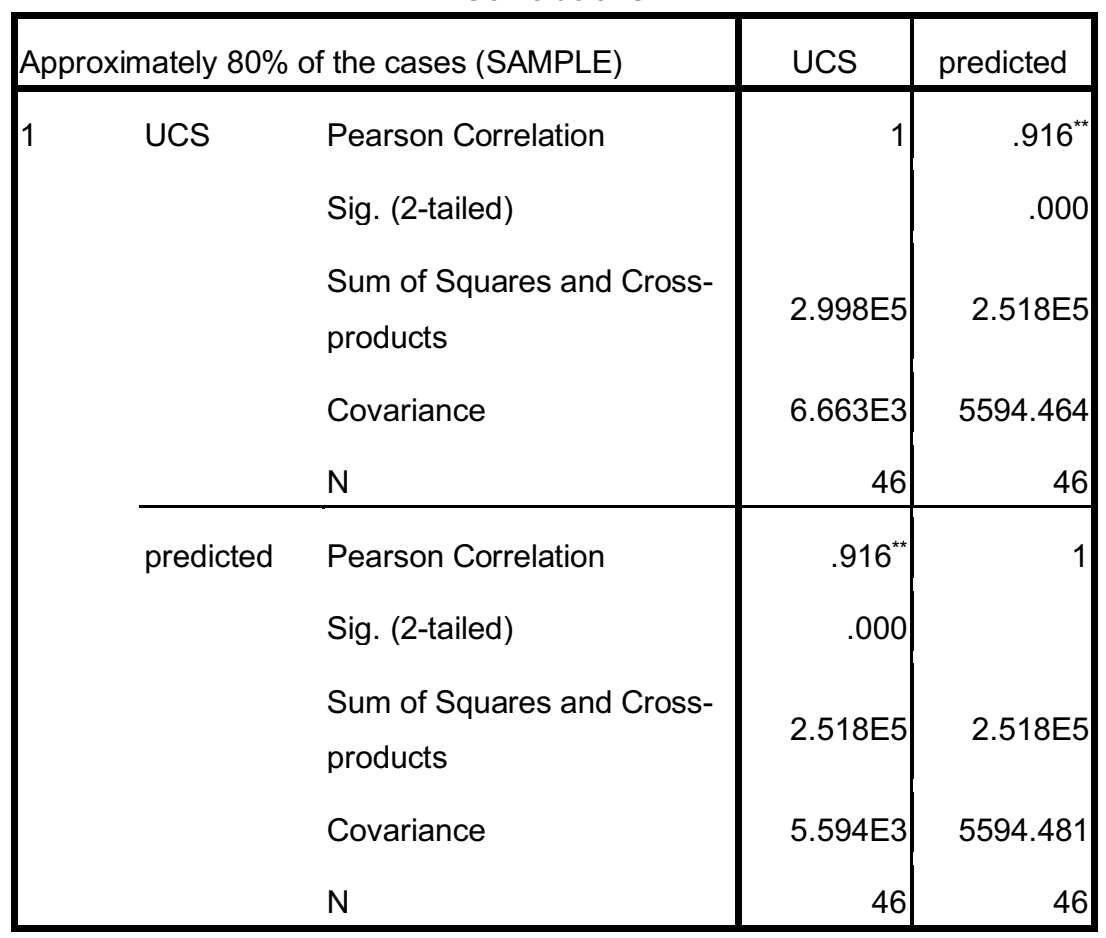

${ }^{* *}$. Correlation is significant at the 0.01 level (2-tailed). 